NBER WORKING PAPER SERIES

\title{
WHY IS POLLUTION FROM U.S. MANUFACTURING DECLINING? THE ROLES OF ENVIRONMENTAL REGULATION, PRODUCTIVITY, AND TRADE
}

\author{
Joseph S. Shapiro \\ Reed Walker \\ Working Paper 20879 \\ http://www.nber.org/papers/w20879
NATIONAL BUREAU OF ECONOMIC RESEARCH
1050 Massachusetts Avenue
Cambridge, MA 02138
January 2015, Revised June 2018

\begin{abstract}
Previously circulated as "Why is Pollution from U.S. Manufacturing Declining? The Roles of Trade, Regulation, Productivity, and Preferences." We thank Joe Altonji, Costas Arkolakis, Randy Becker, Jared Carbone, Brian Copeland, Arnaud Costinot, John Deutch, Sharat Ganapati, Michael Greenstone, Sam Kortum, Arik Levinson, Bill Nordhaus, Noam Yuchtman, and numerous seminar participants for useful comments and discussions. We also thank Elyse Adamic, Adrian Fernandez, Vivek Sampathkumar, David Silver, and Yusuf Mercan for excellent research assistance. The authors acknowledge support from NSF Grant SES-1530494 and a joint grant from the Department of Energy, the Sloan Foundation, and the National Bureau of Economic Research on the Economics of Energy Markets, Shapiro acknowledges additional support from the Yale MacMillan Center, the Yale Program on Applied Economics and Policy Research, and a Weyerhaeuser Research Grant from the Yale Center for Business and the Environment, and Walker acknowledges additional support from the Robert Wood Johnson Foundation and the UC Office of the President through the University of California Center for Energy and Environmental Economics. All results have been reviewed by the U.S. Census Bureau to ensure that no confidential information is disclosed. The authors declare that they have no relevant or material financial interests that relate to the research described in this paper. The views expressed herein are those of the authors and do not necessarily reflect the views of the National Bureau of Economic Research.
\end{abstract}

NBER working papers are circulated for discussion and comment purposes. They have not been peer-reviewed or been subject to the review by the NBER Board of Directors that accompanies official NBER publications.

(C) 2015 by Joseph S. Shapiro and Reed Walker. All rights reserved. Short sections of text, not to exceed two paragraphs, may be quoted without explicit permission provided that full credit, including (C) notice, is given to the source. 
Why is Pollution from U.S. Manufacturing Declining? The Roles of Environmental Regulation, Productivity, and Trade

Joseph S. Shapiro and Reed Walker

NBER Working Paper No. 20879

January 2015, Revised June 2018

JEL No. F18,F64,H23,Q56

\begin{abstract}
Between 1990 and 2008, air pollution emissions from U.S. manufacturing fell by 60 percent despite a substantial increase in manufacturing output. We show that these emissions reductions are primarily driven by within-product changes in emissions intensity rather than changes in output or in the composition of products produced. We then develop and estimate a quantitative model linking trade with the environment to better understand the economic forces driving these changes. Our estimates suggest that the implicit pollution tax that manufacturers face doubled between 1990 and 2008. These changes in environmental regulation, rather than changes in productivity and trade, account for most of the emissions reductions.
\end{abstract}

Joseph S. Shapiro

Yale University

37 Hillhouse Avenue

PO Box 208264

New Haven, CT 06520-8264

and NBER

joseph.shapiro@yale.edu

Reed Walker

Haas School of Business

University of California, Berkeley

2220 Piedmont Ave

Berkeley, CA 94720

and NBER

rwalker@haas.berkeley.edu 


\title{
Why is Pollution from U.S. Manufacturing Declining? The Roles of Environmental Regulation, Productivity, and Trade*
}

\author{
Joseph S. Shapiro \\ Yale University \\ and NBER \\ joseph.shapiro@yale.edu
}

\author{
Reed Walker \\ University of California, Berkeley \\ and NBER \\ rwalker@berkeley.edu
}

June 2018

\begin{abstract}
Between 1990 and 2008, air pollution emissions from U.S. manufacturing fell by 60 percent despite a substantial increase in manufacturing output. We show that these emissions reductions are primarily driven by within-product changes in emissions intensity rather than changes in output or in the composition of products produced. We then develop and estimate a quantitative model linking trade with the environment to better understand the economic forces driving these changes. Our estimates suggest that the implicit pollution tax that manufacturers face doubled between 1990 and 2008. These changes in environmental regulation, rather than changes in productivity and trade, account for most of the emissions reductions.
\end{abstract}

JEL: F18, F64, H23, Q56

Between 1990 and 2008, emissions of the most common air pollutants from U.S. manufacturing fell by 60 percent, even as real U.S. manufacturing output grew substantially. Figure 1 shows just how stark these environmental improvements have been. Between 1990 and 2000, the real value of U.S. manufacturing output grew by a third even as manufacturing's emissions of major regulated air pollutants like nitrogen oxides, particulate matter, sulfur dioxide, and volatile organic compounds fell on average by 35 percent. After 2000,

*Shapiro: joseph.shapiro@yale.edu. Yale Economics Department, 37 Hillhouse Ave, New Haven CT 06511. Walker: rwalker@berkeley.edy. UC Berkeley, Berkeley, CA 94720. We thank Joe Altonji, Costas Arkolakis, Randy Becker, Jared Carbone, Brian Copeland, Arnaud Costinot, John Deutch, Sharat Ganapati, Michael Greenstone, Sam Kortum, Arik Levinson, Bill Nordhaus, Noam Yuchtman, and numerous seminar participants for useful comments and discussions. We also thank Elyse Adamic, Adrian Fernandez, Vivek Sampathkumar, David Silver, and Yusuf Mercan for excellent research assistance. The authors acknowledge support from NSF Grant SES-1530494 and a joint grant from the Department of Energy, the Sloan Foundation, and the National Bureau of Economic Research on the Economics of Energy Markets, Shapiro acknowledges additional support from the Yale MacMillan Center, the Yale Program on Applied Economics and Policy Research, and a Weyerhaeuser Research Grant from the Yale Center for Business and the Environment, and Walker acknowledges additional support from the Robert Wood Johnson Foundation and the UC Office of the President through the University of California Center for Energy and Environmental Economics. All results have been reviewed by the U.S. Census Bureau to ensure that no confidential information is disclosed. The authors declare that they have no relevant or material financial interests that relate to the research described in this paper. 
growth in real manufacturing output slowed, even while manufacturing pollution emissions fell another 25 percentage points relative to 1990 levels.

Research suggests at least three possible explanations for these substantial improvements in U.S. air quality. First, U.S. manufacturing trade has grown substantially (Autor, Dorn, and Hanson, 2013; Pierce and Schott, 2016). When polluting industries like steel or cement move abroad, total U.S. pollution emissions may fall. Second, federal and state agencies require firms to install increasingly effective pollution abatement technologies. Some research directly attributes national changes in air quality to the Clean Air Act and to other environmental regulations (Henderson, 1996; Chay and Greenstone, 2005; Correia, Pope, Dockery, Wang, Ezzati, and Dominici, 2013). Third, if manufacturers use fewer inputs each year to produce the same outputs and pollution is related to inputs, then annual productivity growth could improve air quality. In support of this third explanation, Figure 2 shows a clear negative relationship between plant-level pollution per unit of output and total factor productivity in U.S. manufacturing; as total factor productivity rises, pollution per unit of output falls. ${ }^{1}$

The goal of this paper is to better understand the underlying forces that have caused changes in pollution emissions from U.S. manufacturing. We do this in two complementary ways. We begin by decomposing changes in manufacturing emissions into changes due to the total scale of manufacturing output, the composition of products produced, and the pollution intensity of a given set of products. This data-driven exercise exploits newly available, administrative data on product-level emissions intensities that affords additional granularity relative to the existing literature. While the statistical decomposition delivers clear conclusions, it lacks the ability to uncover the primitive economic forces driving emissions reductions.

We complement this decomposition with a quantitative model of pollution emissions in U.S. manufacturing. The model consists of firms endogenously choosing investments in pollution abatement to avoid a tax on pollution emissions. Production and pollution abatement choices depend on environmental regulation, productivity, and trade costs. The model weaves together elements of workhorse models from the international (Melitz, 2003) and environmental (Copeland and Taylor, 2003) literatures. While the model is highly stylized, it has several attractive features - it has explicit and simple theoretical microfoundations from which all the analysis is derived; it accounts for imperfect competition and can accommodate various market structures; it incorporates firm entry, exit, and cross-firm reallocation; it requires few parameters that can be estimated using reduced-form regressions; it can analyze a wide variety of counterfactuals; and it can account for many general equilibrium forces in settings where partial equilibrium, program evaluation methods may be able to deliver less insight.

We then combine the model with administrative plant-level data from the U.S. Census Bureau and EPA with two main objectives. First, we use intermediate results from the model, combined with actual pollution abatement and emissions decisions, to back out the implicit tax per unit of pollution emissions that firms face. U.S. federal, state, and local environmental regulations take many overlapping forms: commandand-control technology standards, cap-and-trade programs, and many others. ${ }^{2}$ Our quantitative exercise

\footnotetext{
${ }^{1}$ This graph focuses on nitrogen oxides $\left(\mathrm{NO}_{x}\right)$ emissions, though graphs for other pollutants look similar.

${ }^{2}$ Berman and Bui (2001) describe the entire menu of local air quality regulations facing manufacturing firms around Los Angeles, finding 11 local air quality regulations for petroleum refining and 46 for manufacturing (a count which excludes state and federal regulations). Most of the manufacturing policies apply to only a few industries each. The analysis includes the
} 
yields a closed form expression for the overall regulatory burden from these disparate and overlapping environmental policies, allowing us to observe how this measure has changed over time. The second main objective of the quantitative exercise is to evaluate a range of counterfactuals, such as how pollution emissions would have evolved if air pollution regulation had remained unchanged after 1990. Many researchers in environmental economics and international trade use quantitative models to forecast the future - they study untested policies such as a global 10 percent decrease in all trade barriers or a national carbon tax. Unlike such work, this paper uses a model to interpret the past - it quantifies how different kinds of economic shocks (environmental regulation, productivity, and trade costs) led to observed changes in actual pollution emissions. Similar general equilibrium decompositions have been used to understand the causes of the collapse of trade around the Great Recession and the changes in between-group wage inequality (Burstein, Morales, and Vogel, 2017; Eaton, Kortum, Neiman, and Romalis, 2016).

Our results suggest that changes in the scale of manufacturing output or changes to the composition of products produced cannot explain trends in pollution emissions from U.S. manufacturing between 1990 and 2008. Instead, decreases in pollution per unit of output within narrowly defined product categories explain almost all of the changes in emissions over this time. We then show that the model-driven measure of the pollution tax rate that rationalizes observed pollution emissions and abatement decisions - a scalar measure of the stringency of environmental regulation - more than doubled for most pollutants between 1990 and 2008. We find broadly similar increases in regulation across all the main pollutants the Clean Air Act regulates ("criteria pollutants"), but we find no increases in an unregulated pollutant, $\mathrm{CO}_{2}$, over this time period. Lastly, we find that this increasing stringency of environmental regulation accounts for most of the 1990-to-2008 decrease in pollution emissions from U.S. manufacturing. Despite the plant-level relationship between pollution and productivity documented in Figure 2, and similar relationships found in related literature (Bloom, Genakos, Martin, and Sadun, 2010; Martin, 2011; Holladay, 2016), we find that changes in U.S. productivity have had smaller effects on U.S. pollution emissions at the economy-wide level.

This paper departs from the literature in four primary ways. First, it provides new evidence on why pollution from U.S. manufacturing is declining. Some research relates national changes in pollution emissions to three channels: changes in the aggregate level of manufacturing output, changes in the composition of output across manufacturing industries, and changes in the pollution emitted per unit output within an industry (Levinson, 2009). Research describes these channels as scale, composition, and technique. The methodology behind our statistical decomposition resembles this work, but detailed administrative data allow us to extend previous analyses to look within physical products and not merely within industries. ${ }^{3}$ This added granularity helps address previous concerns regarding the inability of industry level data to distinguish between changes in the within-industry reallocation of production towards cleaner products and industry-level reductions in emissions intensity (Koo, 1974; Gamper-Rabindran, 2006; Ederington, Levinson, and Minier, 2008; Levinson, 2009). More importantly, the conclusion of previous research that pollution per

years 1979 to 1993. Los Angeles has among the most stringent air quality regulations in the country. We thank Eli Berman and Linda Bui for sharing details of these regulations.

${ }^{3}$ Throughout the paper, we use "product" to describe 1,440 5-digit Standard Industrial Classifications (SIC), "industry" to describe the 455 4-digit SIC codes, and "sector" to describe the 17 aggregations of 2-digit International Standard Industrial Classification (ISIC) codes this paper's quantitative model analyzes. 
unit output within industries is falling (i.e., pollution is declining due to the "technique" effect) is silent on deeper economic causes. Pollution per unit output is an endogenous outcome of the global economy that numerous possible forces could explain. We use a quantitative model to relate changes in pollution to policy-relevant choices like trade costs and environmental regulation. Our analysis of this quantitative model suggests that environmental regulation accounts for much of the decline in pollution.

A second contribution of this study is to quantify the change in the overall regulatory burden, or shadow price of pollution, that manufacturing firms face due to local and national air pollution regulations. We find that this price more than doubled between 1990 and 2008 for most air pollutants we study, but we find no increase in the shadow price of $\mathrm{CO}_{2}$. While analyzing the overall regulatory burden affecting firms does not prescribe a single law or policy lever, it does explain what all the hundreds of regulations have added up to, which is a question of central importance. Previous model-based attempts to measure regulatory stringency have required equating energy expenditures with pollution, then backing out regulatory costs from cost function estimates (van Soest, List, and Jeppesen, 2006).

Third, this paper estimates, for the first time, a parameter that has played a central role in environmental economics models for at least 30 years - the elasticity governing a firm's tradeoff between production and pollution abatement (Siebert, Eichberger, Gronych, and Pethig, 1980; Copeland and Taylor, 2003). This parameter has equivalent interpretations as the Cobb-Douglas cost share of pollution taxes in production or, alternatively, as the elasticity of pollution emissions with respect to productivity.

Lastly, this paper develops a flexible and tractable approach to analyzing economy-wide changes in pollution. Research studying changes in pollution typically uses quasi-experimental regressions, industrial organization models, or macro-trade models (Copeland and Taylor, 1994; Fabra and Reguant, 2014; Deschenes, Greenstone, and Shapiro, 2017; Isen, Rossin-Slater, and Walker, 2017; Keiser and Shapiro, 2017). Quasi-experimental studies can isolate the effect of individual policies one-at-a-time, but regulators have implemented dozens of overlapping pollution regulations over the last 20 years, many of which have not been analyzed with policy evaluation tools and have no natural comparison group. Industrial organization models have rich industry-specific detail but typically do not study an entire segment of the economy, like all of manufacturing, or account for general equilibrium forces. Theoretical, macro-trade models have provided considerable insight but have generally resisted estimation. Our methodology builds on tools from a recent trade literature sometimes described as "structural gravity" (Costinot and Rodriguez-Clare, 2014), though the application to environmental questions has been limited (Shapiro, 2016; Cherniwchan, Copeland, and Taylor, 2017). A nascent literature explores the environmental implications of models of heterogeneous firms (Bajona, Missios, and Pierce, 2012; Andersen, 2016), though does not analyze the models quantitatively. The analysis of firm heterogeneity reflects growing evidence that firms differ dramatically in their productivity and pollution levels, even within narrowly defined industries (Lyubich, Shapiro, and Walker, 2018). We study the specific counterfactual of explaining historic changes in pollution. Our approach, however, is versatile enough to evaluate prospective environmental policies or design optimal environmental policy. One of our goals is to make clear how similar approaches could be used to study a range of environmental

\footnotetext{
${ }^{4}$ Some research describes a model of the environment and trade and then estimates linear regressions where the explanatory variables proxy for important variables in the theory (Antweiler, Copeland, and Taylor, 2001). We take a literal interpretation of the model by estimating its primitive parameters and then solving for equilibrium outcomes given a vector of inputs.
} 
questions.

The rest of the paper proceeds as follows. Section I presents a statistical decomposition in order to break down aggregate emissions trends in our data, while also highlighting the frontier of what we are able to say with the data alone. Section II outlines our trade-environment model. Section III discusses the data, and

Section IV discusses how we estimate the parameters. Section V presents the main results, and Section VI discusses alternative explanations and additional robustness concerns. Section VII concludes.

\section{A Statistical Decomposition of U.S. Emissions 1990-2008}

Much economic research interprets national changes in industrial air pollution via three pathways (Copeland and Taylor, 1994; Grossman and Krueger, 1995). One is a change in the scale of real output. The second is a change in the composition of production from products that require little pollution emissions to produce, like "household furniture," to products that require substantial pollution emissions to produce, like "carbon black." The third is a change in the production technique used to produce a single product, which could decrease a product's pollution emissions per unit of output.

We begin by presenting a statistical decomposition of manufacturing pollution emissions using newly developed administrative data on manufacturing plant-product-year output from 1990 to 2008. The Census of Manufacturers and the Annual Survey of Manufacturers collect sub-industry, product-level output data, at the plant-product-year level. We use this information to illustrate whether changes in the total scale of output or changes in the composition of products produced are able to explain the observed reductions in air pollution emissions. Our focus on products rather than industries is unique to the literature and is meant to capture the fact that even within a fairly narrow industry code (e.g., 4-digit Standard Industrial Classification (SIC) code), many products differ significantly in their emissions intensities. Previous research has explored trends in manufacturing pollution emissions using industry level data. The previous literature has acknowledged that a limitation of industry level production data is the inability to distinguish changes in the reallocation of production towards cleaner products from industry-level "technique" based reductions in emissions intensity (Koo, 1974; Gamper-Rabindran, 2006; Ederington, Levinson, and Minier, 2008; Levinson, 2009). For example, while all of U.S. manufacturing contains 455 4-digit SIC codes, the product trailer from the Census and Annual Survey of Manufacturers allows us to perform this decomposition using 1,440 products. This granularity allows us to quantify by how much the scale of output versus the types of products produced can explain the observed reductions in manufacturing air emissions.

Consider the following representation of total manufacturing pollution, denoted $Z$ :

$$
Z=\sum_{s} z_{s}=\sum_{s} x_{s} e_{s}=X \sum_{s} \kappa_{s} e_{s}
$$

Total manufacturing pollution $Z$ equals the sum of pollution from each manufacturing product $s, z_{s}$. A manufacturing product in our setting can be thought of as a sub-industry classification, where for example, SIC 3312 (blast furnaces and steel mills) is subdivided into 24 different products ranging from steel wire 
(33125) to cold rolled sheets and strip (excluding metallic coated and electrical) (33127). ${ }^{5}$ Alternatively, we can write manufacturing pollution as equal to the total output of a product $x_{s}$ multiplied by a productspecific emissions factor $e_{s}$. We can also represent manufacturing pollution emissions as the total output shipped by all manufacturing industries, $X$, multiplied by the sum of each product's share of total output, $\kappa_{s} \equiv x_{s} / X$, times an emissions coefficient reflecting pollution per dollar of output shipped of that product $\left(e_{s} \equiv z_{s} / x_{s}\right)$. In vector notation, we have

$$
Z=X \kappa^{\prime} \mathbf{e}
$$

where $\kappa$ and $\mathbf{e}$ are $S \times 1$ vectors containing the market shares of each of the $S$ products and their pollution intensities, respectively. Totally differentiating then dividing through by $Z$ yields three terms representing the scale, composition, and technique effects:

$$
\frac{d Z}{Z}=\underbrace{\frac{d X}{X}}_{\text {scale }}+\underbrace{\frac{d \kappa}{\kappa}}_{\text {composition }}+\underbrace{\frac{d e}{e}}_{\text {technique }}
$$

Taking the decomposition in equation (2) to the data requires annual data on total pollution, total output, each product's contribution to output, and each product's emissions intensity. Pollution and total output come from the EPA's National Emissions Inventory (NEI) and the Census of Manufacturing, respectively. We construct product-level output shares in each year using the product trailer from the Census and Annual Survey of Manufacturers. In order to construct product-level emissions factors, we match the National Emissions Inventory to the Annual Survey of Manufacturers in 1990 via name and address string matching. Appendix III.A describes the string matching process in more detail.

It is useful to distinguish plant- from product-level data. The NEI reports emissions for each plant while the Census reports output for each product within a plant. For single-product plants, the NEI reports emissions at the product level. For multi-product plans, we apportion plant-level emissions to products according to those products' revenue shares within the plant, using year 1990 data. ${ }^{6,7}$ We take the total emissions attributable to each product in 1990 and divide by the total product shipments in 1990 to construct emissions intensities. ${ }^{8}$ We then use these 1990 product-level emissions intensities to project the scale and composition effects forward in time, holding technology (i.e., our emissions intensities) constant at 1990 emissions rates. The decomposition allows us to observe what emissions would have looked like in 2008 if firms still produced products with 1990 emissions intensities. Appendix III.B describes the underlying data.

Figure 3 illustrates the resulting statistical decomposition for nitrogen oxide emissions $\left(\mathrm{NO}_{x}\right)$. Appendix Figure 1 shows graphs for other pollutants, which have similar patterns, and Panel A of Appendix Table 1

\footnotetext{
${ }^{5}$ Output at the five-digit SIC level is the most disaggregate data available for all plants in the Census and Annual Survey of Manufacturers.

${ }^{6}$ Allocating inputs to products based on their revenue shares, an analogous approach, is standard in the productivity literature (Foster, Haltiwanger, and Syverson, 2008; Collard-Wexler and De Loecker, 2015). We discuss alternative approaches below.

${ }^{7}$ Previous research has used the World Bank's Industrial Pollution Projection System (IPPS) for emissions intensities. The IPPS data provides a list of emissions intensities by four-digit Standard Industrial Classification (SIC) codes (Hettige, Martin, Singh, Wheeler, and Mundial, 1995; Levinson, 2009). Levinson (2014) constructs industry-level emissions intensities using the NBER-CES productivity database combined with raw NEI data.

${ }^{8}$ We deflated total product output by industry-year specific price indices, from the NBER-CES database, scaled so year $2008=1$.
} 
shows numbers corresponding to these graphs. The top solid line in Figure 3 depicts the total real value of manufacturing shipments, where each industry's output is deflated by the NBER-CES industry specific price index and then totaled. We scale total output so it equals 100 in 1990. This line summarizes what emissions would have been if emissions rates and product composition had been fixed at their 1990 levels. The middle dashed line plots $\mathrm{NO}_{x}$ emissions that would have occurred if emissions intensities had remained fixed at 1990 levels but the composition of output across manufacturing products had equaled observed, historical values. The bottom dotted line plots actual $\mathrm{NO}_{x}$ emissions from manufacturing, as reported by the NEI. The bottom line implicitly summarizes the joint result of changing the scale, composition, and technique of manufacturing production over this time period.

The statistical decomposition leads to several conclusions. First, the dotted line shows that actual $\mathrm{NO}_{x}$ emissions fell by almost 50 percent. Second, the proximity of the solid and dashed lines shows that the composition between manufacturing products that emit high and low amounts of pollution has not changed much over time. Third, the solid and dashed lines each show that if the pollution intensity of industries had not changed, $\mathrm{NO}_{x}$ emissions would have risen by 20 to 30 percent. Finally, the gap between the solid line on top and dotted line at bottom shows that changes in the pollution intensity of individual products (i.e., "technique") explains why $\mathrm{NO}_{x}$ emissions fell by 50 percent rather than rising by 30 percent.

Appendix Figure 2 compares the results from the product-level decomposition to those that stem from more aggregate, industry level data of the sort used in Levinson (2009). Perhaps surprisingly, the additional granularity afforded by the product-level data provides little additional scope for compositional changes relative to the conclusions from the industry-level decomposition. Put another way, this analysis suggests that there was little or no change in the composition across products within industries that can account for the decrease in pollution.

As mentioned above, we do not observe plant-product-year emissions for plants that produce multiple products. Instead, we divide up a plant's emissions among products using product revenue shares. It is worth considering whether allocating plant-level emissions to product-level output using revenue shares can partly explain the similarity of the product and industry-level analyses. The best way to investigate the sensitivity of our product-level decomposition to this issue is to use the subset of plants that produce a single product, and for which apportionment of plant-level emissions to plant-product level output is no longer an issue. The results, listed in Panel B of Appendix Table 1, yield qualitatively similar conclusions to those from our preferred method. ${ }^{9}$

This relatively clear conclusion, that most reductions in emissions are driven by within-product changes in emissions intensity, echoes previous findings in the literature, albeit with more granular data. The data, however, are relatively silent on what might be causing these changes. The rest of the paper investigates the underlying economic forces driving these patterns in the data. If more productive plants emit less pollution per unit output, then product-level productivity growth could explain these patterns. Alternatively, changes in trade costs like the introduction of NAFTA or China's WTO ascension may have caused a reallocation of production away from unproductive and polluting firms toward more productive and perhaps less polluting

\footnotetext{
${ }^{9} \mathrm{An}$ an alternative exercise, we used the full sample of plants, but apportioned plant-level emissions to plant-product level output equally for all products within a plant (e.g., for a three-product plant, one-third of plant-level emissions are assigned to each product). The results, listed in Panel $\mathrm{C}$ of Appendix Table 1, are also qualitatively similar to the main results.
} 
firms that produce the same product. Lastly, increases in environmental regulatory stringency may also explain these reductions. The subsequent analysis focuses on interpreting the observed changes in the technique effect, rather than on assessing the lack of changes in composition effects. One possibility is that the most important drivers of changes in manufacturing composition are not strongly correlated with pollution intensity. This is an intriguing question we leave for future work.

The quantitative model, which fills the remainder of this paper, makes different and arguably stronger assumptions than this statistical decomposition. The advantage of these stronger assumptions is an ability to explore how environmental regulation, productivity, and trade contribute to the environmental improvements documented in Figures 1 and 3. The disadvantage is that these assumptions only roughly approximate reality. We discuss ways in which these assumptions can be relaxed in future research. The reader interested in additional detail on specific components of this model is referred to Copeland and Taylor (2003), Costinot and Rodriguez-Clare (2014), and Melitz and Redding (2014).

\section{Model of Heterogeneous Firms with Endogenous Pollution Abate- ment}

We describe a model of firm entry, production, trade, and pollution abatement, which is designed to reflect a stylized description of polluting industries. In the model, firms differ in their productivity levels, which leads these firms to differ in their pollution abatement investments and ultimately pollution emissions. The model accounts for endogenous changes in firm entry, exit, production, and export decisions in a tractable way that yields analytical solutions and allows us to analyze counterfactuals. Like all models, this approach seeks to reflect systematic patterns across firms while recognizing that some strict assumptions which enhance tractability, like monopolistic competition and constant elasticity of substitution (CES) utility, are not literally accurate descriptions of firms and consumers.

The model has a straightforward economic environment. We analyze a world of two countries (US and Foreign), each with a representative agent. Each country has one productive factor ("labor") which is inelastically supplied. The following three subsections explain the model's assumptions; present comparative statics for pollution intensity; and describe methodology for analyzing counterfactuals. Appendix B summarizes notation and shows more detailed derivations of results shown here.

\section{II.A Model Assumptions}

1. Preferences. The representative agent in destination country $d$ has the following utility function:

$$
U_{d}=\prod_{s}\left(\left[\sum_{o} \int_{\omega \in \Omega_{o, s}} q_{o d, s}(\omega)^{\frac{\sigma_{s}-1}{\sigma_{s}}} d \omega\right]^{\frac{\sigma_{s}}{\sigma_{s}-1}}\right)^{\beta_{d, s}}
$$

Equation (3) describes CES utility across product varieties within a sector and Cobb-Douglas preferences across sectors. The representative agent allocates expenditure across varieties of goods $\omega$ from the measure $\Omega_{o, s}$ of goods produced by sector $s$ in origin county $o$. The parameter $\beta_{d, s}$ represents the share of country 
$d$ 's expenditure devoted to sector $s$, where $\sum_{s} \beta_{d, s}=1$. The variable $q_{o d, s}(\omega)$ represents the quantity of variety $\omega$ goods in sector $s$ which are shipped from origin country $o$ to destination country $d$. The country subscripts in $q_{o d, s}(\omega)$ reflect the fact that the consumer price of a product, and thus its quantity consumed, depend on its production and trade costs, and hence on its country of origin; a given variety is produced in only one country. The sector-specific parameter $\sigma_{s}>1$ represents the elasticity of substitution across varieties.

The assumption of CES utility, which is common in trade and macroeconomic research, implies that consumers experience decreasing marginal utility from consuming a given variety and increasing utility in the total measure of varieties. We assume this utility function because it provides a simple way to account for different varieties within a sector while leading to parsimonious aggregate descriptions of production and trade flows across countries and sectors. ${ }^{10}$

\section{Firms and Market Structure.}

A competitive fringe of entrepreneurs may choose to pay the sunk entry cost $f_{o, s}^{e}$ to draw a productivity $\varphi$ from some productivity distribution. After observing the productivity draw, an entrepreneur who decides to produce must pay a separate fixed cost. Firms engage in monopolistic competition so that conditional on choosing to operate, an entrepreneur chooses prices $p_{o d, s}$ and abatement investments $a$ to maximize profits:

$$
\begin{aligned}
& \pi_{o, s}(\varphi)=\sum_{d} \pi_{o d, s}(\varphi)-w_{o} f_{o, s}^{e}, \\
& \text { where } \quad \pi_{o d, s}(\varphi)=p_{o d, s}(\varphi) q_{o d, s}(\varphi)-w_{o} l_{o d, s}(\varphi) \tau_{o d, s}-t_{o, s} z_{o d, s}(\varphi) \tau_{o d, s}-w_{d} f_{o d, s}
\end{aligned}
$$

We assume the productivity distribution is Pareto, with cumulative distribution function

$$
G\left(\varphi ; b_{o, s}\right)=1-\left(\frac{\varphi}{b_{o, s}}\right)^{-\theta_{s}}
$$

The location parameter $b_{o, s}$ describes a country's productivity, while the shape parameter $\theta_{s}$ describes the dispersion of productivity draws within a sector $s$. For simplicity, we drop the variety notation $\omega$ and index a firm by its productivity $\varphi$. The firm sells the following number of units:

$$
q_{o d, s}(\varphi)=(1-a(\varphi)) \varphi l_{o d, s}(\varphi)
$$

The profit function $\pi_{o d, s}(\varphi)$ involves several terms. A consumer in destination $d$ pays price $p_{o d, s}(\varphi)$ for goods from firm $\varphi$. Each firm receives revenue $p_{o d, s}(\varphi) q_{o d, s}(\varphi)$ and requires $l_{o d, s}(\varphi)$ units of productive labor at wage $w_{o}$ to produce goods for sending to destination $d$. A fraction of this labor $1-a$ is used to produce output and the remaining fraction $a$ to abate pollution. We write the dependence of abatement on productivity $a(\varphi)$ to emphasize that the firm sees abatement as an endogenous choice that ultimately

\footnotetext{
${ }^{10}$ Research finds that non-CES utility functions, such as the linear demand system, translog utility, and certain generalizations which can allow for endogenous markups can be described as part of the same "gravity" family of models. While this implies that their measures of the gains from trade are closely related, these structures do not always obtain the kind of tractable closedform relationships we use here (Melitz and Ottaviano, 2008; Feenstra and Weinstein, 2017; Arkolakis, Costinot, Donaldson, and Rodriguez-Clare, Forthcoming).
} 
varies with a firm's productivity. Each firm pays the pollution tax $t_{o, s}$ per ton on $z_{o d, s}(\varphi)$ tons of pollution emitted for producing goods shipped to destination $d$. Firms face iceberg trade costs, so $\tau_{o d, s} \geq 1$ units must be shipped for one unit to arrive (hence, the firm produces $\tau_{o d, s}(\varphi) q_{o d, s}(\varphi)$ in order to sell $q_{o d, s}(\varphi)$ ). A firm that chooses to enter the destination market $d$ must pay the fixed cost $f_{o d, s}$. Domestic trade costs are normalized so $\tau_{o o, s}=f_{o o, s}=1$. We assume that pollution tax revenues are lost to rent-seeking. While this assumption is made for simplicity, the considerable sums that corporations spend to lobby on energy and environmental legislation give one basis for it.

We assume this market structure for several reasons. Many industries like cement and steel that have substantial pollution emissions are also concentrated and have barriers to entry (Ganapati, Shapiro, and Walker, 2016). By accounting for fixed entry costs and sector-specific markups, our assumptions reflect a stylized version of polluting sectors. At the same time, this approach accounts for firm entry and exit and for reallocation of productive factors and output across firms. Finally, the Pareto technology distribution has plausible theoretical microfoundations (Gabaix, 1999; Luttmer, 2007) and provides a good fit to the empirical firm distribution, at least in the upper tail (Axtell, 2001; Eaton, Kortum, and Kramarz, 2011). ${ }^{11}$

It is useful to clarify the difference between firm-level and sector-level productivity in this model, and the relevance of environmental regulation to each. An entrepreneur may draw a productivity $\varphi$ representing the number of units of output produced per worker involved in production. A sector in a country has a productivity level $b_{o, s}$ describing the central value of the distribution of $\varphi$ levels from which entrepreneurs draw. Our use of "productivity" generally refers to $b_{o, s}$, though our references to an an individual firm's productivity refer to $\varphi$. One related concept that is commonly discussed and could respond to environmental regulation in this model is the number of workers per unit of output in a firm, $q_{o d, s}(\varphi) / l_{o d, s}(\varphi)=\varphi(1-a(\varphi))$. This depends on environmental regulation since regulation increases the share of factors $a$ allocated to abatement rather than to producing output. ${ }^{12}$

3. Pollution. Firms produce pollution emissions with the following technology:

$$
z_{o d, s}(\varphi)=(1-a(\varphi))^{1 / \alpha_{s}} \varphi l_{o d, s}(\varphi)
$$

We assume pollution regulations are stringent enough that all firms engage in some abatement. We also assume that $\theta_{s}>\left(\sigma_{s}-1\right)\left(1-\alpha_{s}\right)$ so that entrants have finite expected profits; later we verify that this assumption actually holds for the parameter values we estimate. Equation (7) states that pollution is an increasing function of output and a decreasing function of abatement. It is essentially the pollution production technology adopted in Copeland and Taylor (2003), except that it incorporates the role of productivity $\varphi$ and allows the pollution elasticity $\alpha_{s}$ to differ by sector. The extent to which a sector is

\footnotetext{
${ }^{11}$ Most of the literature following Melitz (2003) and using parametric distributions assumes that technology has a Pareto distribution. A few studies explore other productivity distributions, including the lognormal (Head, Mayer, and Thoenig, 2014) and bounded Pareto (Feenstra, Forthcoming). Some research suggests that the Pareto distribution provides a more accurate fit to the distribution of U.S. firms than the lognormal does (Axtell, 2001).

${ }^{12}$ In principle, one could imagine that some firms comply with environmental regulation by increasing their overall productivity levels, which is a version of the Porter (1991) hypothesis. Empirical support for this idea has been mixed (Greenstone, List, and Syverson, 2012; Ambec, Cohen, Elgie, and Lanoie, 2013). Like much of the literature on heterogeneous firms, this static model rules out such channels: a firm's productivity level $\varphi$ is its fixed attribute and cannot respond to economic forces, though the measure of entrepreneurs choosing to form firms can respond to such forces.
} 
"dirty" here depends on a primitive attribute of each industry $(\alpha)$, which can reflect the sector's production technology, its inputs, or other features.

Modeling emissions in this way is appealing because several sensible and seemingly different ways of describing pollution turn out to be equivalent to equation (7). As we show later, $\alpha$ represents the elasticity of pollution emissions intensity with respect to pollution abatement intensity. Pollution emissions intensity is measured as units of pollution emitted per unit of output, and pollution abatement intensity is measured as abatement expenditures divided by total factor costs. We also show that pollution emissions in this model can be described as another factor of production in a Cobb-Douglas production technology. Solving for $1-a$ then substituting into equation (6) shows that we can write total output as a Cobb-Douglas function of pollution emissions and productive factors:

$$
q_{o d, s}=\left(z_{o d, s}\right)^{\alpha_{s}}\left(\varphi l_{o d, s}\right)^{1-\alpha_{s}}
$$

In this interpretation, $\alpha$ is the Cobb-Douglas share for pollution emissions. Copeland and Taylor (2003) discuss other equivalent interpretations of this model of abatement.

These points give conceptual reasons for equation (7), but we emphasize that it plays a critical role in our analysis. Our approach to recovering an important elasticity and our analysis of counterfactuals both rely on output being a Cobb-Douglas function of pollution and productive factors (see Section IV). Without this Cobb-Douglas relationship, which follows from Assumptions 2 and 3, it would be more difficult to analyze the model quantitatively. ${ }^{13}$ While this kind of tractability is one reason why most of the relevant environmental literature has used this functional form, another is perhaps more important. Theory and evidence do not give clear guidance on how to think about pollution emissions in a firm's environmental decisions. Is pollution a second output, on which firms are taxed via environmental regulation? Or is pollution best thought of an input to production, which has a price due to environmental regulation? Or alternatively, should we think of firms as optimizing standard production decisions subject to a constraint on pollution emissions? An advantage of this Cobb-Douglas framework is that it does not require choosing one of these interpretations as correct and the others as incorrect, since in this framework these interpretations are equivalent.

Equation (7) shows that for an operating firm, pollution emissions decline when the firm reallocates productive factors to abatement investments. However, the model more broadly accounts for a variety of ways in which firm and consumer behavior affect pollution emissions - firm entry, exit, production, and trade in this model can all respond to environmental regulation, and all of these forces can interact to determine pollution emissions. ${ }^{14}$

\footnotetext{
${ }^{13}$ This Cobb-Douglas assumption appears in the analysis through two channels. First, it directly leads to the first-order condition for abatement in equation (10). This first-order condition is what drives the role of the abatement elasticity $\alpha_{s}$ in subsequent results, including the free entry condition in equation (11), the equilibrium equations in changes in equations (12) and (13), and the expressions for competitiveness shocks in equations (19) and (21). This first-order condition also determines the expression for shocks to environmental regulation, in equation (23). The second channel by which this Cobb-Douglas assumption affects the analysis is through providing a simple regression equation to estimate the abatement elasticity, in equations (17) and (8).

${ }^{14}$ The pollution technology assumption implies constant returns to scale in pollution abatement. A model with increasing returns to scale in abatement would have different structure (see e.g., Forslid, Okubo, and Ultveit-Moe 2011). We considered the implications of such a model but chose not to pursue it for two reasons. First, the importance of fixed costs for abatement technologies is empirically unknown. Scale economies could be positive for capital investments like scrubbers, zero for fuel-
} 
4. Competitive Equilibrium. Consumers maximize utility; firms maximize profits; and in each country, labor supply equals labor demand:

$$
L_{o}=L_{o}^{e}+L_{o}^{p}+L_{o}^{t}+L_{o}^{m}+L_{o}^{n x}
$$

A country's labor supply $L_{o}$ is allocated to five uses: paying the fixed cost to draw a productivity $\left(L_{o}^{e}\right)$; engaging in production, including pollution abatement $\left(L_{o}^{p}\right)$; paying pollution taxes $\left(L_{o}^{t}\right)$; paying market entry costs $\left(L_{o}^{m}\right)$; and paying for net exports $\left(L_{o}^{n x}\right)$. Pollution taxes require labor because we assume these are real resources lost to rent seeking. Net exports (i.e., trade imbalances) require labor because they represent a transfer of real resources between countries.

This completes our description of the model, and we now turn to analyze its implications.

\section{II.B Comparative Statics}

One motivation for the model is the conclusion of Section I that most of the change in pollution during the period 1990-2008 came from emitting less pollution per unit of output, i.e., from lower pollution intensity or the technique effect. We now show that in this model, each of the three main shocks we consider - pollution taxes, productivity, and trade liberalization - decreases pollution intensity within a sector. This implies that any of these three channels could explain the decrease in pollution intensity.

Additional notation helps explain this result. Let $i_{o, s}(\varphi) \equiv \sum_{j} z_{o j, s}(\varphi) / \sum_{j} q_{o j, s}(\varphi)$ denote the pollution intensity of a firm with productivity $\varphi$, defined as the physical units of pollution emitted per physical unit of output. Let $I_{o, s} \equiv Z_{o, s} P_{o, s} / R_{o, s}$ denote the pollution intensity of a sector, defined as the physical units of pollution emitted per real unit of output. The term $P_{o, s}$ represents the sectoral price index, $Z_{o, s}$ is total emissions, and $R_{o, s}$ is total revenue. Let $A_{o, s} \equiv E_{o, s} P_{o, s}^{\sigma_{s}-1}$ index market size, where $E_{o, s}$ is expenditure. Finally, let $\lambda_{o d, s}$ denote the share of country $d$ 's expenditure in sector $s$ which is purchased from country $o$, which also measures openness to trade. Appendix II.B and Appendix II.C derive expressions for the price index and for sectoral expenditure shares.

Proposition 1. Pollution intensity of a firm is locally decreasing in productivity. Pollution intensity of a sector is locally decreasing in pollution taxes, in productivity, and in trade liberalization.

Proof. For a firm with productivity $\varphi$, pollution intensity and its derivative are

$$
i_{o, s}(\varphi)=\frac{\alpha_{s}}{\varphi^{1-\alpha_{s}}} \frac{\left(t_{o, s}\right)^{\alpha_{s}-1}\left(w_{o}\right)^{1-\alpha_{s}}}{\left(\alpha_{s}\right)^{\alpha_{s}}\left(1-\alpha_{s}\right)^{1-\alpha_{s}}} \frac{\sum_{j} \tau_{o j, s}^{1-\sigma_{s}} A_{d, s}}{\sum_{j} \tau_{o j, s}^{-\sigma_{s}} A_{d, s}} \quad \frac{\partial i_{o, s}(\varphi)}{\partial \varphi}=\left(\alpha_{s}-1\right) \frac{i_{o, s}(\varphi)}{\varphi}
$$

Noting that $\alpha_{s} \in(0,1)$ and that $\varphi, i_{o, s}(\varphi)>0$ implies the conclusion. Sector-level pollution intensity and

switching like low-sulfur coal, and negative due to principal-agent issues for management innovations. Second, prices in such a model depend directly on market size, and market size appears in the equilibrium conditions in ways that prevent us from backing out shocks and undertaking the decomposition this paper reports. 
its derivatives are

$$
\begin{array}{rr}
I_{o, s}=\frac{\alpha_{s}}{t_{o, s}} \frac{\sigma_{s}-1}{\sigma_{s}} P_{o, s} & \frac{\partial I_{o, s}}{\partial t_{o, s}}=\frac{I_{o, s}}{t_{o, s}}\left[\alpha_{s} \lambda_{o o, s}-1\right] \\
\frac{\partial I_{o, s}}{\partial b_{o, s}}=-\left(1-\alpha_{s}\right) \frac{I_{o, s}}{b_{o, s}} \lambda_{o o, s} & \frac{\partial I_{o, s}}{\partial \tau_{d o, s}}=\frac{I_{o, s}}{\tau_{d o, s}} \lambda_{d o, s} \\
\frac{\partial I_{o, s}}{\partial f_{d o, s}}=\frac{1-\alpha_{s}}{\theta_{s}}\left(\frac{\theta_{s}}{\left(\sigma_{s}-1\right)\left(1-\alpha_{s}\right)}-1\right) \frac{I_{o, s}}{f_{d o, s}} \lambda_{d o, s}
\end{array}
$$

The facts that $\alpha_{s} \in(0,1), \lambda_{o o, s} \in[0,1]$, and $I_{o, s}, t_{o, s}>0$ imply the conclusion $\partial I_{o, s} / \partial t_{o, s}<0$. We conclude $\partial I_{o, s} / \partial b_{o, s}<0$ since all terms in that expression are positive except the leading minus sign, and we conclude $\partial I_{o, s} / \partial \tau_{d o, s}>0$ for any country pair with nonzero trade and trade costs since $I_{o, s}, \tau_{d o, s}, \lambda_{d o, s}>0$. Finally, $\frac{\partial I_{o, s}}{\partial f_{d o, s}}>0$ since all terms in it are positive; we assume (and verify empirically) that $\theta_{s}>\left(\sigma_{s}-1\right)\left(1-\alpha_{s}\right)$.

The economics underlying Proposition 1 are informative. For an individual firm, productivity affects pollution intensity through abatement decisions. Solving the firm's profit-maximization problem for the optimal share $a$ of factors invested in abatement gives the following first-order condition:

$$
1-a=\left(\frac{w_{o}}{\varphi t_{o, s}} \frac{\alpha_{s}}{1-\alpha_{s}}\right)^{\alpha_{s}}
$$

Productivity decreases a firm's pollution intensity in Proposition 1 because it increases abatement investments in this first-order condition. More productive firms charge lower prices, implying that the ratio of pollution taxes to output prices increases with productivity. ${ }^{15}$ We focus on firm-level results only for productivity since this is the only term in $i_{o, s}(\varphi)$ (and the only primitive attribute in the model) which varies across firms within a sector.

For an entire sector, pollution taxes also decrease pollution intensity. This can be seen from the denominator of the expression for $I_{o, s}$ in the proof, and also in the first-order condition (10). Pollution taxes make firms redirect productive resources to abatement, which makes the sector's pollution intensity decline. Similarly, productivity growth increases the real output produced for a given level of pollution emitted, thereby decreasing pollution intensity.

At the sector-wide level, lower iceberg trade costs imply a smaller portion of a firm's output must be paid in order to export goods. Thus, lower iceberg trade costs let a sector emit less pollution in order to obtain the same total value. Decreasing fixed trade costs causes a reallocation of market share to firms that are more productive and have lower pollution intensity. This can be seen when setting $\theta_{s}=\left(1-\alpha_{s}\right)\left(\sigma_{s}-1\right)$,

\footnotetext{
${ }^{15}$ The prediction that more productive firms charge lower prices comes from the assumption of monopolistic competition but would also result from many other market structures and has empirical support (Foster, Haltiwanger, and Syverson, 2008). Certainly some specific innovations do increase pollution intensity. The use of pesticides in agriculture, for example, probably increased both productivity and pollution intensity. This model envisions a broad set of factor-neutral productivity changes which allow producers to use fewer inputs for obtaining the same output, and such broad factor-neutral productivity improvements are likely to decrease pollution emitted to produce a given output.
} 
which shuts off firm heterogeneity.

While productivity features prominently in the foregoing explanations, we emphasize that not all changes in pollution can be ascribed to it. The three terms in equation (7) show that emissions can change via several channels: the investment of productive factors in abatement $a$, the selection of which productivity levels $\varphi$ entrepreneurs choose to form into firms, and the reallocation of productive factors across operating firms, $l_{o d, s}$. The discussion above highlights the relevance of these channels to the various shocks.

What is the magnitude of trade liberalization's effect on pollution intensity? Proposition 1 shows that for both fixed and variable trade costs, this magnitude grows with baseline pollution intensity and with baseline openness, and decreases with baseline iceberg or fixed trade costs. Thus, a relatively closed country like the U.S., where international trade accounts for a relatively small share of expenditure, will have relatively limited effects of trade liberalization on pollution.

Proposition 1 describes the sign of local, partial equilibrium changes. Discrete changes in pollution taxes, productivity, and trade costs might lead to different patterns, and they provide one reason to analyze the model quantitatively. One general conclusion which arises from this model even without quantification is that a sector's pollution intensity can fall due to productivity, trade, and environmental regulation.

\section{II.C Methodology for Analyzing Counterfactuals}

We now describe how we use this model to analyze counterfactuals. We combine the model's assumptions into two conditions that summarize firm behavior. In a competitive equilibrium, these conditions must be satisfied at a given point in time. We then use these conditions to analyze how counterfactuals affect welfare.

The first condition for a competitive equilibrium, shown earlier in equation (9), is that labor demand must equal labor supply in each country. The second condition for a competitive equilibrium says that the expected profit that an entrepreneur obtains from drawing a productivity must equal the fixed cost of drawing a productivity:

$$
\frac{1-\alpha_{s}}{\theta_{s}} \frac{\sigma_{s}-1}{\sigma_{s}} R_{o, s}=w_{o} f_{o, s}^{e} M_{o, s}^{e}
$$

(See derivation in Appendix II.D.) This is also known as a free entry condition. The left-hand side describes the profit entrepreneurs expect from drawing a productivity. This expected profit equals total revenues divided by markups, and scaled by the Pareto shape parameter and the pollution elasticity. On the righthand side, the term $f_{o, s}^{e}$ represents the fixed cost of forming a firm, which is paid in local wages and multiplied by the mass of firms entering.

To analyze counterfactual changes in environmental regulation, productivity, and trade costs, we rewrite each variable as a proportional change from a base year, which is a methodology developed in Dekle, Eaton, and Kortum (2008). The benefit of this methodology is that many variables which are difficult to measure do not appear in changes.

Formally, we use this methodology as follows. Let $x$ denote any variable from the model, let $x^{\prime}$ denote the value of this variable under a counterfactual scenario, and let $\hat{x} \equiv x^{\prime} / x$ denote the proportional change in this variable due to the counterfactual. Written in changes, the two equilibrium equations (9) and (11) 
become the following:

$$
\begin{gathered}
1=\psi_{o}\left(\frac{\sum_{s} \hat{M}_{o, s}^{e} R_{o, s} \frac{\left(\sigma_{s}-1\right)\left(\theta_{s}-\alpha_{s}+1\right)}{\sigma_{s} \theta_{s}}+\eta_{o}^{\prime}}{\sum_{s} R_{o, s} \frac{\left(\sigma_{s}-1\right)\left(\theta_{s}-\alpha_{s}+1\right)}{\sigma_{s} \theta_{s}}+\eta_{o}}\right) \\
\hat{w}_{o}=\sum_{d} \frac{\zeta_{o d, s}\left(\frac{\hat{w}_{o}}{\hat{b}_{o, s}}\right)^{-\theta_{s}}\left(\hat{\tau}_{o d, s}\right)^{-\frac{\theta_{s}}{1-\alpha_{s}}}\left(\hat{f}_{o d, s}\right)^{1-\frac{\theta_{s}}{\left(\sigma_{s}-1\right)\left(1-\alpha_{s}\right)}}\left(\hat{t}_{o, s}\right)^{-\frac{\alpha_{s} \theta_{s}}{1-\alpha_{s}}}}{\sum_{i} \lambda_{i d, s} \hat{M}_{i, s}^{e}\left(\frac{\hat{w}_{o}}{\hat{b}_{o, s}}\right)^{-\theta_{s}}\left(\hat{\tau}_{o d, s}\right)^{-\frac{\theta_{s}}{1-\alpha_{s}}}\left(\hat{f}_{o d, s}\right)^{1-\frac{\theta_{s}}{\left(\sigma_{s}-1\right)\left(1-\alpha_{s}\right)}}\left(\hat{t}_{o, s}\right)^{-\frac{\alpha_{s} \theta_{s}}{1-\alpha_{s}}}} \hat{\beta}_{d, s} \frac{R_{d}^{\prime}-N X_{d}^{\prime}}{R_{d}-N X_{d}}
\end{gathered}
$$

(See derivations in Appendix II.E and Appendix II.F.) We assume for simplicity that the fixed cost of drawing a productivity is constant over time. In these equilibrium conditions, we have defined the parameter combinations $\eta_{o}$ and $\psi_{o}$, and export shares $\zeta_{o d, s} \equiv X_{o d, s} / \sum_{d} X_{o d, s}$, where $X_{o d, s}$ is the value of trade from country $o$ to country $d$ of goods from sector $s .{ }^{16}$ Equation (12) says that in any counterfactual, labor demand must equal labor supply in each country. Equation (13) says that in any counterfactual, the expected profit from drawing a productivity must equal the fixed cost of drawing a productivity. We use equations (12) and (13) to find the wages and firm entry decisions that characterize each counterfactual.

To measure pollution emissions associated with a counterfactual, we integrate pollution emissions from (7) over the measure of operating firms. The change in country o's pollution emissions between a baseline year and a counterfactual is

$$
\hat{Z}_{o}=\frac{\sum_{s} \frac{\hat{M}_{o, s}^{e} \hat{w}_{o}}{\hat{t}_{o, s}} Z_{o, s}}{\sum_{s} Z_{o, s}}
$$

(See derivation in Appendix II.G.) The denominator of equation (14) describes the sum over sectors of baseline pollution. The numerator shows the same sum, but each sector's pollution is multiplied by the proportional change in that sector's pollution due to a counterfactual,

$$
\hat{Z}_{o, s}=\frac{\hat{M}_{o, s}^{e} \hat{w}_{o}}{\hat{t}_{o, s}}
$$

A sector's change in pollution emissions increases proportionally with firm entry $\hat{M}_{o, s}^{e}$ and wages $\hat{w}_{o}$, and decreases with regulation $\hat{t}_{o, s}$.

\section{Data}

The data for this paper fall into two categories: plant-level microdata for estimating the model's parameters, and country-by-sector aggregates used to analyze counterfactuals. We use a few additional data sources for sensitivity analyses described in Section VI.

We use plant-level microdata to estimate three parameters of the model, calculated separately for each sector: the elasticity of substitution across product varieties; the shape parameter of the Pareto distribution of firm productivities; and a pollution elasticity. Estimating the elasticity of substitution requires input costs and the value of total sales for each sector. We obtain these data from the U.S. Census Bureau's Annual

\footnotetext{
${ }^{16}$ Specifically, $\eta_{o, s} \equiv \sum_{s}\left[-\frac{\theta_{s}-\left(\sigma_{s}-1\right)\left(1-\alpha_{s}\right)-\sigma_{s} \theta_{s}}{\sigma_{s} \theta_{s}} \beta_{o, s} N X_{o}-N X_{o, s} \frac{\left(\sigma_{s}-1\right)\left(\theta_{s}-\alpha_{s}+1\right)}{\sigma_{s} \theta_{s}}\right]$ and $\psi_{o} \equiv\left[1-\sum_{s} \frac{\theta_{s}-\left(\sigma_{s}-1\right)\left(1-\alpha_{s}\right)}{\sigma_{s} \theta_{s}} \beta_{o, s}\right] /[1-$ $\sum_{s} \frac{\theta_{s}-\left(\sigma_{s}-1\right)\left(1-\alpha_{s}\right)}{\sigma_{s} \theta_{s}} \beta_{o, s}^{\prime}$, where $N X_{o, s}$ are net exports (exports minus imports) in sector $s$.
} 
Survey of Manufactures (ASM) in the first year of our sample, 1990. The ASM is a probabilistic sample of approximately 60,000 establishments per year. ${ }^{17}$ All our calculations with the ASM use sampling weights provided by the Census Bureau so the calculations are representative of the sector as a whole. We also use the ASM data to estimate the Pareto shape parameter; details are described below.

Estimating the pollution elasticity requires two additional pieces of information: pollution abatement expenditures and pollution emissions. Pollution abatement expenditures come from the Pollution Abatement Costs and Expenditures (PACE) survey, which was developed jointly by the U.S. Environmental Protection Agency and the U.S. Census Bureau. ${ }^{18}$ We also use data on air pollution emissions from the U.S. Environmental Protection Agency's National Emissions Inventory (NEI), which provides a comprehensive and detailed report of air pollution emissions from all sources above a low minimum reporting threshold. The NEI was created to provide EPA, federal and state decision makers, the U.S. public, and foreign countries with accurate measures of U.S. pollution emissions. ${ }^{19}$

We compile aggregate data for the U.S. and foreign countries separately for each sector and for each of the years 1990-2008. In particular, we need production and trade data from each country, and we need a measure of pollution emissions in the United States. For production in years 1990-1995, we use data from the Structural Analysis Database of the Organization for Economic Co-operation and Development (OECD). For trade in years 1990-1995, we use data from the OECD's Structural Analysis Database. For production and trade in years 1995-2008, we use data from the World Input-Output Dataset (WIOD). We adjust the WIOD values to exactly match the OECD data in the year 1995. These datasets are reported in twodigit International Standard Industrial Classification codes, third revision. We convert trade data, which are reported in foreign currencies, to nominal U.S. dollars using annual exchange rates from the OECD Statistics dataset (see III.C for more details). We aggregate these data to two countries (the U.S. and Foreign) and to 17 manufacturing sectors defined in Appendix Table 2. We abstract from non-manufacturing activity. Although almost no countries report intra-national trade (goods produced in the same country where they are consumed), we measure it as total production minus total exports.

We measure U.S. pollution emissions with the same National Emissions Inventory (NEI) data used to measure pollution parameters. The NEI is conducted roughly triennially, and we use years 1990, 1996,

\footnotetext{
${ }^{17}$ Between 1990 and 1996, firms with at least 250 employees or $\$ 500$ million in sales were sampled with certainty. Beginning in 1998 , firms with at least 500 employees or $\$ 1$ billion in sales were sampled with certainty. Below these thresholds, the probability of appearing in the sample increases with a firm's size.

${ }^{18}$ Empirical research has used the PACE survey to show that pollution abatement expenditures respond to Clean Air Act county-specific regulations; other work has shown that PACE expenditures are correlated with state-specific foreign direct investment (Keller and Levinson, 2002; Becker, 2005). The 1990 and 2005 PACE data that we use have similar structure and are broadly comparable. The 1999 PACE data, which we do not use, was not comparable with these surveys (Becker and Shadbegian, 2005).

${ }^{19}$ Our measures of particulate matter pollution in the NEI include only filterable particulate matter. This category includes particulates that can be captured on a filter during sampling. It excludes condensible particulate matter, which are gaseous particles that condense to small particles after they cool. It also excludes "secondary" particulate matter, which is formed in the atmosphere through reactions involving other gases like $\mathrm{NO}_{x}$ and $\mathrm{SO}_{2}$. Filterable particulate matter is the only type of particulate matter reported in all NEI years 1990-2008. Several recent studies have used NEI microdata to explore temporal and spatial patterns in emissions trends and to incorporate air pollution into national accounts (Levinson, 2009; Muller and Mendelsohn, 2009; Muller, Mendelsohn, and Nordhaus, 2011). The classification of "polluting" industries in other studies (Greenstone, 2002; Greenstone, List, and Syverson, 2012) relies on an EPA study that used pollution emissions data from the AIRS dataset, which were later integrated into the NEI.
} 
1999, 2002, 2005, 2008. The year 1993 had no inventory. We focus on sector-level emissions of six of the main air pollutants regulated under the Clean Air Act: carbon monoxide $(\mathrm{CO})$, nitrogen oxides $\left(\mathrm{NO}_{x}\right)$, particulate matter less than 10 micrometers $\left(\mathrm{PM}_{10}\right)$, particulate matter less than 2.5 micrometers $\left(\mathrm{PM}_{2.5}\right)$, sulfur dioxide $\left(\mathrm{SO}_{2}\right)$, and volatile organic compounds (VOCs).

\section{Estimation and Results: Parameters and Shocks}

\section{IV.A Estimating Parameters}

We first describe estimation of pollution parameters, then trade and macro parameters. To estimate the pollution parameters, we divide $z_{o d, s}(\varphi)=(1-a(\varphi))^{1 / \alpha_{s}} \varphi l_{o d, s}(\varphi)$ from Assumption 3 by equation (6) from Assumption 2 to show that pollution intensity is a function of abatement investments:

$$
\frac{z}{q}=(1-a)^{(1-\alpha) / \alpha}
$$

Taking logs of equation (16), taking first differences $\Delta$ over time, and allowing for national trends $\eta_{t}$ in emissions intensity and idiosyncratic disturbances $\epsilon_{i, t}$ to pollution intensity gives

$$
\Delta \ln \left(\frac{z_{i, t}}{q_{i, t}}\right)=\frac{1-\alpha}{\alpha} \Delta \ln \left(1-a_{i, t}\right)+\eta_{t}+\epsilon_{i, t}
$$

Since $a$ is the abatement cost share, we expect $(1-\alpha) / \alpha$ to be positive (i.e., pollution intensity increases with 1 minus the abatement expenditure share). Appendix III.C describes the data extract used in these regressions, which combines emissions from NEI, value of shipments and costs from ASM, and pollution abatement costs from PACE. Pollution abatement costs may be endogenous here, leading to biased estimates of $\alpha$. If regulators require the dirtiest plants to spend more on pollution abatement, then reverse causality will bias estimates of $(1-\alpha) / \alpha$ downward. Moreover, our measures of abatement costs and total factor costs are based on PACE and ASM surveys, both of which may contain measurement error. An additional possibility is that abatement costs decrease precisely because regulation causes exit of the dirtiest firms (Levinson and Taylor, 2008).

To address all three of these possible endogeneity concerns, we instrument for changes in the abatement cost share $\ln \left(1-a_{i, t}\right)$ in equation (17) using changes in local environmental regulatory stringency. The EPA requires polluting firms in areas that exceed air quality standards ("nonattainment" counties) to install pollution abatement technologies. These instruments directly address the reverse causality and measurement error concerns described in the previous paragraph. We aggregate data to the county-sector-year level so it helps address the third concern about endogenous plant exit.

We estimate a single $\alpha$ using this regression approach, and we use an additional implication from the model to scale this estimate for each sector. ${ }^{20}$ We use the fact that $\alpha_{s}$ represents pollution tax payments as

\footnotetext{
${ }^{20}$ In principle, we could use our instrumental variables regression approach to estimate $\alpha$ for each of the 17 sectors in our analysis. In practice, we have a limited sample of plants that we observe in all three of the NEI, PACE, and ASM datasets. When dividing these plants into 17 sectors, the samples are too small to estimate equation (17) separately for each sector.
} 
a share of production costs. As equation (8) implies, under Cobb-Douglas production with constant returns to scale, the output elasticity $\alpha_{s}$ is equal to the share of firm costs which represent pollution taxes.

Since the U.S. does not have pollution taxes, we cannot directly observe the share of firm costs that represent pollution taxes. If the pollution tax rate is constant across sectors, however, then the relative value of $\alpha_{s}$ across sectors is proportional to the tons of pollution emitted per dollar of input costs in each sector. For example, if the basic metals sector emitted twice as much pollution per dollar of input costs as the textiles sector did, then we would have $\alpha_{\text {basic-metals }}=2 \alpha_{\text {textiles }}$. We use this approach to measure relative differences in $\alpha$ across sectors. We then scale these values so the mean across all sectors equals the economywide elasticity of pollution emissions intensity with respect to abatement costs from our equation (17) regression estimate.

As discussed earlier, this approach to recovering pollution elasticities relies heavily on Assumptions 2 and 3, which together imply this Cobb-Douglas result. Without this Cobb-Douglas relationship, regardless of whether it is assumed directly or derived from microfoundations like (17) and (8), it would be much less straightforward to recover estimates of the pollution elasticity $\alpha$ or to use the model to study counterfactuals.

Table 1 reports the first-stage, reduced-form, and instrumental variable regressions of equation (17) for the five pollutants in the NEI for which we have an instrumental variable for abatement expenditures. It analyzes each pollutant in a separate regression, where county-level nonattainment designations imposed under the Clean Air Act serve as instrumental variables for the abatement cost shares in Panel C. ${ }^{21}$ Columns (1) through (5) analyze each pollutant separately, and Column (6) uses total emissions of all pollutants in tons as a summary measure of emissions. All regressions report standard errors in parentheses, clustered by commuting zone.

Panel A of Table 1 presents the first-stage regressions which show that designating a county as nonattainment increases the proportion of firm costs devoted to pollution abatement in sectors that account for a larger share of pollutant $p$ emissions. All of these first-stage regressions have negative signs, implying that regulated firms increase the share of costs devoted to pollution abatement by 6 percent relative to the baseline share. For the pooled regression in column (6), the first-stage F statistic of 42 (equal to the square of the t-statistic) suggests this instrument is quite strong. For the pollutant-specific regressions, estimates for $\mathrm{CO}, \mathrm{NO}_{x}$, and VOCs have strong instruments (F-statistics ranging from 14 to 49), though the first-stage F-statistics for particulate matter are fairly small (1.4 and 3.4).

Panel B presents evidence from reduced form regressions of pollution emissions intensity on the regulation instrument. ${ }^{22}$ The regression estimates show that polluting sectors in newly regulated counties decrease their

\footnotetext{
${ }^{21}$ Technically, the instrumental variable we use for changes in abatement expenditures is an interaction between a variable indicating the pollution intensity of pollutant $p$ of a sector in 1990 (i.e., PolluterShare ${ }_{j p}=\frac{\text { IndustryEmissions }_{j p}}{\text { TotalEmissions }_{p}}$ ) and whether the county switches into nonattainment for any pollutant between 1990 and 1993 (i.e., 1[Nonattain ${ }_{c}$ ]=1). Thus, the instrumental variable is PolluterShare ${ }_{j} \times 1$ [Nonattain ${ }_{c}$ ]. We allow for a county to be in nonattainment if it violates the EPA standards for any of the pollutants regulated under the Clean Air Act. In practice, nonattainment is pollutant specific. We model nonattainment in this way in order to capture cross-pollutant regulatory spillovers and to ameliorate the fact that many pollutants have little variation over this time period (e.g. CO). The focus on counties that switched into nonattainment between 1990 and 1993 is meant to capture all the counties that became newly regulated under the 1990 Clean Air Act Amendments. We include the lower order interaction terms in all regression models to facilitate identification of the difference-in-differences interaction term.

${ }^{22}$ The dependent variable in Panels $\mathrm{B}$ and $\mathrm{C}$ is $\log ($ (pollution+1)/output) in order to prevent attrition for non-polluting county $\times$ sector $\times$ year cells in the sample.
} 
pollution per unit of output after the regulations go into place. The relationship between nonattainment and pollution emission rates is negative for all pollutants, imprecise for most pollutants, but precise for VOC emissions and for total pollution emissions. Panel $\mathrm{C}$, which presents our instrumental variable regression estimates, shows that changes in pollution abatement cost shares, instrumented with changes in Clean Air Act regulations, predict changes in pollution intensity. Panel D presents our estimates of $\alpha$ that come from a nonlinear transformation of the regression coefficient $(1-\alpha) / \alpha$. The estimates of $\alpha$ range from 0.008 to 0.017 . When we aggregate over pollutants in column (6), we obtain the value $\alpha=0.011$, which is statistically significant at the one-percent level.

Table 2 shows estimates separately for each sector; the various pollutants have similar patterns (Appendix Table 3). The resulting pollution elasticities, estimated using the pooled sample of all pollutants in Table 2, range from 0.001 to 0.048. The dirtiest sectors are Basic Metals and Other Non-Metallic Minerals.

The overall estimate of 0.011 implies that firms are behaving as if they pay one percent of their total production costs to pollution taxes. We lack a method to test this number independently, but we can compare it to two related statistics. First, the PACE data report that manufacturing pollution abatement costs are about half a percent of total manufacturing sales (U.S. Census Bureau, 2008). Second, Greenstone, List, and Syverson (2012) find that nonattainment designations decrease the total factor productivity of regulated firms by 2.6 percent. Because these numbers all characterize the economic costs of environmental regulation, it is notable that are of the same order of magnitude.

We also estimate the elasticity of substitution and shape parameter of the Pareto distribution separately for each sector, by building on the approach used in Hsieh and Ossa (2016) and Antras, Fort, and Tintelnot (2017) (Table 2). Since these parameters have been estimated elsewhere with similar methodology, methodological details are described in Appendix III.D. We estimate the Pareto shape parameter $\theta_{s}$ by regressing the log of a firm's sales rank on the log of its sales using the microdata from the 1990 Annual Survey of Manufactures. The regression estimates of the Pareto shape parameter are extremely precise, which reflects the fact that power law distributions describe firm size well, at least in the upper tail (Gabaix, 2009). We estimate the elasticity of substitution $\sigma_{s}$ by taking the ratio of the value of shipments to production costs. ${ }^{23}$ The estimates support our assumption that $\theta_{s}>\left(\sigma_{s}-1\right)\left(1-\alpha_{s}\right)$.

\section{IV.B Recovering Historic Values of Shocks}

This paper's research question of why pollution followed its historical path requires studying counterfactuals where some shocks take on their actual, historical values, and other shocks do not. Analyzing such counterfactuals requires measuring the historic values of each shock for each year in 1990-2008. We now explain

\footnotetext{
${ }^{23}$ These methods are literally consistent with the model, but it is worth emphasizing that they do not extrapolate well to other models. Our methodology for estimating the trade elasticity relies on the assumption that productivity has a Pareto distribution. Our methodology for estimating the elasticity of substitution relies on the assumption that firms engage in monopolistic competition. It is feasible in principle to use other features of the model to estimate these parameters, such as gravity equations for bilateral trade, which are more robust to model misspecification and which extrapolate more easily to other models. With our data on the total value of bilateral trade flows, however, it is difficult to implement such methods. We are not aware of other papers that estimate both of these two parameters separately for a variety of sectors using such other methods, though it is noteworthy that the mean values we obtain for these parameters are similar to economy-wide estimates of these parameters from other studies.
} 
how we use implications of the model together with country $\times$ sector aggregate data to recover historic values of the paper's four main shocks: foreign competitiveness; domestic competitiveness; expenditure shares; and environmental regulation.

\section{Foreign Competitiveness}

Informally, "competitiveness" in the model measures the ability of a country to sell a wide variety of products at relatively low prices. We describe a single "foreign competitiveness" shock because analyzing the causes of changes in U.S. pollution does not require distinguishing which underlying forces change foreign competitiveness. $^{24}$ Formally, foreign competitiveness combines foreign productivity, foreign environmental regulation, and foreign exporting trade costs:

$$
\begin{aligned}
\hat{\Gamma}_{o d, s}^{*} \quad & \equiv\left(1 / \hat{b}_{o, s}\right)^{-\theta_{s}}\left(\hat{\tau}_{o d, s}\right)^{-\theta_{s} /\left(1-\alpha_{s}\right)}\left(\hat{f}_{o d, s}\right)^{1-\theta_{s} /\left(\sigma_{s}-1\right)\left(1-\alpha_{s}\right)}\left(\hat{t}_{o, s}\right)^{-\alpha_{s} \theta_{s} /\left(1-\alpha_{s}\right)}, o \neq U . S . \\
& =\frac{\hat{\lambda}_{o d, s}}{\hat{M}_{o, s}^{e} \hat{w}_{o}^{-\theta_{s}}}\left(\hat{P}_{d, s}\right)^{-\frac{\theta_{s}}{1-\alpha_{s}}}\left(\frac{\hat{\beta}_{d, s}}{\hat{w}_{d}} \frac{R_{d}^{\prime}-\widehat{N X_{d}} N X_{d}}{R_{d}-N X_{d}}\right)^{1-\frac{\theta_{s}}{\left(\sigma_{s}-1\right)\left(1-\alpha_{s}\right)}}
\end{aligned}
$$

(For derivation, see Appendix II.H.) The first equation defines this shock, and the second shows how we measure it. One can see where this shock contributes to the analysis of counterfactuals by observing that the right-hand side of equation (18) appears in both the numerator and denominator of the second equilibrium condition in changes, which is equation (13). An asterisk $\left(^{*}\right)$ denotes the actual, historic value of a shock. The right-hand side of equation (19) shows that the change in foreign competitiveness can be measured by the change in the share of U.S. expenditure on goods from a foreign country, divided by the change in nominal income times firm entry.

\section{U.S. Competitiveness}

Shocks to U.S. competitiveness represent changes in U.S. productivity and trade costs for exports, which are allowed to vary across sectors and over time. These have similar definition and measurement:

$$
\begin{aligned}
\hat{\Gamma}_{o d, s}^{*} & \equiv\left(1 / \hat{b}_{o, s}\right)^{-\theta_{s}}\left(\hat{\tau}_{o d, s}\right)^{-\theta_{s} /\left(1-\alpha_{s}\right)}\left(\hat{f}_{o d, s}\right)^{1-\theta_{s} /\left(\sigma_{s}-1\right)\left(1-\alpha_{s}\right)}, o=U . S . \\
& =\hat{t}_{o, s}^{\frac{\alpha_{s} \theta_{s}}{1-\alpha}} \frac{\hat{\lambda}_{o d, s}}{\hat{M}_{o, s}^{e} \hat{w}_{o}^{-\theta_{s}}} \hat{P}_{d, s}^{-\frac{\theta_{s}}{1-\alpha_{s}}}\left(\frac{\hat{\beta}_{d, s}}{\hat{w}_{d}} \frac{R_{d}^{\prime}-\widehat{N X_{d}} N X_{d}}{R_{d}-N X_{d}}\right)^{1-\frac{\theta_{s}}{\left(\sigma_{s}-1\right)\left(1-\alpha_{s}\right)}}
\end{aligned}
$$

(For derivation, see Appendix II.H.) Again the first equation defines the shock and the second shows how we measure it. Because we have pollution emissions data for the U.S. but not foreign countries, we separate the environmental regulation term $\hat{t}_{o, s}$ from other components of U.S. competitiveness.

We recover a separate foreign competitiveness shock for each sector and year and also a separate domestic competitiveness shock for each sector and year. For example, we recover one foreign competitiveness shock

\footnotetext{
${ }^{24}$ We also lack the data to measure each component of foreign competitiveness separately. Separately measuring productivity and trade costs would require foreign producer price index data, which are not available for most countries, sectors, and years. Separately measuring the effect of foreign environmental regulation requires data on air pollution emissions for each country $\times$ sector, which are not available.
} 
for the basic metals sector, a separate foreign competitiveness shock for the chemicals sector, etc. If some force has increased foreign competitiveness only in dirty industries, these shocks are designed to capture that force. For example, foreign countries might have improved their productivity in dirty industries, might have begun facing lower trade costs for exports in dirty industries, or might have decreased the stringency of environmental regulation for dirty industries. ${ }^{25}$

\section{Expenditure Shares}

We measure shocks to sectoral expenditure shares as the share of a country's expenditure on sector $s$ in a counterfactual, divided by the share of the country's expenditure on sector $s$ in a baseline year. ${ }^{26}$

$$
\hat{\beta}_{d, s}^{*}=\frac{\sum_{o} X_{o d, s}^{\prime} / \sum_{o, s} X_{o d, s}^{\prime}}{\sum_{o} X_{o d, s} / \sum_{o, s} X_{o d, s}}
$$

We include this shock in our analysis because with it, when all shocks are set to exactly match their historic levels, the model can re-create historic paths of emissions, production, and trade. ${ }^{27}$

\section{Environmental Regulation}

Finally, we measure shocks to environmental regulation by rearranging equation (14):

$$
\hat{t}_{o, s}=\frac{\hat{M}_{o, s}^{e} \hat{w}_{o}}{\hat{Z}_{o, s}}
$$

The change in environmental regulation equals the change in the mass of entering firms times the change in factor prices, divided by the change in pollution emissions.

This result helps contrast the technique effect from the statistical decomposition with the environmental regulation shock analyzed in this model. The technique effect for a specific sector is defined as the change in pollution per real unit of output within a sector, or $\hat{Z}_{o, s} /\left(\hat{R}_{o, s} / \hat{P}_{o, s}\right)$. Combining the previous expressions

\footnotetext{
${ }^{25}$ Because sector is the finest unit of analysis in our model, these shocks do not separately distinguish within-sector changes. Suppose China became less competitive at producing dirty structural steel from blast furnace plants, but became more competitive at producing cleaner rebar steel from mini-mill plants. Our sector-level analysis might interpret this as no aggregate change in foreign competitiveness for the basic metals sector, whereas competitiveness actually grew in the dirty products within this sector but decreased in the clean products within this sector. The finding of the statistical decomposition that composition effects are similarly small both across industries and products provides suggestive evidence that this is not a first-order channel for studying pollution intensity.

${ }^{26}$ Our specification of CES preferences implies that we abstract from consumer tastes changing among varieties within a sector.

${ }^{27}$ Exactly matching historic data requires a fifth shock, to trade imbalances; see Appendix III.E. Consumer expenditure in this model involves two stages of budgeting: expenditure is first allocated to each sector, with expenditure shares equal to Cobb-Douglas exponents; and then across varieties within a sector. The model can therefore only match historic changes in expenditure shares across sectors if it allows changes in the Cobb-Douglas exponents over time. In the absence of changes in the Cobb-Douglas exponents, the model could match all historic changes in the data except changes in expenditure shares across sectors. One could therefore think of this expenditure share shock as a residual. This shock will primarily affect the composition of production and consumption across sectors, rather than the emissions intensity within a given sector. Given the conclusion of Section 2 that most historic decreases in emissions intensity have been within rather than across products, this shock to expenditure shares is unlikely to play a large role in explaining decreases in emissions.
} 
for changes in pollution $\hat{Z}_{o, s}$, changes in factor prices $\hat{w}_{o}$, and changes in firm entry $\hat{M}_{o, s}$ shows that environmental regulation in this model can be written as $\hat{t}_{o, s}=\hat{Z}_{o, s} / \hat{R}_{o, s}$ (see derivation in Appendix II.I). In other words, all three forces we study - trade costs, productivity, and environmental regulation - determine the technique effect in the statistical decomposition, but trade costs and productivity do so through changes in the price index $\hat{P}_{o, s}$.

\section{IV.C Description of Environmental Regulation Shocks}

The previous subsection described how we calculate historic values of each of the shocks in the model. We calculate these shocks primarily to use them in decomposing historic changes in pollution emissions into the share accounted for by changes in environmental regulation, productivity, and trade costs. The levels of some of these shocks, however, are interesting in their own right. We focus on the environmental regulation shock here; shocks to expenditure shares, wages, and firm entry are less directly relevant to the question of why pollution emissions have declined so we discuss these in Appendix III.E. ${ }^{28}$

Figure 4 suggests that the implied pollution tax for $\mathrm{NO}_{x}$ for U.S. manufacturing nearly doubled between 1990 and 2008. As Section VI.B describes, the rate of increase in implicit taxes for other pollutants was if anything more rapid. While the level of pollution taxes for dirty industries may have been much greater in 1990, the rate of increase in the stringency of implicit taxes on dirty industries between 1990 and 2008 generally resembled the rate of increase of taxes for clean industries over this period.

Is this a realistic change in the stringency of environmental regulation? We emphasize that the U.S. does not actually have a pollution tax on $\mathrm{NO}_{x}$. A way to think about the meaning of this tax is as follows: if all U.S. environmental regulation relevant to $\mathrm{NO}_{x}$ emissions from manufacturing were replaced with a pollution tax, what change in that tax rate would lead to the changes in firm behavior that we actually observe? Given dramatic expansion of $\mathrm{NO}_{x}$ regulation over these 18 years, a doubling in the implicit tax on pollution seems plausible. A very incomplete list of actual changes in $\mathrm{NO}_{x}$ regulations includes: a nearly doubling of the number of counties in ozone nonattainment between 2003 and 2004, which may be the largest expansion of nonattainment areas since the Clean Air Act began; the 1990 Clean Air Act Amendments, which required large $\mathrm{NO}_{x}$ emitters in ozone nonattainment areas to install stringent pollution controls by 1995; the RECLAIM cap-and-trade for Los Angeles, which began in 1993; the Ozone Transport Commission cap-and-trade for New England, which began in 1999; and the $\mathrm{NO}_{x}$ Budget Trading Program for the Eastern U.S., which began in $2003 .^{29}$

\footnotetext{
${ }^{28}$ We focus on results for $\mathrm{NO}_{x}$ regulation, both since $\mathrm{NO}_{x}$ emissions are measured with higher-quality methods than most other pollutants are, and because we have detailed data on one major regulation, the $\mathrm{NO}_{x}$ Budget Trading Program. According to the $2008 \mathrm{NEI}$, which reports monitoring method for almost all plants, over half of manufacturing $\mathrm{NO}_{x}$ emissions are reported based on continuous emissions monitoring systems or other direct measures. We considered focusing on $\mathrm{SO}_{2}$, but according to plant-level data we obtained from the EPA Clean Air Markets Division, the Acid Rain Program which created a cap-and-trade system for $\mathrm{SO}_{2}$ in most years included only one or two manufacturing plants.

${ }^{29}$ Ozone nonattainment regulations target $\mathrm{NO}_{x}$ and VOC emissions since ozone pollution forms through photochemical reactions involving $\mathrm{NO}_{x}$, VOCs, heat, and sunlight. The 1990 Clean Air Act Amendments began requiring plants in ozone nonattainment areas to install Reasonably Available Control Technology (RACT). Some of these policies focus more on electricity generating units than on manufacturing. However, the relevant statistic here is the share of manufacturing pollution to which these policies applied.
} 


\section{Counterfactuals}

\section{Methodology}

To analyze counterfactuals. We choose a counterfactual scenario (e.g., what if U.S. environmental regulation had evolved as we observe in the years 1990-2008, but other shocks had remained fixed at their 1990 levels?). For each year 1990-2008, we then find the firm decisions, including pollution emissions, which would have prevailed in that counterfactual. Finally, we compare those counterfactual emissions against the actual emissions that occurred. Appendix III.F describes this procedure in more detail. We show some results separately for "dirty" and "clean" sectors; these results define dirty sectors as sectors with values of the pollution elasticity $(\alpha)$ above the national mean of 0.011 , and clean sectors as all others. ${ }^{30}$

Each counterfactual creates direct and indirect effects. For example, a shock to environmental regulation will affect pollution directly. Environmental regulation may also affect average output per worker, and this change in output per worker may create indirect effects on pollution. In this example, we attribute both the direct and indirect effects to environmental regulation, and not to productivity. More broadly, when we add a shock to a specific counterfactual (e.g., changing environmental regulation), we attribute all resulting changes in pollution to that shock, regardless of whether these changes in pollution occur directly or indirectly. This is a general equilibrium decomposition in which all prices and quantities can change in response to a single exogenous shock.

\section{Results}

Figure 5 plots the time paths of pollution emissions under four separate counterfactuals, indicated in the legend; Appendix Table 1 summarizes some numbers corresponding to these graphs. The solid line shows actual historic pollution emissions. Each dashed line shows the model's counterfactual prediction of what would have happened if the indicated shock had followed its historic path and other shocks had remained fixed at their 1990 levels. For example, the line with stars shows the pollution which the U.S. would have emitted in a counterfactual where foreign competitiveness followed its historic path but other shocks remained fixed at their 1990 levels. Each line is normalized to 100 in the year 1990. The markers on the dashed lines show the years when pollution emissions are observed in the NEI rather than linearly interpolated.

Figure 5 suggests that foreign competitiveness had a limited effect on U.S. manufacturing pollution emissions. Between 1990 and 2000, in a counterfactual where foreign competitiveness followed its actual historic path and other shocks remained unchanged at their 1990 values, pollution would have increased by a few percentage points. After 2000, when China's growth accelerated, foreign competitiveness led to modest decreases in U.S. pollution of a few percentage points. By 2008, in this counterfactual, U.S. pollution emissions were a few percent below their 1990 value. Ultimately, shocks to foreign competitiveness account for little of the total decline in U.S. pollution.

\footnotetext{
${ }^{30}$ The dirty sectors are: Paper and Publishing; Coke, Refined Petroleum, and Fuels; Chemicals; Other Non-metallic Minerals; and Basic Metals. The clean sectors are: Food, Beverages, and Tobacco; Textiles, Apparel, Fur, and Leather; Wood Products; Rubber and Plastics; Fabricated Metals; Machinery and Equipment; Office, Computing, and Electrical; Radio, Television, and Communication; Medical, Precision, and Optical; Motor Vehicles and Trailers; Other Transport Equipment; and Furniture, Other, and Recycling.
} 
Given the large effects of China's economic growth over this time on U.S. manufacturing employment (Autor, Dorn, and Hanson, 2013), or the scope of NAFTA for Mexico's access to U.S. markets (Caliendo and Parro, 2014), one might have expected foreign competitiveness to cause large decreases in pollution. Figure 5 suggests that this was not the case. Why didn't Chinese or other foreign competition more substantially affect U.S. pollution over this time period? A few ideas help explain. Although China's exports are concentrated in low-skilled sectors, they were not especially concentrated in dirty sectors. Moreover, aggregate data on U.S. manufacturing show that the effect of China's growth on manufacturing output or on value added was much smaller than its effect on employment (Pierce and Schott, 2016). Finally, one effect of foreign competition would be to shift the composition of U.S. production to cleaner or dirtier types of products, and the statistical decomposition from Section I provided little evidence that such a shift occurred.

Figure 5 suggests that changes to U.S. competitiveness explain most of the change in U.S. manufacturing $\mathrm{NO}_{x}$ emissions. Between 1997 and 2003, the effect of U.S. competitiveness alone caused U.S. pollution emissions to increase by about 10 percent. After 2003, the effect of this shock was to decrease pollution, but for most pollutants by much less than the observed decrease. How can we make sense of this finding that U.S. competitiveness does not explain most of the change in pollution? Figure 2 and plant-level regressions from papers discussed in the introduction suggest that more productive firms emit less pollution per unit of output. The model reflects this fact, since at the plant level, more productive firms in the model emit less pollution per unit of output. However, at the economy-wide level, while productivity growth may diminish factor demand per unit of output, factors are used for other output in the same or other plants. Unless productivity growth is much larger in dirty industries, productivity growth may have limited scope to affect pollution. ${ }^{31}$

Figure 5 also quantifies how changing consumer expenditure shares across sectors affected pollution emissions, and it suggests they play little role in explaining the historic trends in pollution emissions. Between the years 1990 and 2000, expenditure shares on clean sectors decreased slightly, and this decreased U.S. pollution emissions. After 2000, by contrast, increasing expenditure on pollution-intensive sectors leads to an increase in U.S. pollution emissions of 10 to 20 percent.

The first three counterfactuals suggest that foreign competitiveness, domestic competitiveness, and U.S. expenditure shares do not account for a majority of the decrease in pollution emissions. By contrast, Figure 5 suggests that changes in environmental regulation over this time period account for much of the decrease in pollution emissions. In the early years of this analysis, regulation by itself would have caused about 10 percent less pollution reduction than actually occurred. By the year 2008, regulation explains most of the change in pollution. The pattern is similar across pollutants and years.

The findings of this section that regulation explains most of the observed changes in emissions across pollutants and that most pollutants had similar magnitude declines in emissions together imply that environmental regulation had similar effects over this time period for the pollutants we study. It is difficult to assess

\footnotetext{
${ }^{31}$ Another way to think about these patterns is in terms of scale and technique effects. Proposition 1 shows that increasing a sector's productivity decreases its emissions intensity, which corresponds to the technique effect decreasing total emissions. But given inelastic factor supply, the increased productivity leads to increased total output, which corresponds to the scale effect increasing total emissions. The offsetting signs of the technique and scale effects here may help explain why even large productivity growth may have limited effects on total pollution emissions.
} 
this conclusion independently, but cursory reflection suggests it is plausible. Most pollutants experienced increased regulatory stringency over this time period. We have discussed in previous sections the many $\mathrm{NO}_{x}$ regulations that took place over this time period. The pollutants PM and VOC also experienced large expansions in Clean Air Act county nonattainment designations (and increasingly stringent nonattainment standards within these designations). The 1990 Clean Air Act Amendments also established new guidelines for CO that depend on the degree of local air quality violations. Areas in "moderate" or "serious" violation were required to implement programs introducing oxygenated fuels and/or enhanced emission inspection programs, among other measures. The 1990 Clean Air Act Amendments established the Acid Rain Program, which was designed to control $\mathrm{SO}_{2}$ emissions over this time period. As mentioned above, there are additional air pollution programs at local, state, and regional levels, but the relative importance of these regulations compared to federal regulations is empirically unknown. In addition, firms and industries which emit large amounts of one pollutant often emit large amounts of other pollutants. This suggests that some types of abatement for one pollutant may affect other pollutants at the plant.

\section{Alternative Explanations}

This analysis finds that the stringency of environmental regulation for criteria air pollutants more than doubled between 1990 and 2008, and this change explains much of the observed national decrease in pollution emissions. We now consider alternative explanations for the decrease in pollution emissions.

\section{VI.A Do Shocks Besides Environmental Regulation Affect Pollution Intensity?}

Proposition 1 provided analytical evidence that marginal increases in pollution taxes, productivity, and trade liberalization each decrease sector-specific pollution intensity. We now provide some quantitative evidence as to how other channels, aside from pollution taxes, affect pollution intensity.

We consider a series of counterfactuals which each take data for 1990, increase or decrease the level of foreign competitiveness in a sector, then calculate the resulting change in U.S. pollution intensity for that sector. Appendix Figure 5 plots the result. ${ }^{32}$ The $\mathrm{x}$-axis describes the change in foreign competitiveness and the y-axis records the resulting change in U.S. sector-specific emissions intensity. The value 1 on the $\mathrm{x}$-axis describes a counterfactual where a shock does not change, and the value 100 on the $\mathrm{y}$-axis describes an outcome where pollution intensity for the sector does not change. We plot results separately for each of the 17 sectors (thin grey lines), and also show the mean change in pollution intensity across all sectors (thick blue line).

Appendix Figure 5 shows that increasing foreign competitiveness in a sector decreases U.S. pollution intensity in that sector. This shows that the analytical results of Proposition 1 hold quantitatively for non-marginal changes. This also implies that the conclusions of the model-based decomposition are not

\footnotetext{
${ }^{32}$ For brevity, we present this sensitivity analysis for $\mathrm{NO}_{x}$ emissions only. To create these graphs, we consider shocks ranging from 0.50 to 2.0 in increments of 0.25 . For example, a shock of 0.50 in Appendix Figure 5 represents a counterfactual where foreign competitiveness falls to half of its 1990 value but U.S. competitiveness and U.S. environmental regulation remain at their 1990 values. For each counterfactual, we measure the resulting change in pollution. We then plot these results for the entire range of shocks from 0.50 to 2.0 .
} 
predestined given the findings of Section I (i.e., foreign competitiveness in this model can affect pollution intensity). This figure also shows that the magnitude of this effect is not large. Doubling foreign competitiveness only decreases pollution intensity by a few percentage points for most sectors.

Two reasons help explain why these magnitudes are not large. First, the U.S. is among the world's most

closed countries, with an import penetration ratio below 10 percent. Proposition 1 shows that the effect of trade liberalization on pollution intensity is larger for relatively open countries and sectors, and so increasing foreign competitiveness may have limited effects on pollution intensity for a closed country like the U.S.

Second, models with similar trade assumptions to ours find that trade liberalization does not have large magnitude effects on real income. Even extreme trade policies like a 40 percent uniform global tariff (whereas mean current U.S. and EU tariffs are around 2 percent) would only decrease U.S. GDP by less than one percent (Costinot and Rodriguez-Clare, 2014). The key potential channels for those effects - reallocation and selection, and associated price index changes - are similar in that setting and ours. In monopolistic competition models with heterogeneous firms like we study, part of the benefit of trade liberalization comes through reallocation of output to more productive firms. The correlation of productivity and firm-level pollution intensity is around minus one (see Figure 2), so the magnitude of the increase in productivity and real income due to trade liberalization may be broadly similar to the decrease in pollution intensity due to trade liberalization.

In order for trade liberalization to account for more than a small share of the decreases in emissions documented in Figure 1, trade must have very different effects on pollution emissions than trade does on real income. One way to interpret our results is that in our model, which reflects a set of leading frameworks from the international and environmental literatures, trade's effects on emissions are not vastly larger than trade's effects on real income.

As discussed earlier, one important caveat in this analysis deals with the ability of the model to account for composition changes within a sector. Because sector is the finest unit of analysis in the model, a decrease in foreign competitiveness for dirty products within a sector and an increase in foreign competitiveness for clean products within that sector could offset each other and appear in the model as no net change in foreign competitiveness for that sector. If such changes were widespread, they could represent a channel which is not captured in this model and through which trade decreases emissions intensities. The conclusion of Section I that product-level patterns in emissions intensities are very similar to industry-level patterns in emissions intensities provides some evidence that this is not a first-order issue in reality, though it remains an issue the model is not designed to accommodate.

\section{VI.B Does the Model Describe Environmental Regulation?}

We now provide two tests of whether the shock we call "environmental regulation" corresponds to true regulation. We first compare our model-based measure of regulation to one well-known change in environmental regulation, the $\mathrm{NO}_{x}$ Budget Trading Program (NBP). We then calculate model-based measures of regulation for carbon dioxide, a pollutant which largely has not been regulated. 


\section{NO $x$ Budget Trading Program}

The NBP was a cap-and-trade program for $\mathrm{NO}_{x}$ emissions from power plants and large industrial plants in the Eastern U.S.. The EPA distributed permits to each source and allowed trading of permits. Most sources were electricity generating units but many oil refineries, chemical plants, and other manufacturing plants faced NBP regulation. ${ }^{33}$ We obtain data from the EPA's Air Markets Program Data (AMPD) on facilities regulated under the NBP. We link the AMPD data to the NEI data by requiring an exact match on county and industry and a non-exact match on facility name, longitude, and latitude. ${ }^{34}$ About 13 percent of manufacturing emissions of $\mathrm{NO}_{x}$ came from manufacturing plants that were subject to the NBP.

We explore how our model-driven measure of pollution taxes corresponds with the NBP by using the following difference-in-difference-in-differences regression model:

$$
\ln \left(t_{r s t}\right)=\beta_{1}\left(1\left[N B P_{r}\right] \times 1[N B \text { PIndustry }] \times 1[\text { Year }>2002]\right)+\eta_{r t}+\gamma_{s t}+\psi_{r s}+\epsilon_{r s t}
$$

We regress our measure of implied pollution taxes, $t$, as defined in equation (23), in sector $s$ of NBP region $r$ and year $t$, on a three-way interaction term describing the effect of being in an NBP-regulated sector in an NBP state in the years after the regulation went into place. We aggregate the data to the sector $\times$ region $\times$ year level, where a region is defined as inside/outside the NBP region, and sectors are defined by the 17 manufacturing sectors defined in Table $2 .{ }^{35}$ We control for region $\times$ year fixed effects $\eta_{r t}$, sector $\times$ year fixed effects $\gamma_{s t}$, and region $\times$ sector fixed effects $\psi_{r s}$. With these sets of fixed effects, the model effectively controls for time-invariant observed or unobserved determinants of pollution taxes by sector $\times$ region, common transitory shocks to sectors across regions, and transitory shocks within a region that affect all sectors similarly. The identifying assumption of the model is that there exist no transitory shocks specific to regulated sectors in the NBP region in the years after the NBP went into place. While this assumption is inherently untestable, the data permit some indirect tests. For example, data from years prior to the change in regulations permit the analysis of pre-trends across treatment and control groups prior to the change in policy. The coefficient of interest, $\beta_{1}$, describes how the NBP affected pollution taxes in polluting sectors of regulated states.

Appendix Table 4 presents results from several versions of equation (24). Each column represents a separate regression, and parentheses show standard errors robust to clustering at the sector $\times$ region level. The first column represents the baseline specification and suggests that polluting manufacturing firms in the NBP region in the years after the NBP went into place experienced a 1.195 log point increase in pollution taxes, or approximately $2.3 \times$ increase relative to the counterfactual. ${ }^{36}$ Column $(2)$ adds sector $\times$ year fixed effects, and the results are nearly identical. Columns (3) and (4) add region $\times$ year fixed effects which slightly

\footnotetext{
${ }^{33}$ Economic research has studied the NBP, including differences-in-differences-in-differences research designs to measure effects on pollution, health, and employment (Fowlie, 2010; Curtis, 2018; Deschenes, Greenstone, and Shapiro, 2017).

${ }^{34}$ The NPB data's only measure of industry is a facility's "source category." We exclude NBP participants with cogeneration, electric utility, or small power producer as source category, since these are typically not manufacturing.

${ }^{35}$ States in the NBP region include Alabama, Connecticut, Delaware, Illinois, Indiana, Kentucky, Maryland, Massachusetts, Michigan, New Jersey, New York, North Carolina, Ohio, Pennsylvania, Rhode Island, South Carolina, Tennessee, Virginia, Washington DC, and West Virginia. All other states are defined as outside the NBP region.

${ }^{36} 2.3 \times$ is calculated as $\exp (1.195)-1=2.303$.
} 
attenuate results, but the results remain statistically significant across all 4 specifications.

Figure 6 shows an event study version of equation (24), including leads and lags in event time. ${ }^{37}$ The figure suggests two main findings: First, in the years leading up to the policy, the implied taxes in the treatment and control groups are relatively similar and are not statistically different. This lends some reassurance that the research design is capturing a sharp event that affects NBP-regulated plants in the NBP region in the years after the NBP rather than some underlying trend in the data. Second, the years after the policy reveal a sharp and statistically significant increase in the implied pollution taxes for the $\mathrm{NO}_{x}$ polluting sectors in the NBP region. The magnitudes of these estimates correspond closely to those from Appendix Table 4.

\section{Carbon Dioxide}

This paper focuses on six "criteria" air pollutants which have been a focus of U.S. environmental regulations, in part because they have available data. This section analyzes a pollutant that has not experienced much regulation over this period, $\mathrm{CO}_{2} \cdot{ }^{38} \mathrm{CO}_{2}$ emissions also contribute to climate change, so it is important to understand the underlying forces driving changes in manufacturing $\mathrm{CO}_{2}$ emissions. ${ }^{39}$ Appendix III.C provides additional details on the $\mathrm{CO}_{2}$ data.

Figure 7a shows our inferred measure of the stringency of environmental regulation for each of the pollutants in this study, including $\mathrm{CO}_{2}$. The dashed lines in that figure show that between 1990 and 2008 , the stringency of regulation for most air pollutants increased by 75 to 250 percent. However, the solid line suggests the stringency of $\mathrm{CO}_{2}$ regulation was more flat over this entire time period, and if anything actually decreased modestly. ${ }^{40}$ Although criteria air pollution regulation became much more stringent over this time period, $\mathrm{CO}_{2}$ regulation hardly changed. The fact that we find such large increases in the implicit tax rate for air pollution emissions and smaller changes in the implicit tax rate for $\mathrm{CO}_{2}$ emissions provides an additional piece of evidence that the model-driven measures of pollution taxes capture realistic features of the regulatory environment rather than changes in other associated economic variables.

Figure $7 \mathrm{~b}$ shows the counterfactual decomposition for $\mathrm{CO}_{2}$ emissions. The graph is the same as Appendix Figure 5, except that it shows results for $\mathrm{CO}_{2}$ rather than for criteria air pollutants. The solid blue line

${ }^{37}$ Specifically, we estimate models of the following form

$$
\ln \left(\hat{t}_{r s t}\right)=\sum_{\tau=1990}^{2008} \beta_{k}\left(1\left[N B P_{r}\right] \times 1\left[N B \text { Regulated }_{s}\right] \times 1[\text { Year }=\tau]\right)+\eta_{r t}+\gamma_{s t}+\psi_{r s}+\epsilon_{r s t} .
$$

We normalize the event-time coefficient in the year prior to the policy to 0 .

${ }^{38}$ The Northeast states began a cap-and-trade system for $\mathrm{CO}_{2}$ emissions, the Regional Greenhouse Gas Initiative (RGGI), in 2008. Boulder, Colorado, and San Francisco implemented small carbon taxes in 2006 and 2008, respectively. States and the federal governments operate other taxes on various fuels which emit $\mathrm{CO}_{2}$.

${ }^{39}$ Local pollution regulation may have limited effects on $\mathrm{CO}_{2}$ emissions because end-of-pipe abatement technologies for local pollution (e.g., scrubbers) do not decrease $\mathrm{CO}_{2}$. For example, the $\mathrm{NO}_{x}$ Budget Trading Program discussed above caused 3540 percent decreases in $\mathrm{NO}_{x}$ emissions from regulated power plants but essentially no change in $\mathrm{CO}_{2}$ emissions $($ Deschenes, Greenstone, and Shapiro, 2017). Although local pollution regulation might have small effects on $\mathrm{CO}_{2}$ emissions, $\mathrm{CO}_{2}$ regulation could substantially decrease local pollution emissions because there is no economically viable end-of-pipe abatement technology for $\mathrm{CO}_{2}$, so fuel switching from coal to gas due to a $\mathrm{CO}_{2}$ tax would decrease local pollutants (Parry, Veung, and Heine, 2015).

${ }^{40}$ For all pollutants, Figure 7 a shows the mean across sectors. For each pollutant, some sectors have inferred pollution taxes above and others below this mean value across sectors. 
shows that $\mathrm{CO}_{2}$ emissions from manufacturing initially increased then decreased, but overall changed little relative to 1990. The dashed lines show counterfactual $\mathrm{CO}_{2}$ emissions under different sets of shocks. Overall, no one set of shocks completely explains the modest changes in $\mathrm{CO}_{2}$ emissions, and regulation plays a limited role.

\section{VI.C Other Technical Aspects of the Model}

We now briefly discuss the extent to which the model accounts for several other important issues, and we consider the possible importance of each. ${ }^{41}$ We first consider the importance of reallocation and selection effects. Formally, we shut off selection and reallocation by analyzing how a model with monopolistic competition but homogeneous firms affects the decomposition. Mathematically, we shut off firm heterogeneity by setting $\sigma_{s}-1=\theta_{s} /\left(1-\alpha_{s}\right)$.

Appendix Table 1 shows that shutting off firm heterogeneity has small effects on the decomposition results; when we shut off firm heterogeneity, environmental regulation alone accounts for a nearly equivalent decrease in pollution emissions. For the other shocks, shutting off firm heterogeneity has quantitatively larger effects on the decomposition, but the qualitative conclusions are unchanged.

Why does firm heterogeneity have small effects on our estimates, particularly given the strong relationship between plant-level pollution intensity and plant-level productivity documented in Figure 2? We emphasize two explanations. First, as discussed earlier, more productive firms may have lower pollution intensity at the plant level, but increasing plant-level productivity for a given level of output may free up productive factors which can be used in other factories to make widgets and pollution elsewhere. Second, in some settings, the effects of firm heterogeneity on the magnitude from gains from trade are not large. ${ }^{42}$ Our environmental setting differs from this literature's focus, but the intuition persists that adding more margins by which policy can affect welfare need not mean policy has larger effects on welfare.

As highlighted earlier, multiple channels in this model transmit a change in a given shock to pollution. Here we discuss a partial equilibrium version of the model which assumes no change in factor prices or firm entry: $\hat{w}_{o}=\hat{M}_{o, s}^{e}=0$. We then calculate the change in pollution from a given shock merely from the change in pollution taxes: $\hat{Z}_{o, s}=1 / \hat{t}_{o, s}$. One could think of this as including the "direct" channel discussed at the beginning of this section, but turning off "indirect" channels. Row 8 of Appendix Table 1 shows the results. By definition, because shocks to foreign competitiveness, U.S. competitiveness, U.S. expenditure shares, and trade deficits do not change pollution taxes in this model, these shocks lead to no change in pollution in this partial equilibrium scenario. In contrast, shocks to environmental regulation still substantially decrease pollution in this setting. Put another way, the general and partial equilibrium results

\footnotetext{
${ }^{41}$ Appendix III.G describes additional sensitivity analyses we we explore and which leave the main conclusions unchanged, including alternative values of the Pareto shape parameter and the pollution elasticity and adding a non-manufacturing sector to the quantitative exercise.

${ }^{42}$ Costinot and Rodriguez-Clare (2014) find that in a model with multiple sectors but no intermediate goods, a 40 percent global tariff would create a 1.2 percent global decrease in welfare (measured as the average across regions) in a world with monopolistic competition and heterogeneous firms and a 1.4 percent decrease in welfare in a world with monopolistic competition and homogeneous firms. More broadly, Arkolakis, Costinot, and Rodriguez-Clare (2012) show that the gains from trade are equivalent in these two frameworks for a model with one sector, no intermediate goods, and the same trade elasticity. Melitz and Redding (2014) argue that the gains from trade are strictly larger in a model with firm heterogeneity because given primitive parameters, the trade elasticity differs across models.
} 
are more similar for the counterfactual where only environmental regulation changes, and are less similar for the other counterfactuals. One interpretation of this is finding that the general equilibrium price, wage, and firm entry adjustments in the model are relatively less important for our conclusions about the effects of environmental regulation on pollution, and relatively more important for our conclusions about the effects of the other shocks.

Another abstraction is aggregation. If firms have changed their focuses of production within one of our 17 sectors from more- to less-dirty sectors and products, then our analysis may confound regulation with product substitution. Additionally, if firms offshore particularly dirty parts of their production processes, then trade might affect pollution through the exchange of intermediate goods. The statistical decomposition presented in Section I at the product level suggests that compositional changes in the type of goods produced within narrow product categories are not able to explain a significant fraction of the observed emissions reductions. If U.S. manufacturing had disproportionately increased offshoring of dirty products, then one would expect the offshoring of these dirty products to change the composition of U.S. production to cleaner goods. Our statistical decomposition, however, provides very little role for composition effects, and looking at product rather than industry level delivers similar results. This evidence suggests that fragmenting production or offshoring is not likely to account for a large share of the reductions in emissions intensities.

Another important issue is technical change which decreases pollution emissions or pollution intensity. A few findings in our analysis suggest that such technical change is not a predominant source of bias. Secular technical change decreases the demand for all productive inputs. The productivity shock in our model is designed to account for such technical change, and we find that it does not account for the majority of changes in pollution emissions. This suggests that for any such technical change to explain the observed decrease in pollution, it must be biased towards increasing the use of relatively cleaner inputs. The inputs which produce the local air pollutants we study, however, generally also produce $\mathrm{CO}_{2}$. Thus, it is likely that if biased technical change explained the observed decrease in local air pollutants, then that technical change would also reduce $\mathrm{CO}_{2}$. We showed that $\mathrm{CO}_{2}$ from manufacturing changed very little, and local air pollutants from manufacturing fell considerably. It seems relatively unlikely that technical change would decrease demand for inputs which are intensive in the six pollutants that have been heavily regulated, but would leave unchanged the demand for inputs intensive in $\mathrm{CO}_{2}$.

Finally, we consider the assumption that pollution is proportional to a firm's outputs rather than to its inputs, which is implicit in equation (7). This paper's model implies that more productive firms emit less pollution only because they invest more in pollution abatement. One could imagine a different model in which more productive firms emit less pollution because they use fewer factor inputs to produce a unit of output. We investigated this alternative by removing the productivity term $\varphi$ from equation (7), giving an expression for pollution which is proportional to inputs rather than outputs. We then re-derived expressions for a firm's chosen pollution emissions under that modified assumption. This modification produces identical expressions for firm-level and economy-level pollution emissions both in observed data and in counterfactuals. This modification does produce a different mechanism by which productivity affects pollution-by decreasing factor inputs rather than increasing abatement investments. However, the magnitude of the effect of productivity on pollution in the two models is numerically equivalent. 
Every model is an abstraction, and the goal of our model-based analysis is to analyze several prominent explanations for pollution's decline. While we have emphasized advantages of our approach, one disadvantage is that one can always come up with additional hypotheses to explain an observed change in pollution.

\section{Conclusions}

Public observers once worried that U.S. economic growth would lead to increasingly dangerous levels of pollution. Instead, U.S. air quality has improved dramatically. This paper focuses on U.S. manufacturing and assesses three candidate explanations for why pollution emissions have fallen since 1990.

The first explanation is that increasing production of pollution-intensive goods in China, Mexico, and other foreign countries has decreased U.S. pollution. Second, environmental regulation may have led to adoption of increasingly effective abatement technologies. Third, if productivity decreases pollution intensity, then rising productivity may have decreased pollution emissions.

We begin with a statistical decomposition which shows that almost all of the change in pollution emissions from U.S. manufacturing is due to changes in pollution intensity within narrowly defined product-categories. To quantify the importance of environmental regulation, productivity, and trade, we build on recent trade and environmental research to develop a model of heterogeneous firms that choose optimal investments in pollution abatement in response to environmental regulation. Although the methods we use are typically applied to research questions in international trade, we use them to address an open question in environmental economics: why are pollution emissions from U.S. manufacturing declining? While many quantitative models are used to forecast how untested future policies like carbon taxes or tariff reductions would affect pollution and welfare, we use our model to analyze the past - to recover the implied changes in environmental regulation and other shocks that firms actually faced in each year 1990-2008. We then use the implied changes to quantify how pollution would have changed under scenarios other than those that actually occurred.

The paper obtains three main conclusions. First, the fall in pollution emissions is due to decreasing pollution per unit output in narrowly defined manufacturing product categories, rather than reallocation across products or changes in the scale of real manufacturing output. Second, environmental regulation has grown increasingly stringent, and the pollution tax that explains U.S. data roughly doubled between 1990 and 2008. Third, environmental regulation accounts for most of the observed reduction in pollution emissions from manufacturing. Productivity improvements and trade costs play relatively smaller roles.

We believe there are a number of worthwhile extensions to the work presented here. First, like most models of monopolistic competition, our model assumes that prices are a constant markup over marginal cost. While theory makes predictions about how markups should respond to various competitive forces, the empirical evidence on the relationship between environmental policy and markups is limited. Second, the decomposition methodology developed in the paper could be applied to other settings. For example, why has energy efficiency improved across the United States? Has this been driven by efficiency standards? Rising energy prices? Population migration? One could adapt the tools from this paper to address this important policy question. We leave these extensions and questions for future work. 


\section{References}

Ambec, S., M. A. Cohen, S. Elgie, and P. Lanoie (2013): "The Porter Hypothesis at 20: Can Environmetnal Regulation Enhance Innovation and Competitiveness?," Review of Environmental Economics E Policy, 7(1), 2-22.

Andersen, D. C. (2016): "Credit Constraints, Technology Upgrading, and the Environment," Journal of the Association of Environmental and Resource Economists, 3(2), 283-319.

Antras, P., T. Fort, And F. Tintelnot (2017): "The Margins of Global Sourcing: Theory and Evidence from U.S. Firms," American Economic Review, 107(9), 2514-64.

Antweiler, W., B. R. Copeland, and M. S. Taylor (2001): "Is Free Trade Good for the Environment?," American Economic Review, 91(4), 877-908.

Arkolakis, C., A. Costinot, D. Donaldson, and A. Rodriguez-Clare (Forthcoming): "The Elusive Pro-Competitive Effects of Trade," Review of Economic Studies.

Arkolakis, C., A. Costinot, and A. Rodriguez-Clare (2012): "New Trade Models, Same Old Gains?," American Economic Review, 102(1), 94-130.

Autor, D. H., D. Dorn, and G. H. Hanson (2013): "The China Syndrome: Local Labor Market Effects of Import Competition in the United States," American Economic Review, 103(6), 2121-68.

Axtell, R. L. (2001): "Zipf Distribution of U.S. Firm Sizes," Science, 293, 1818-1820.

Bajona, C., P. Missios, And A. Pierce (2012): "Trade and the Environment with Heterogeneous Firms," Working Paper, Ryerson University.

Becker, R. (2005): "Air pollution abatement costs under the Clean Air Act: evidence from the PACE survey," Journal of Environmental Economics and Management, 50(1), 144-169.

Becker, R. A., and R. J. Shadbegian (2005): "A Change of PACE: Comparing the 1994 and 1999 Pollution Abatement Costs and Expenditures Surveys," Journal of Economic and Social Measurement, 30(1), 63-95.

Berman, E., And L. T. Bui (2001): "Environmental regulation and labor demand: evidence from the South Coast Air Basin," Journal of Public Economics, 79, 265-295.

Bloom, N., C. Genakos, R. Martin, and R. Sadun (2010): "Modern Accounting: Good for the Environment or Just Hot Air?," Economic Journal, 120, 551-572.

Burstein, A., E. Morales, And J. Vogel (2017): "Changes in between-group inequality: computers, occupations, and international trade," Unpublished Mimeograph, UCLA.

Caliendo, L., and F. Parro (2014): "Estimates of the Trade and Welfare Effects of NAFTA," The Review of Economic Studies, 82(1), 1-44.

Chay, K. Y., and M. Greenstone (2005): "Does Air Quality Matter? Evidence from the Housing Market," Journal of Political Economy, 113(2), 376-424.

Cherniwchan, J., B. R. Copeland, and M. S. Taylor (2017): "Trade and the Environment: New Methods, Measurements, and Results," Annual Review of Economics, 9, 59-85. 
Collard-Wexler, A., and J. De Loecker (2015): "Reallocation and Technology: Evidence from the US Steel Industry," American Economic Review, 105(1), 131-171.

Copeland, B. R., And M. S. Taylor (1994): "North-South Trade and the Environment," Quarterly Journal of Economics, 109(3), 755-787.

(2003): Trade and the Environment: Theory and Evidence. Princeton University Press.

Correia, A. W., C. A. Pope, D. W. Dockery, Y. Wang, M. Ezzati, and F. Dominici (2013): "Effect of Air Pollution Control on Life Expectancy in the United States," Epidemiology, 24(1), 23-31.

Costinot, A., And A. Rodriguez-Clare (2014): Handbook of International Economics, Vol. 4chap. Trade Theory with Numbers: Quantifying the Consequences of Globalization, pp. 197-262. North-Holland.

Curtis, E. M. (2018): "Who Loses Under Cap-and-Trade Programs? The Labor Market Effects of the NOx Budget Trading Program," Review of Economics and Statistics, 100(1), 151-166.

Dekle, R., J. Eaton, and S. Kortum (2008): "Global Rebalancing with Gravity: Measuring the Burden of Adjustment," IMF Staff Papers, 55(3), 511-539.

Deschenes, O., M. Greenstone, and J. S. Shapiro (2017): "Defensive Investments and the Demand for Air Quality: Evidence from the NOx Budget Program," American Economic Review, 107(10), 2958-89.

Eaton, J., S. Kortum, and F. Kramarz (2011): "An Anatomy of International Trade: Evidence from French Firms," Econometrica, 79(5), 1453-1498.

Eaton, J., S. Kortum, B. Neiman, and J. Romalis (2016): "Trade and the Global Recession," American Economic Review, 106(11), 3401-38.

Ederington, J., A. Levinson, And J. Minier (2008): "Trade Liberalization and Pollution Havens," Advances in Economic Analysis 8 Policy, 4.2.

Fabra, N., and M. Reguant (2014): "Pass-Through of Emissions Costs in Electricity Markets," American Economic Review, 104(9), 2872-99.

Feenstra, R. C. (Forthcoming): "Restoring the Product Variety and Pro-competitive Gains from Trade with Heterogeneous Firms," Journal of Internatoinal Economics.

Feenstra, R. C., And D. E. Weinstein (2017): "Globalization, Markups and US Welfare," Journal of Political Economy, 125(4), 1040-1074.

Forslid, R., T. Okubo, and K.-H. Ultveit-Moe (2011): "International Trade, CO2 Emissions and Heterogeneous Firms," CEPR Discussion Paper No. 8583.

Foster, L., J. Haltiwanger, and C. Syverson (2008): "Reallocation, Firm Turnover, and Efficiency: Selection on Productivity or Profitability?," American Economic Review, 98(1), 394-425.

Fowlie, M. (2010): "Emissions Trading, Electricity Industry Restructuring, and Investment in Pollution Control," American Economic Review, 100(3).

Gabaix, X. (1999): "Zipf's law for cities: an explanation," The Quarterly Journal of Economics, 114(3), $739-767$.

(2009): "Power Laws in Economics and Finance," Annual Review of Economics. 
Gamper-Rabindran, S. (2006): "NAFTA and the Environment: What can the Data Tell Us?," Economic Development and Cultural Change, 54(3), 605-633.

Ganapati, S., J. S. Shapiro, and R. Walker (2016): "Energy Prices, Pass-Through, and Incidence in U.S. Manufacturing," Discussion paper, NBER Working Paper 22281.

Greenstone, M. (2002): "The Impacts of Environmental Regulations on Industrial Activity: Evidence from the 1970 and 1977 Clean Air Amendments and the Census of Manufactures," Journal of Political Economy, 110(6), 1175-1219.

Greenstone, M., J. A. List, and C. Syverson (2012): "The Effects of Environmental Regulation on the Competitiveness of U.S. Manufacturing," Unpublished Mimeograph, MIT.

Grossman, G. M., and A. B. Krueger (1995): "Economic Growth and the Environment," Quarterly Journal of Economics, 110(2), 353-377.

Head, K., T. Mayer, and M. Thoenig (2014): "Welfare and Trade Without Pareto," American Economic Review Papers and Proceedings.

Henderson, V. J. (1996): "Effects of Air Quality Regulation," American Economic Review, 86(4), 789-813.

Hettige, H., P. Martin, M. Singh, D. Wheeler, and B. Mundial (1995): The industrial pollution projection system. World Bank.

Holladay, J. S. (2016): "Exporters and the Environment," Canadian Journal of Economics, 49(1), 147172.

Hsien, C.-T., And R. Ossa (2016): "A Global View of Productivity Growth in China," Journal of International Economics, 102, 209-224.

Isen, A., M. Rossin-Slater, and R. Walker (2017): "Every Breath You Take - Every Dollar You'll Make: The Long-Term Consequences of the Clean Air Act of 1970," Journal of Political Economy, 125(3), $848-902$.

Keiser, D. A., And J. S. Shapiro (2017): "Consequences of the Clean Water Act and the Demand for Water Quality," NBER Working Paper 23070.

Keller, W., And A. Levinson (2002): "Pollution Abatement Costs and Foreign Direct Investment Inflows to U.S. States," Review of Economics and Statistics, 84(4), 691-703.

Koo, A. Y. C. (1974): "Environmental Repercussions and Trade Theory," Review of Economics and Statistics, 56(2), 235-244.

Levinson, A. (2009): "Technology, International Trade, and Pollution from US Manufacturing," American Economic Review, 99(5), 2177-2192.

(2014): "A Direct Estimate of the Technique Effect: Changes in the Pollution Intensity of US Manufacturing, 1990-2008," Journal of the Association of Environmental and Resource Economists.

Levinson, A., And M. S. Taylor (2008): "Unmasking the Pollution Haven Effect," International Economic Review, 49(1), 223-254.

Luttmer, E. G. J. (2007): "Selection, Growth, and the Size Distribution of Firms," Quarterly Journal of Economics, 122(3), 1103-1144. 
Lyubich, E., J. S. Shapiro, and R. Walker (2018): "Regulating Mismeasured Pollution: Implications of Firm Heterogeneity for Environmental Policy," AEA Papers and Proceedings, 108, 136-42.

Martin, L. A. (2011): "Energy efficiency gains from trade: greenhouse gas emissions and India's manufacturing sector," Mimeograph, Berkeley ARE.

Melitz, M. J. (2003): "The Impact of Trade on Intra-Industry Reallocations and Aggregate Industry Productivity," Econometrica, 71(6), 1695-1725.

Melitz, M. J., and G. I. P. Ottaviano (2008): "Market Size, Trade, and Productivity," Review of Economic Studies, 75, 295-316.

Melitz, M. J., And S. J. Redding (2014): Handbook of International Economics, Vol. 4chap. Heterogeneous Firms and Trade, pp. 1-54. North-Holland.

Muller, N. Z., And R. Mendelsohn (2009): "Efficient Pollution Regulation: Getting the Prices Right," American Economic Review, 99(5), 1714-1739.

Muller, N. Z., R. Mendelsohn, and W. Nordhaus (2011): "Environmental Accounting for Pollution in the United States Economy," American Economic Review, 101(5), 1649-1675.

Parry, I., C. Veung, and D. Heine (2015): Climate Change Economics6(4), 1-26.

Pierce, J. R., and P. K. Schott (2016): "The Surprisingly Swift Decline of U.S. Manufacturing Employment," American Economic Review, 106(7), 1632-1662.

Porter, M. E. (1991): “America's Green Strategy,” Scientific American, April, 168.

Shapiro, J. S. (2016): "Trade Costs, CO2, and the Environment," American Economic Journal: Economic Policy, 8(4), 220-54.

Siebert, H., J. Eichberger, R. Gronych, and R. Pethig (1980): Trade and Environment: A Theoretical Enquiry. Elsevier.

U.S. Census Bureau (2008): Pollution Abatement Costs and Expenditures: 2005. U.S. Government Printing Office.

van Soest, D. P., J. A. List, and T. Jeppesen (2006): "Shadow prices, environmental stringency, and international competitiveness," European Economic Review, 50(5), 1151-1167. 


\section{Figures and Tables}

Figure 1: Trends in Manufacturing Pollution Emissions and Real Output

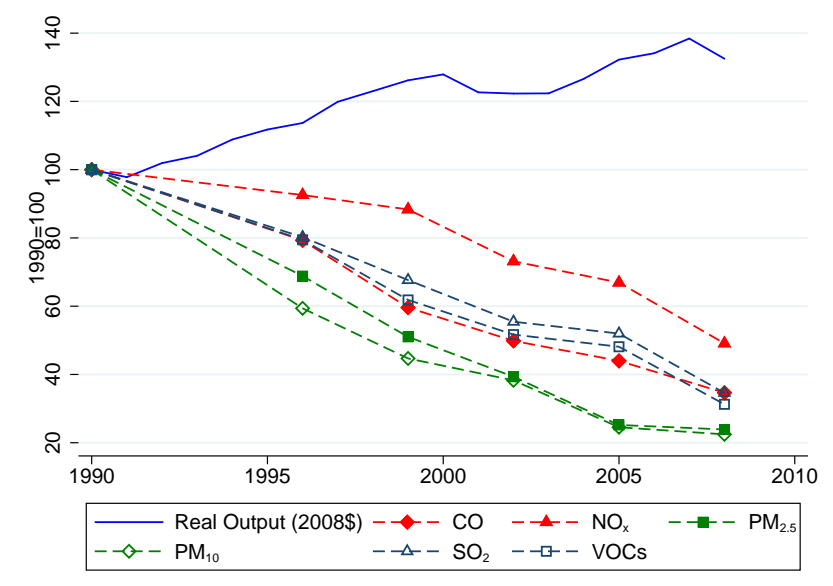

Note: Real output is measured from the NBER-CES database, using its industry-specific output price deflators and expressed in 2008\$. Emissions come from the EPA's National Emissions Inventory in years 1990, 1996, 1999, 2002, 2005, and 2008. Values are normalized to 100 in 1990.

Figure 2: Plant Level Pollution Intensity vs. Total Factor Productivity

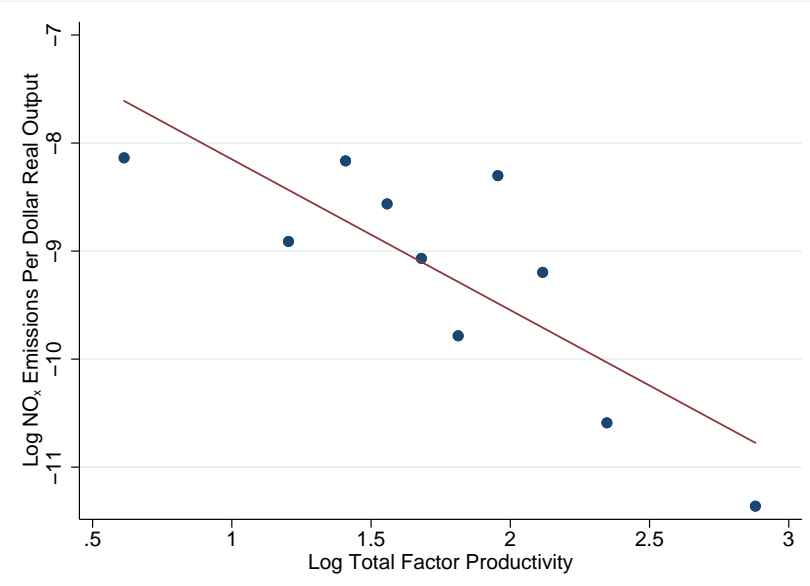

Note: This figure plots the relationship between plant-level total factor productivity and $\mathrm{NO}_{x}$ pollution per unit of output for U.S. manufacturing in 1990. The plant-level productivity measure is constructed from the U.S. Annual Survey of Manufacturers, using a total factor productivity index measure. We divide the sample into 10 deciles based on this plant-level productivity measure. We then compute the mean values of log productivity and log pollution per unit of real output within each decile, weighting the decile mean by plant-level inventory-adjusted, real output. The plot is accompanied by a linear fit, relating plant-specific emissions intensities to total factor productivity at the same plant. The line is fit to the entire sample, not simply the decile means. See Appendix III.H for additional details. 


\section{Figure 3: Nitrogen Oxides Emissions From United States Manufacturing}

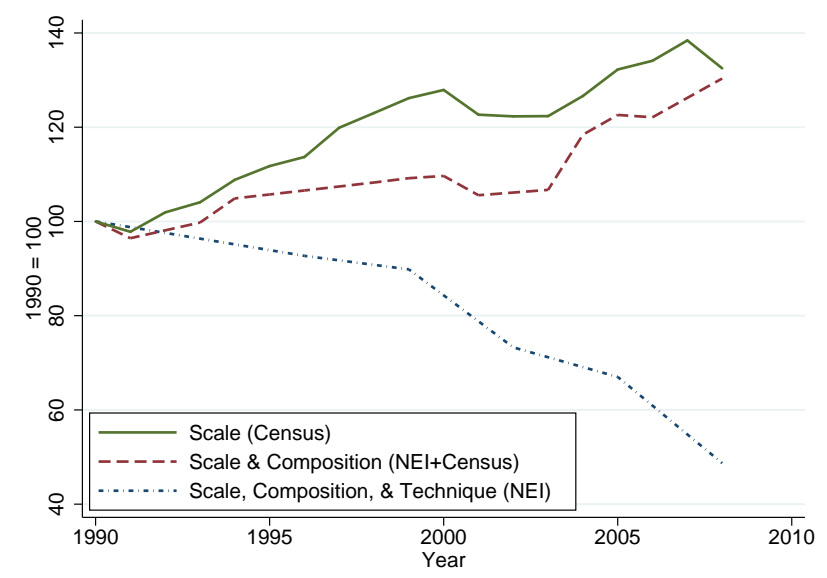

Notes: This figure plots observed and counterfactual trends in $\mathrm{NO}_{x}$ emissions based on the statistical decomposition from equation (2). The top line plots the counterfactual emissions with the same composition of goods and techniques as in 1990. The middle line represents emissions with the same emissions per unit of output as in 1990. The final line represents the actual observed emissions trends, which consists of changes to both the scale, composition, and techniques associated with production since 1990. Source: NBER-CES database, CMF, ASM, and NEI.

Figure 4: Shocks to Implicit $\mathrm{NO}_{x}$ Pollution Tax, 1990-2008.

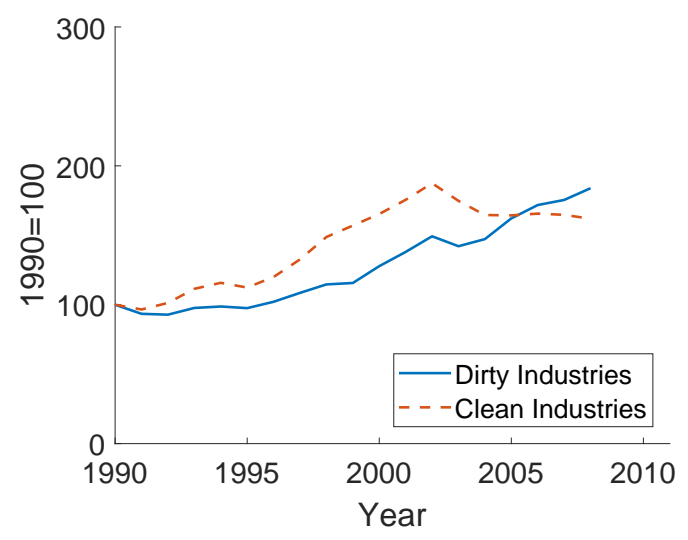

Notes: This figure plots the time path of the shock to environmental regulation for $\mathrm{NO}_{x}$ that we recover from the model outlined in Section II and derived using equation (23). The model delivers the value of the indicated shock for each of the 17 industries in our sample in each year. Here, we summarize the results by plotting the mean separately for both dirty industries (solid line) and clean industries (dotted line), weighted by baseline revenue in each industry. As described in the main text, dirty industries are defined as those with a value of the pollution elasticity $\alpha_{s}$ above the economy-wide mean of 0.011 , and clean industries are defined as those with a value of this pollution elasticity below 0.011 . 
Figure 5: Counterfactual U.S. Manufacturing Pollution Emissions Under Subsets of Shocks, 1990-2008

(a) $\mathrm{CO}$

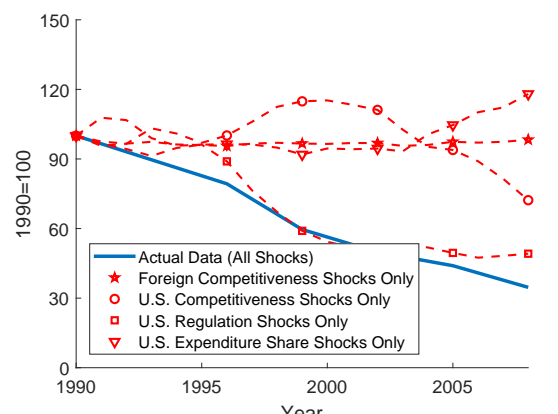

(d) $\mathrm{PM}_{10}$

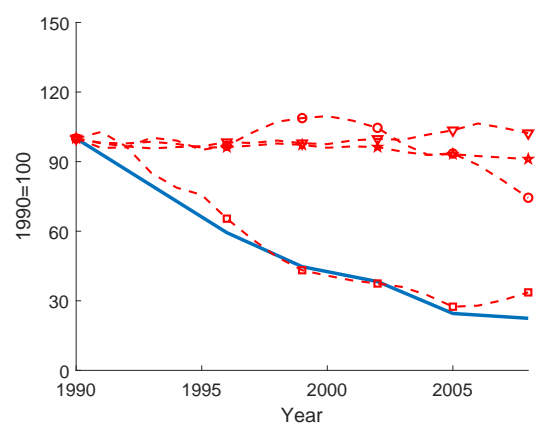

(b) $\mathrm{NO}_{x}$

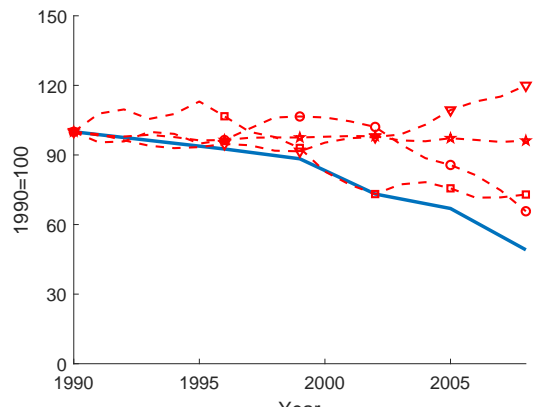

(e) $\mathrm{SO}_{2}$

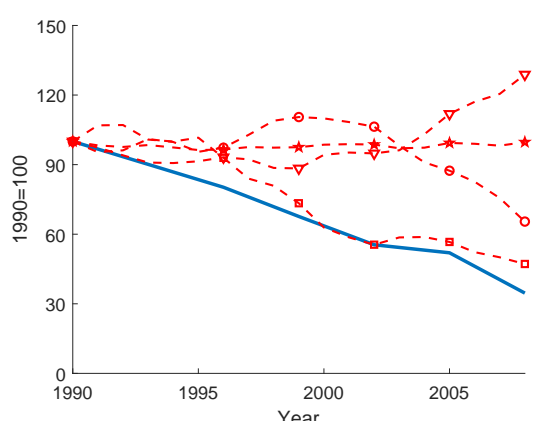

(c) $\mathrm{PM}_{25}$

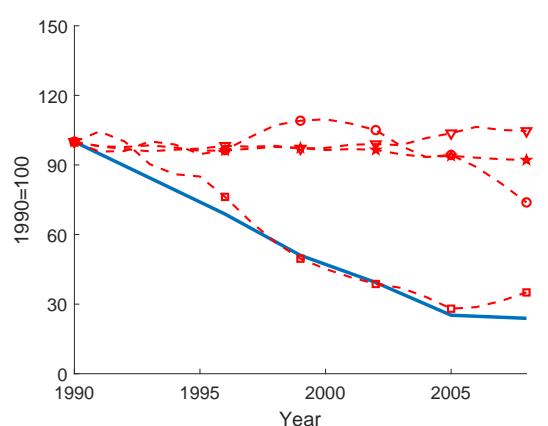

(f) $\mathrm{VOCs}$

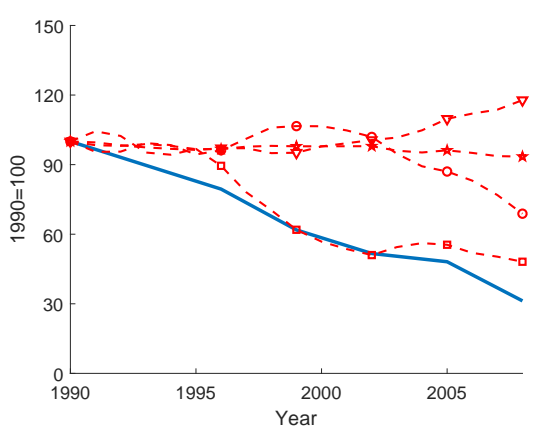

Notes: This figure plots a separate counterfactual exercise for each pollutant and shock. Each subfigure plots the actual and counterfactual time path of the indicated pollutant emissions in U.S. manufacturing. The solid blue line displays the actual time path of emissions, and the dotted red lines show the counterfactual emissions in a scenario where only a single explanatory factor is allowed to take on its actual historical values. The scenario for each explanatory factor, or "shock," is indicated in the legend in Subfigure 5a. For each counterfactual, all other explanatory factors are constrained to take their base year, 1990, values. The year 1990 values have been normalized to 100 in all figures. The star, circle, triangle, and square markers on the dashed lines show the years 1990, 1996, 1999, 2002, 2005, and 2008, when pollution data from NEI are observed rather than linearly interpolated. 
Figure 6: $\mathrm{NO}_{x}$ Pollution Tax Changes as a Function of $\mathrm{NO}_{x}$ Budget Trading Program Status

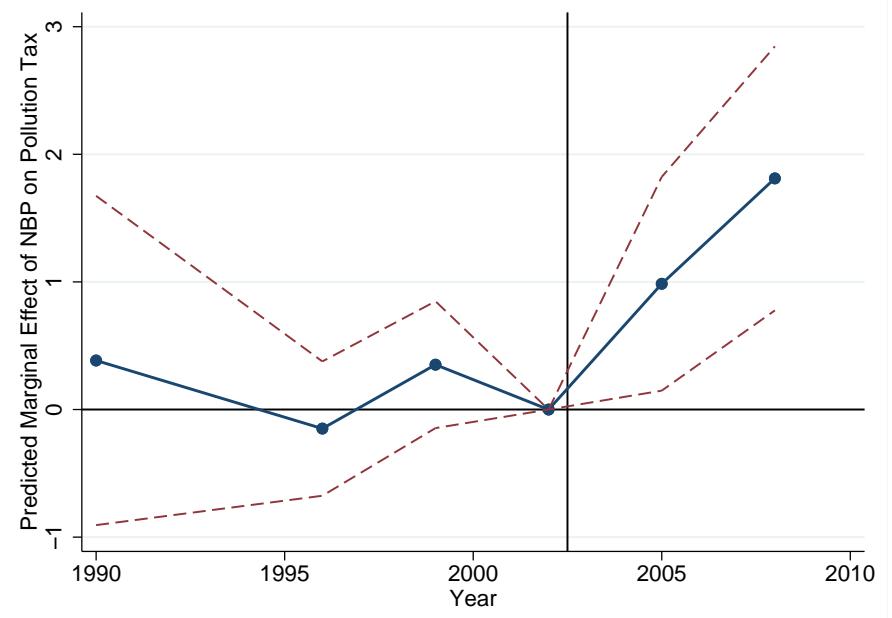

Notes: This figure reports regression coefficients from an event-study version of equation (24) in the text. The coefficients are plotted in blue and represent the time path of pollution taxes in polluting industries of NBP regions in the years just before and just after the NBP rollout, measured relative to a counterfactual. The dashed red lines represent 95 percent confidence intervals. The dependent variable is the model-driven measure of pollution taxes for a region $\times$ sector $\times$ year. The regression model includes region $\times$ year fixed effects, sector $\times$ year fixed effects, and region $\times$ sector fixed effects. Standard errors are clustered by sector $\times$ region.

Figure 7: Analysis of Carbon Dioxide Emissions

(a) Pollution Taxes for Air Pollution and $\mathrm{CO}_{2}$

(b) Historic $\mathrm{CO}_{2}$ Decomposition
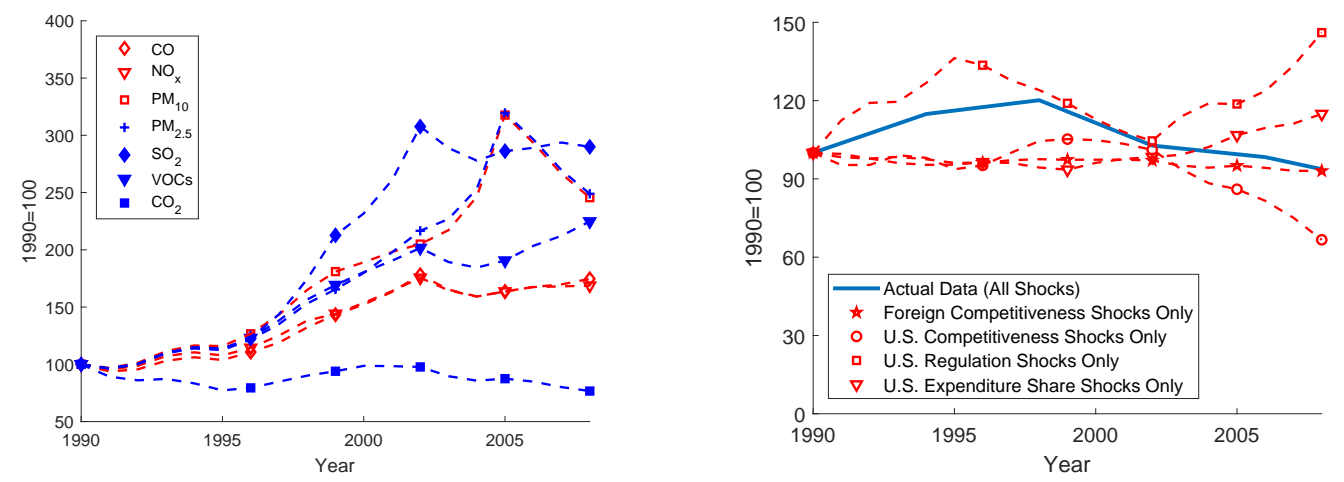

Notes: Subfigure (a) plots implicit pollution taxes recovered for each pollutant and year, including $\mathrm{CO}_{2}$. Subfigure (b) shows the same decomposition as Figure 5, except for $\mathrm{CO}_{2}$ rather than for a criteria pollutant. The star, circle, triangle, and square markers on the dashed lines show the years when pollution data from NEI or MECS are observed rather than linearly interpolated. 
Table 1: Pollution Elasticity: Instrumental Variables Regressions, by Pollutant

\begin{tabular}{|c|c|c|c|c|c|c|}
\hline & $\mathrm{CO}$ & $\mathrm{NO}_{x}\left(\mathrm{O}_{3}\right)$ & $\mathrm{PM}_{10}$ & $\mathrm{PM}_{2.5}$ & $\operatorname{VOC}\left(\mathrm{O}_{3}\right)$ & Total (Any) \\
\hline & \multicolumn{6}{|c|}{ Panel A: First Stage } \\
\hline \multirow{3}{*}{ Nonattain $_{c p} \times$ Polluter $_{p}$} & $(1)$ & $(2)$ & $(3)$ & $(4)$ & $(5)$ & $(6)$ \\
\hline & $\begin{array}{l}-0.057 \\
(0.015)\end{array}$ & $\begin{array}{l}-0.061 \\
(0.011)\end{array}$ & $\begin{array}{l}-0.101 \\
(0.085)\end{array}$ & $\begin{array}{l}-0.126 \\
(0.068)\end{array}$ & $\begin{array}{l}-0.063 \\
(0.009)\end{array}$ & $\begin{array}{l}-0.058 \\
(0.009)\end{array}$ \\
\hline & \multicolumn{6}{|c|}{ Panel B: Reduced Form } \\
\hline \multirow[t]{2}{*}{ Nonattain $_{c p} \times$ Polluter $_{p}$} & $\begin{array}{c}-7.386 \\
(5.244)\end{array}$ & $\begin{array}{l}-5.985 \\
(4.782)\end{array}$ & $\begin{array}{l}-9.474 \\
(6.860)\end{array}$ & $\begin{array}{l}-7.399 \\
(4.427)\end{array}$ & $\begin{array}{l}-7.812 \\
(1.214)\end{array}$ & $\begin{array}{l}-5.346 \\
(1.979)\end{array}$ \\
\hline & \multicolumn{6}{|c|}{ Panel C: Instrumental Variables } \\
\hline Abatement Expenditure Ratio & $\begin{array}{c}130.030 \\
(64.278)\end{array}$ & $\begin{array}{c}98.592 \\
(72.412)\end{array}$ & $\begin{array}{c}94.118 \\
(78.483)\end{array}$ & $\begin{array}{c}58.551 \\
(46.795)\end{array}$ & $\begin{array}{l}124.907 \\
(36.827)\end{array}$ & $\begin{array}{c}91.604 \\
(25.373)\end{array}$ \\
\hline $\mathrm{N}$ & $\approx 3500$ & $\approx 3500$ & $\approx 3500$ & $\approx 3500$ & $\approx 3500$ & $\approx 3500$ \\
\hline \multirow[t]{2}{*}{ First Stage F-Stat } & 14 & 30 & 1.4 & 3.4 & 52 & 42 \\
\hline & \multicolumn{6}{|c|}{ Panel D: Pollution Elasticity Parameter } \\
\hline Pollution Elasticity $(\alpha)$ & $\begin{array}{c}0.008 \\
(0.004)\end{array}$ & $\begin{array}{c}0.010 \\
(0.007) \\
\end{array}$ & $\begin{array}{c}0.011 \\
(0.009) \\
\end{array}$ & $\begin{array}{c}0.017 \\
(0.013) \\
\end{array}$ & $\begin{array}{c}0.008 \\
(0.002) \\
\end{array}$ & $\begin{array}{c}0.011 \\
(0.003) \\
\end{array}$ \\
\hline County-NAICS FE & $\mathrm{X}$ & $\mathrm{X}$ & $\mathrm{X}$ & $\mathrm{X}$ & $\mathrm{X}$ & $\mathrm{X}$ \\
\hline
\end{tabular}

Notes: This table presents a series of regression coefficients from 18 separate regressions, one for each column of each Panel A through C. An observation is a county $\times$ industry $\times$ year, where industry is a 6 digit NAICS code. The dependent variable in Panel $\mathrm{A}$ is the same in each column and represents the $\log$ of 1 minus the abatement cost share of county $\times$ industry $\times$ year production. The regressor of interest is an interaction between two indicator variables that denote whether the industry is in a county that was newly regulated (i.e., Nonattain ${ }_{c p}=1$ ) and whether the industry is a polluting industry (i.e., Polluter $p_{p}=1$ ). The variable "Nonattain" changes across columns, reflecting different pollutant-specific nonattainment designations as indicated in the column headings. Parentheses in the column headings describe the type of nonattainment used as the regressor. The dependent variable in Panels B and $\mathrm{C}$ represent the log emissions intensity, defined as pollution emissions per dollar of real output. The dependent variable in Panels B and C changes in each column, where the pollution emissions are indicated in the column headings. Panel $\mathrm{C}$ presents the instrumental variable estimates of log pollution intensity regressed on log abatement cost shares, which in practice represents the ratio of the estimates presented in Panel A and Panel B. Lastly, Panel D transforms the regression estimates in Panel $\mathrm{C}$ to back out a measure of $\alpha$ for each pollutant, where the standard errors are calculated using the delta method. Robust standard errors are in parentheses, clustering by commuting zone. Source: ASM, NEI, PACE. 
Table 2: Parameter Estimates

\begin{tabular}{|c|c|c|c|c|c|c|}
\hline Sector & $\begin{array}{l}\text { Tons Pollution } \\
\text { Per Dollar Costs } \\
\text { (1) }\end{array}$ & $\begin{array}{c}\text { Pollution } \\
\text { Elasticity }(\alpha) \\
(2)\end{array}$ & $\begin{array}{c}\text { Input } \\
\text { Share } \\
(3)\end{array}$ & $\begin{array}{c}\text { Elasticity of } \\
\text { Substitution }(\sigma) \\
(4)\end{array}$ & $\begin{array}{c}\text { Pareto Shape } \\
\text { Parameter }(\theta) \\
(5)\end{array}$ & $\begin{array}{c}\text { Shape Parameter } \\
\text { Standard Error } \\
(6)\end{array}$ \\
\hline Food, Beverages, Tobacco & 2.60 & 0.0040 & 0.74 & 3.79 & 3.89 & $(0.13)$ \\
\hline Textiles, Apparel, Fur, Leather & 1.44 & 0.0022 & 0.79 & 4.87 & 4.80 & $(0.10)$ \\
\hline Wood Products & 6.75 & 0.0103 & 0.83 & 5.94 & 6.20 & $(0.17)$ \\
\hline Paper and Publishing & 14.61 & 0.0223 & 0.79 & 4.80 & 5.21 & $(0.10)$ \\
\hline Coke, Refined Petroleum, Fuels & 13.88 & 0.0212 & 0.88 & 8.18 & 9.91 & $(1.67)$ \\
\hline Chemicals & 13.42 & 0.0205 & 0.70 & 3.28 & 3.50 & $(0.08)$ \\
\hline Rubber and Plastics & 3.13 & 0.0048 & 0.78 & 4.59 & 4.62 & $(0.08)$ \\
\hline Other Non-metallic Minerals & 19.91 & 0.0303 & 0.73 & 3.66 & 4.05 & $(0.11)$ \\
\hline Basic Metals & 36.57 & 0.0557 & 0.85 & 6.66 & 10.01 & $(0.50)$ \\
\hline Fabricated Metals & 1.24 & 0.0019 & 0.79 & 4.77 & 4.80 & $(0.06)$ \\
\hline Machinery and Equipment & 1.00 & 0.0015 & 0.76 & 4.25 & 4.19 & $(0.14)$ \\
\hline Office, Computing, Electrical & 1.52 & 0.0023 & 0.81 & 5.24 & 5.32 & $(0.15)$ \\
\hline Radio, Television, Communication & 0.32 & 0.0005 & 0.79 & 4.66 & 4.77 & $(0.23)$ \\
\hline Medical, Precision, and Optical & 0.94 & 0.0014 & 0.65 & 2.89 & 2.86 & $(0.06)$ \\
\hline Motor Vehicles, Trailers & 1.03 & 0.0016 & 0.82 & 5.62 & 5.60 & $(0.18)$ \\
\hline Other Transport Equipment & 1.26 & 0.0019 & 0.74 & 3.88 & 3.87 & $(0.13)$ \\
\hline Furniture, Other, Recycling & 3.06 & 0.0047 & 0.73 & 3.77 & 3.75 & $(0.03)$ \\
\hline Mean Across Industries & 7.22 & 0.011 & 0.77 & 4.76 & 5.14 & $(0.23)$ \\
\hline
\end{tabular}

Notes: This table presents summary means and regression estimates for 17 separate industries, one per row, using data from a single year, 1990. Column 1 presents the total tons of pollution per dollar input costs for each sector, where pollution data comes from the NEI and data on input costs come from the ASM. Column 2 presents the sector specific pollution elasticity, which is calculated using the economy-wide estimate of 0.011 from Table 1 , scaled across industries by the tons pollution per dollar costs from column (1). Column 3 presents the input share that is defined as the ratio of costs to revenues using data from the ASM. We deflate revenues and input expenditures using industry-specific price output and input price deflators, respectively. Column 4 displays the sector-specific elasticity of substitution, which is calculated from equation (38). Columns 5 and 6 present regression estimates and standard errors for the Pareto shape parameter, derived from equation (39). The actual parameter is a non-linear transformation of the regression coefficient, where the reported standard errors are calculated using the delta method, clustering by four digit NAICS code. 


\section{Why is Pollution from U.S. Manufacturing Declining?}

The Roles of Environmental Regulation, Productivity, and Trade: Online Appendix

\author{
Joseph S. Shapiro \\ Yale University \\ and NBER \\ joseph.shapiro@yale.edu
}

\author{
Reed Walker \\ University of California, Berkeley \\ and NBER \\ rwalker@berkeley.edu
}

June 2018 


\section{A For Online Publication: Figures and Tables}

Figure 1: Emissions Statistical Decomposition From United States Manufacturing
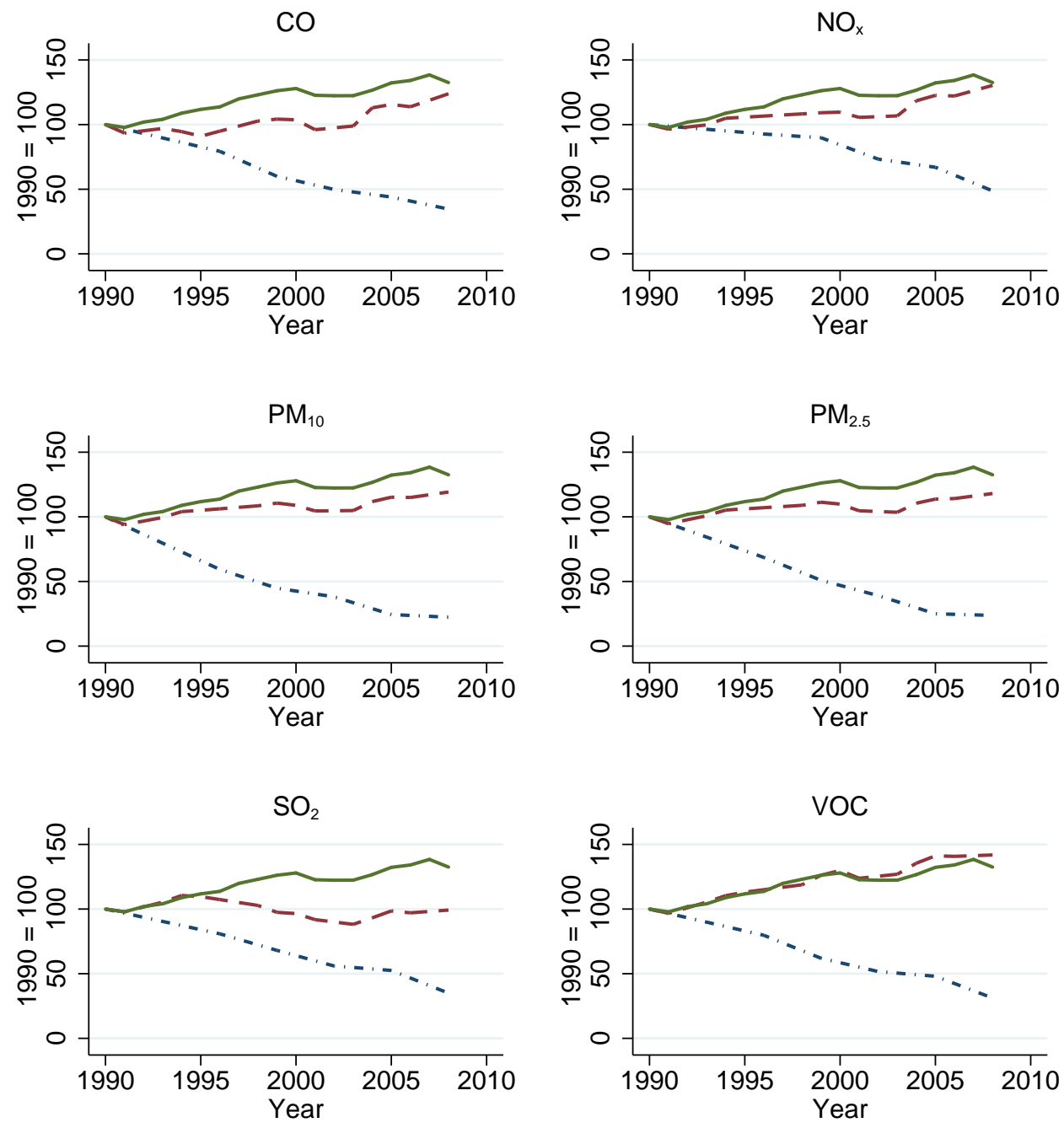

$$
\begin{aligned}
& \text { - Scale (Census) } \\
& \text { - - Scale \& Composition (NEI+Census) } \\
& \text { - - } \quad \text { Scale, Composition, \& Technique (NEI) }
\end{aligned}
$$

Notes: This figure plots the observed and counterfactual trends in emissions for 6 separate pollutants based on the statistical decomposition from equation (2). The solid line of each panel plots the counterfactual for what emissions would have looked like in a world with the same composition of goods and techniques of production as was observed in the base year, 1990. The dashed line represents what emissions would have looked like if we maintained the same production techniques (defined as emissions per unit of output) as in the base year, 1990. The dashed-dotted line represents the actual observed emissions trends, which consists of changes to both the scale, composition, and techniques associated with production since 1990. Source: NBER-CES database, ASM, and NEI. 
Figure 2: Comparing Product-Level and Industry-Level Statistical Emissions Decompositions

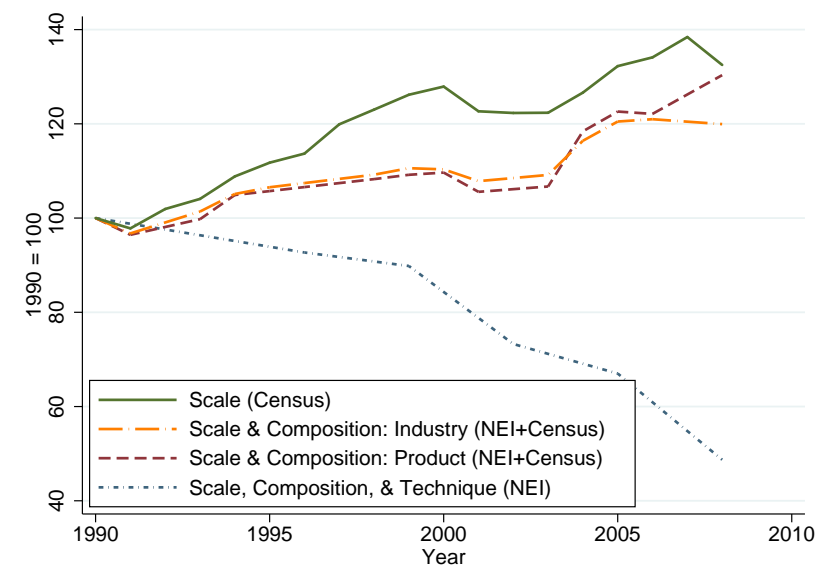

Notes: This figure plots observed and counterfactual trends in $\mathrm{NO}_{x}$ emissions based on the statistical decomposition from equation (2). The top, solid line plots the counterfactual emissions with the same composition of goods and techniques as in 1990. The middle two dashed lines represent emissions with the same emissions per unit of output as in 1990, using either the industry level emissions factors or the product level emissions factors. The final line represents the actual observed emissions trends, which consists of changes to both the scale, composition, and techniques associated with production since 1990. Source: NBER-CES database, ASM, and NEI.

Figure 3: Historic Values of Preference Shocks, 1990-2008

(a) Foreign Expenditure Shares

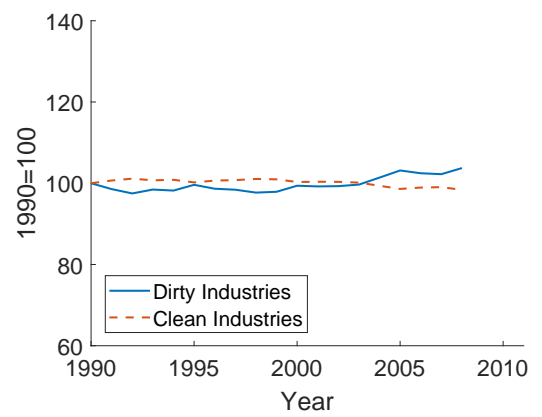

(b) U.S. Expenditure Shares

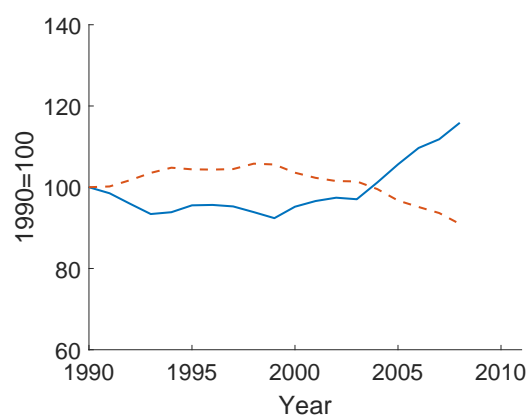

Notes: This figure plots the time path of shocks to expenditure shares that we recover from the model outlined in Section II and derived using equation (22). The model delivers the value of the indicated shock for each of the 17 industries in our sample in each year. Here, we summarize the results graphically by plotting the unweighted mean separately for both dirty industries (solid line) and clean industries (dotted line). As described in the main text, dirty industries are defined as those with a value of the pollution elasticity $\alpha_{s}$ above the economy-wide mean of 0.011 , and clean industries are defined as those with a value of this pollution elasticity below 0.011 . 
Figure 4: Historic Values of Endogenous Variables, 1990-2008.

(a) Foreign Wages

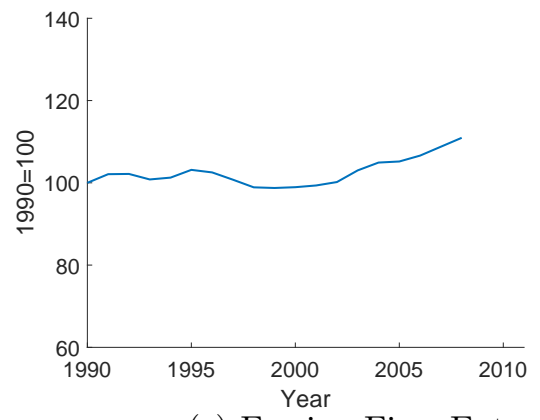

(c) Foreign Firm Entry

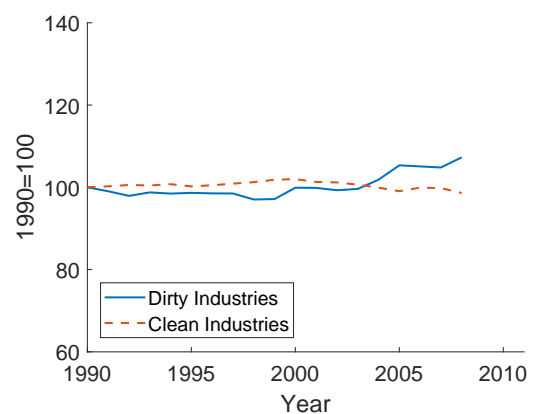

(b) U.S. Wages

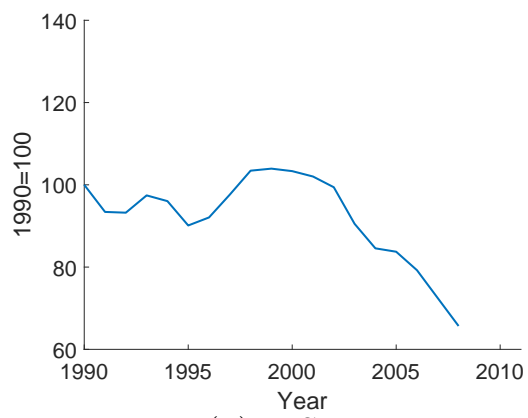

(d) U.S. Firm Entry

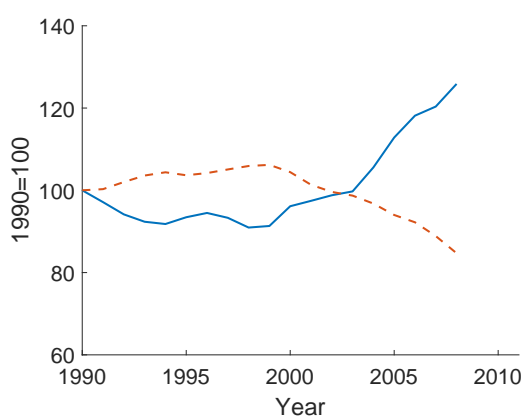

NotEs: This figure plots the time path of endogenous variables that we recover from the model outlined in Section II. The model delivers the value of firm entry changes for each of the 17 industries in our sample in each year. Here, we summarize the results graphically by plotting the unweighted mean for the indicated country-year. In subfigures (c) and (d) we plot the unweighted mean separately for both dirty industries or clean industries. As described in the main text, dirty industries are defined as those with a value of the pollution elasticity $\alpha_{s}$ above the economy-wide mean of 0.011 , and clean industries are defined as those with a value of this pollution elasticity below 0.011 .

Figure 5: Counterfactual Pollution Intensity Under Arbitrary Shocks to Foreign Competitiveness, by Sector

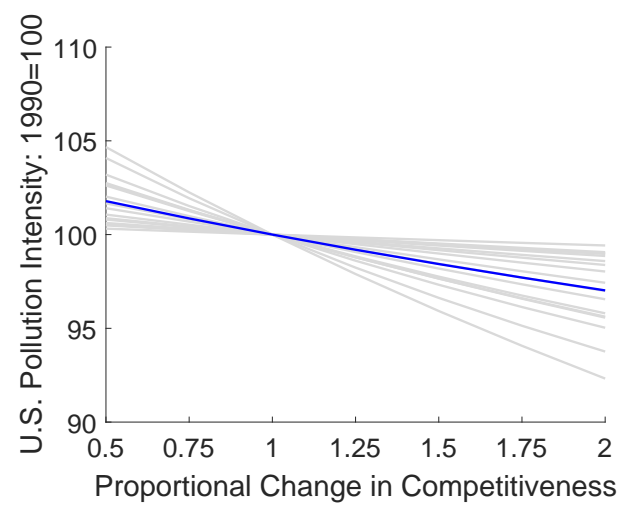

NotEs: This figure plots 6 separate counterfactual exercises for each sector. In each counterfactual, foreign competitiveness takes on a value ranging from 0.50 to 2 times baseline levels, in 0.25 increments. For each counterfactual, we measure the resulting change in $\mathrm{NO}_{x}$ pollution intensity, which is indicated on the y-axis, with the baseline value normalized to 100. Pollution intensity is defined as pollution emissions per real unit output. Each grey line describes pollution intensity for a single sector, and the blue line shows the cross-sector mean. 
Table 1: Statistical Decomposition - 2008 Values

\begin{tabular}{lcccccc}
\hline & $\mathrm{CO}$ & $\mathrm{NO}_{x}$ & $\mathrm{PM} 10$ & $\mathrm{PM}^{2.5}$ & $\mathrm{SO}_{2}$ & VOC \\
& $(1)$ & $(2)$ & $(3)$ & $(4)$ & $(5)$ & $(6)$ \\
\hline & \multicolumn{7}{c}{ Panel A: Baseline Values } \\
\cline { 2 - 7 } Scale (Census) & 1.32 & 1.32 & 1.32 & 1.32 & 1.32 & 1.32 \\
Scale \& Composition (NEI+Census) & 1.24 & 1.30 & 1.19 & 1.18 & 0.99 & 1.42 \\
Scale, Composition, \& Technique (NEI) & 0.34 & 0.49 & 0.22 & 0.24 & 0.35 & 0.31 \\
\hline & \multicolumn{7}{c}{ Panel B: Single-Product Plants } \\
\cline { 2 - 8 } Scale (Census) & 1.32 & 1.32 & 1.32 & 1.32 & 1.32 & 1.32 \\
Scale \& Composition (NEI+Census) & 0.93 & 1.08 & 0.95 & 0.89 & 1.09 & 1.19 \\
Scale, Composition, \& Technique (NEI) & 0.34 & 0.49 & 0.22 & 0.24 & 0.35 & 0.31 \\
\hline & \multicolumn{7}{c}{ Panel C: Uniform Apportionment } \\
\cline { 2 - 8 } Scale (Census) & 1.32 & 1.32 & 1.32 & 1.32 & 1.32 & 1.32 \\
Scale \& Composition (NEI+Census) & 1.33 & 1.40 & 1.27 & 1.25 & 1.06 & 1.46 \\
Scale, Composition, \& Technique (NEI) & 0.34 & 0.49 & 0.22 & 0.24 & 0.35 & 0.31 \\
\hline
\end{tabular}

Notes: This table displays the observed and counterfactual 2008 levels of emissions for 6 separate pollutants, relative to their 1990 values. The full counterfactual trend lines are plotted in Appendix Figure 1. The counterfactuals stem from the statistical decomposition embodied in equation (2). "Scale" refers to the counterfactual for what emissions would have looked like in a world with the same composition of goods and techniques of production as was observed in the base year, 1990. "Scale \& Composition" refer to what emissions would have looked like if we maintained the same production techniques (defined as emissions per unit of output) as in the base year, 1990. "Scale, Composition, \& Technique" refers to the actual observed emissions trends, which consists of changes to both the scale, composition, and techniques associated with production since 1990. Source: NBER-CES database, ASM, and NEI. 
Table 2: Sector Definitions

\begin{tabular}{llc}
\hline Code & Description & ISIC Rev. 3 Codes \\
\hline 1 & Food, beverages, tobacco & $15-16$ \\
2 & Textiles, apparel, fur, leather & $17-19$ \\
3 & Wood products & 20 \\
4 & Paper and publishing & $21-22$ \\
5 & Coke, refined petroleum, nuclear fuel & 23 \\
6 & Chemicals & 24 \\
7 & Rubber and plastics & 25 \\
8 & Other non-metallic minerals & 26 \\
9 & Basic metals & 27 \\
10 & Fabricated metals & 28 \\
11 & Machinery and equipment & 29 \\
12 & Office, accounting, computing, and electrical machinery & $30-31$ \\
13 & Radio, television, communication equipment & 32 \\
14 & Medical, precision, and optical, watches, clocks & 33 \\
15 & Motor vehicles, trailers & 34 \\
16 & Other transport equipment & 35 \\
17 & Furniture, manufactures n.e.c., recycling & $36-37$ \\
\hline
\end{tabular}

Notes: This table presents the sector definitions used in the analysis and their corresponding two-digit International Standard Industrial Classification, third revision (ISIC Rev. 3) codes. 
Table 3: Estimates of Pollution Elasticity, by Pollutant

\begin{tabular}{lccccccc}
\hline & $\begin{array}{c}\text { Total } \\
\text { (Main Estimates) }\end{array}$ & $\mathrm{CO}$ & $\mathrm{NO}_{x}$ & $\mathrm{PM}_{10}$ & $\mathrm{PM}_{2.5}$ & $\mathrm{SO}_{2}$ & VOCs \\
Sector & $(1)$ & $(2)$ & $(3)$ & $(4)$ & $(5)$ & $(6)$ & $(7)$ \\
\hline Food, Beverages, Tobacco & 0.0040 & 0.0016 & 0.0054 & 0.0057 & 0.0061 & 0.0047 & 0.0054 \\
Textiles, Apparel, Fur, Leather & 0.0022 & 0.0004 & 0.0024 & 0.0013 & 0.0013 & 0.0028 & 0.0064 \\
Wood Products & 0.0103 & 0.0101 & 0.0089 & 0.0183 & 0.0252 & 0.0030 & 0.0142 \\
Paper and Publishing & 0.0223 & 0.0204 & 0.0275 & 0.0161 & 0.0222 & 0.0275 & 0.0172 \\
Coke, Refined Petroleum, Fuels & 0.0212 & 0.0151 & 0.0248 & 0.0066 & 0.0089 & 0.0354 & 0.0224 \\
Chemicals & 0.0205 & 0.0243 & 0.0241 & 0.0081 & 0.0089 & 0.0159 & 0.0265 \\
Rubber and Plastics & 0.0048 & 0.0008 & 0.0038 & 0.0021 & 0.0023 & 0.0042 & 0.0191 \\
Other Non-metallic Minerals & 0.0303 & 0.0048 & 0.0539 & 0.0972 & 0.0713 & 0.0363 & 0.0064 \\
Basic Metals & 0.0557 & 0.1033 & 0.0218 & 0.0227 & 0.0295 & 0.0450 & 0.0159 \\
Fabricated Metals & 0.0019 & 0.0003 & 0.0016 & 0.0007 & 0.0009 & 0.0011 & 0.0085 \\
Machinery and Equipment & 0.0015 & 0.0010 & 0.0014 & 0.0011 & 0.0015 & 0.0014 & 0.0034 \\
Office, Computing, Electrical & 0.0023 & 0.0031 & 0.0011 & 0.0010 & 0.0013 & 0.0022 & 0.0028 \\
Radio, Television, Communication & 0.0005 & 0.0003 & 0.0005 & 0.0002 & 0.0002 & 0.0004 & 0.0014 \\
Medical, Precision, and Optical & 0.0014 & 0.0001 & 0.0039 & 0.0014 & 0.0021 & 0.0013 & 0.0025 \\
Motor Vehicles, Trailers & 0.0016 & 0.0004 & 0.0010 & 0.0003 & 0.0004 & 0.0011 & 0.0068 \\
Other Transport Equipment & 0.0019 & 0.0003 & 0.0025 & 0.0015 & 0.0013 & 0.0018 & 0.0060 \\
Furniture, Other, Recycling & 0.0047 & 0.0005 & 0.0024 & 0.0027 & 0.0037 & 0.0027 & 0.0219 \\
\hline
\end{tabular}

Notes: This table presents estimates of the pollution elasticity for each sector and pollutant. Column (1) corresponds to column (2) of Table 2 that is calculated using the economy-wide estimate of 0.011 from Table 1 , scaled across industries by the tons pollution per dollar costs from column (1) of Table 2. Columns (2)-(7) scale the economy-wide value of 0.011 according to the tons of each pollutant emitted per dollar of cost inputs. 
Table 4: Relationship Between Implied Manufacturing Pollution Tax and $\mathrm{NO}_{x}$ Budget Program

\begin{tabular}{lcccc}
\hline & $(1)$ & $(2)$ & $(3)$ & $(4)$ \\
\hline $1\left[\mathrm{NBP}_{r}\right] \times 1\left[\mathrm{NBPRegulated}_{s}\right] \times 1\left[\right.$ Year $\left._{t}>2002\right]$ & 1.195 & 1.195 & 1.186 & 1.186 \\
$\mathrm{~N}$ & $(0.422)$ & $(0.424)$ & $(0.404)$ & $(0.405)$ \\
& 1583 & 1583 & 1583 & 1583 \\
\hline Industry $\times$ region FE & $\mathrm{X}$ & $\mathrm{X}$ & $\mathrm{X}$ & $\mathrm{X}$ \\
Industry $\times$ year FE & & $\mathrm{X}$ & & $\mathrm{X}$ \\
Region $\times$ year FE & & & $\mathrm{X}$ & $\mathrm{X}$ \\
\hline
\end{tabular}

Notes: This table reports regression coefficients from 4 separate versions of equation (24), one per column. The dependent variable in all regressions is the model-driven measure of pollution taxes for a region $\times$ industry $\times$ year. All specifications control for the lower order interaction terms that ensure identification of the difference-in-difference-in-differences regression equation presented above. Standard errors are clustered by industry $\times$ region and are in parentheses. 


\section{B Theory}

This appendix derives results of the model in more detail. We begin by summarizing the main notation.

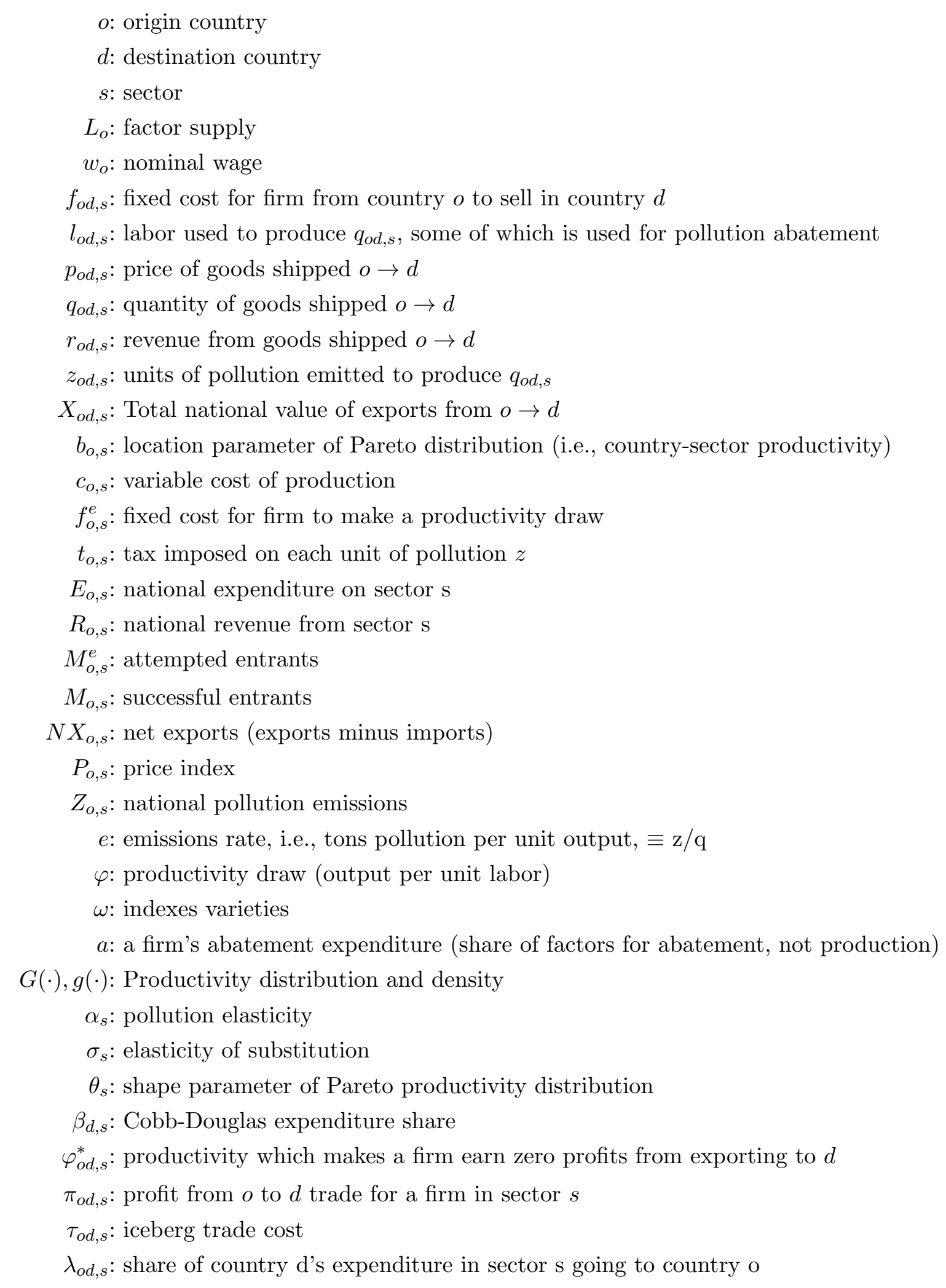




\section{II.A Intermediate Results Used to Derive Expressions from the Main Text}

This subsection describes several intermediate steps that will be used below to derive results shown in the main text. Several parts of this subsection mirror more standard models of heterogeneous firms with monopolistic competition except they incorporate pollution taxes and abatement.

\section{Consumers}

Solving the representative agent's utility-maximization problem for the optimal quantity $q_{o d, s}$ gives the following consumer demand for variety $\omega$ in destination country $d$ :

$$
q_{o d, s}(\omega)=\frac{\left(p_{o d, s}(\omega)\right)^{-\sigma_{s}}}{\left(P_{d, s}\right)^{1-\sigma_{s}}} E_{d, s}
$$

where the price index (the cost of one unit of utility) is

$$
P_{d, s}=\left[\sum_{o} \int_{\omega \in \Omega_{o, s}} p_{o d, s}(\omega)^{1-\sigma_{s}}\right]^{\frac{1}{1-\sigma_{s}}}
$$

\section{Firms}

Firms engage in monopolistic competition. They choose prices $p_{o d, s}$ and abatement investments $a$ to maximize profits. Recall from main text equation (10) that the firm's first-order condition for pollution abatement is

$$
1-a=\left(\frac{w_{o}}{\varphi t_{o, s}} \frac{\alpha_{s}}{1-\alpha_{s}}\right)^{\alpha_{s}}
$$

Combining this with the first-order condition for prices implies that prices equal a constant markup over marginal costs:

$$
p_{o d, s}(\varphi)=\frac{\sigma_{s}}{\sigma_{s}-1} \frac{c_{o, s} \tau_{o d, s}}{\varphi^{1-\alpha_{s}}}
$$

where

$$
c_{o, s} \equiv \frac{\left(t_{o, s}\right)^{\alpha_{s}}\left(w_{o}\right)^{1-\alpha_{s}}}{\left(\alpha_{s}\right)^{\alpha_{s}}\left(1-\alpha_{s}\right)^{1-\alpha_{s}}}
$$

In some of the following results, a simpler expression for firm profits is useful:

$$
\pi_{o d, s}(\varphi)=\frac{r_{o d, s}(\varphi)}{\sigma_{s}}-w_{d} f_{o d, s}
$$

where a firm's revenues are $r_{o d, s}(\varphi) \equiv p_{o d, s}(\varphi) q_{o d, s}(\varphi)$ This expression can be derived from the firm's profit function by substituting in abatement (27) and prices (28) then simplifying. Finally, several derivations below use the following part of Assumption 2 from Section II.A of the main text, restated here for convenience:

$$
l_{o d, s}(\varphi)=\frac{q_{o d, s}(\varphi)}{\varphi(1-a(\varphi))}
$$




\section{Productivity Distribution}

The Pareto productivity distribution from equation (5) of the main text is restated here for convenience:

$$
G\left(\varphi ; b_{o, s}\right)=1-\frac{\left(b_{o, s}\right)^{\theta_{s}}}{\varphi^{\theta_{s}}}
$$

Several results below use the conditional density, which in general is $g\left(\varphi \mid \varphi>\varphi_{\text {od,s }}^{*}\right)=g(\varphi) /\left(1-G\left[\varphi_{\text {od,s }}^{*}\right]\right)$, where $g(\varphi)$ is the unconditional density. For the Pareto distribution, the conditional density is

$$
g\left(\varphi \mid \varphi>\varphi_{o d, s}^{*}\right)=\theta_{s} \frac{\left(\varphi_{o d, s}^{*}\right)^{\theta_{s}}}{\varphi^{\theta_{s}+1}}
$$

\section{Cutoff Productivity}

Let $\varphi_{o d, s}^{*}$ describe the productivity level which makes a firm earn zero profits from exporting to destination $d$, and therefore which makes a firm indifferent about whether to export to $d$. In other words, if $\pi_{o d, s}(\varphi)$ is the profit that a firm with productivity $\varphi$ in origin country $o$ and sector $s$ earns from exporting to destination country $d$, then this cutoff is implicitly given by $\pi_{o d, s}\left(\varphi_{o d, s}^{*}\right)=0$. Combining consumer demand (25) with firm profits (29) lets us write the cutoff implicitly as

$$
w_{d} f_{o d, s}=\frac{1}{\sigma_{s}} \frac{p_{o d, s}\left(\varphi_{o d, s}^{*}\right)^{1-\sigma_{s}}}{P_{d, s}^{\left(1-\sigma_{s}\right)}} E_{d, s}
$$

Substituting in prices (28) then solving for $\varphi_{o d, s}^{*}$ gives

$$
\varphi_{o d, s}^{*}=\left(\frac{\sigma_{s}}{\sigma_{s}-1} \frac{c_{o, s} \tau_{o d, s}}{P_{d, s}}\left(\frac{\sigma_{s} w_{d} f_{o d, s}}{E_{d, s}}\right)^{\frac{1}{\sigma_{s}-1}}\right)^{\frac{1}{1-\alpha_{s}}}
$$

\section{Free Entry}

In equilibrium, the fixed cost of drawing a productivity must equal an entrepreneur's expected profit from drawing a productivity:

$$
w_{o} f_{o, s}^{e}=\left(1-G\left[\varphi_{o o, s}^{*}\right]\right) \mathbb{E}\left[\pi \mid \varphi>\varphi_{o o, s}^{*}\right]
$$

Here $\varphi_{o o, s}^{*}$ is the productivity level which makes a firm earn zero profits from producing domestically. Substituting in prices (28), profits (29), the Pareto conditional density (32), and the cutoff productivity (33) gives

$$
f_{o, s}^{e} \frac{\theta_{s}-\left(\sigma_{s}-1\right)\left(1-\alpha_{s}\right)}{\left(\sigma_{s}-1\right)\left(1-\alpha_{s}\right)}=\sum_{d} \frac{\left(b_{o, s}\right)^{\theta_{s}}}{\left(\varphi_{o d, s}^{*}\right)^{\theta_{s}}} \frac{w_{d}}{w_{o}} f_{o d, s}
$$

This concludes our explanation of intermediate steps, and we now combine several of these results to derive equations highlighted in the main text.

\section{II.B Deriving Equation (26), the Sector-Specific Price Index}

We obtain the price index for a country and sector by rewriting the price index (26) as

$$
P_{d, s}^{\left(1-\sigma_{s}\right)}=\sum_{o} \int_{0}^{M_{o d, s}} p_{o d, s}(v)^{1-\sigma_{s}} d v
$$


where $M_{o d, s}$ is the mass of firms exporting. Substituting in prices (28), the Pareto conditional density (32), and the productivity cutoff (33) lets us rewrite this price index as

$$
\left(P_{d, s}\right)^{-\frac{\theta_{s}}{1-\alpha_{s}}}=\sum_{o} M_{o, s}^{e}\left(\frac{w_{o}}{b_{o, s}}\right)^{-\theta_{s}}\left(\tau_{o d, s}\right)^{-\frac{\theta_{s}}{1-\alpha_{s}}}\left(f_{o d, s}\right)^{1-\frac{\theta_{s}}{\left(1-\alpha_{s}\right)\left(\sigma_{s}-1\right)}}\left(t_{o, s}\right)^{-\frac{\alpha_{s} \theta_{s}}{1-\alpha_{s}}}\left(\frac{E_{d, s}}{w_{d}}\right)^{\frac{\theta_{s}}{\left(1-\alpha_{s}\right)\left(\sigma_{s}-1\right)}-1} \chi_{s}
$$

where $M_{o, s}^{e}$ is the mass of entrepreneurs drawing a productivity, $E_{d, s}$ is total expenditure, and $\chi_{s}$ is a constant. $^{1}$

\section{II.C Deriving Bilateral Expenditure Shares}

The value of bilateral trade equals the proportion of firms exporting, times the mass of firms operating, times exports per exporter:

$$
\begin{aligned}
X_{o d, s} & =\frac{\operatorname{Pr}\left(\varphi>\varphi_{o d, s}^{*}\right)}{\operatorname{Pr}\left(\varphi>\varphi_{o o, s}^{*}\right)} M_{o, s} \mathbb{E}\left[r_{o d, s} \mid \varphi>\varphi_{o d, s}^{*}\right] \\
& =\frac{M_{o, s}^{e}\left(w_{o} / b_{o, s}\right)^{-\theta_{s}}\left(\tau_{o d, s}\right)^{-\frac{\theta_{s}}{1-\alpha_{s}}}\left(f_{o d, s}\right)^{1-\frac{\theta_{s}}{\left(\sigma_{s}-1\right)\left(1-\alpha_{s}\right)}}\left(t_{o, s}\right)^{-\frac{\alpha_{s} \theta_{s}}{1-\alpha_{s}}}}{\left(P_{d, s}\right)^{-\frac{\theta_{s}}{1-\alpha_{s}}}}\left(\frac{E_{d, s}}{w_{d}}\right)^{\frac{\theta_{s}}{\left(\sigma_{s}-1\right)\left(1-\alpha_{s}\right)}}\left(w_{d}\right) \chi_{s}(36
\end{aligned}
$$

The second equality follows from using demand (25), prices (28), the Pareto distribution (31), free entry (34), and the cutoff productivity (33). Here $E_{d, s}$ denotes the expenditure of country $d$ on goods from sector $s$, and we have collected parameters into the constant $\chi_{s}$. This constant has the same value as in equation (35). We can then write $\lambda_{o d, s}$, the share of country $d$ 's expenditure on sector $s$ that is purchased from country $o$, as

$$
\lambda_{o d, s}=\frac{M_{o, s}^{e}\left(w_{o} / b_{o, s}\right)^{-\theta_{s}}\left(t_{o, s}\right)^{-\frac{\alpha_{s} \theta_{s}}{1-\alpha_{s}}}\left(\tau_{o d, s}\right)^{-\frac{\theta s}{1-\alpha_{s}}}\left(f_{o d, s}\right)^{1-\frac{\theta s}{\left(\sigma_{s}-1\right)\left(1-\alpha_{s}\right)}}}{\sum_{i} M_{i, s}\left(w_{i} / b_{i, s}\right)^{-\theta_{s}}\left(t_{o, s}\right)^{-\frac{\alpha_{s} \theta_{s}}{1-\alpha_{s}}}\left(\tau_{i d, s}\right)^{-\frac{\theta s}{1-\alpha_{s}}}\left(f_{i d, s}\right)^{1-\frac{\theta s}{\left(\sigma_{s}-1\right)\left(1-\alpha_{s}\right)}}}
$$

\section{II.D Deriving Equation (11), the Second Equilibrium Condition}

To derive the second equilibrium condition in equation (11), we substitute in the cutoff productivity (33), the free entry condition (34), and the price index (35). This gives the following version of the second equilibrium condition:

$$
f_{o, s}^{e} \frac{\sigma_{s} \theta_{s}}{\left(\sigma_{s}-1\right)\left(1-\alpha_{s}\right)}=\sum_{d} \frac{\left(w_{o}\right)^{-1}\left(w_{o} / b_{o, s}\right)^{-\theta_{s}}\left(\tau_{o d, s}\right)^{-\frac{\theta_{s}}{1-\alpha_{s}}}\left(f_{o d, s}\right)^{1-\frac{\theta_{s}}{\left(\sigma_{s}-1\right)\left(1-\alpha_{s}\right)}}\left(t_{o, s}\right)^{-\frac{\alpha_{s} \theta_{s}}{1-\alpha_{s}}}}{\sum_{i} M_{i, s}^{e}\left(w_{i} / b_{i, s}\right)^{-\theta_{s}}\left(\tau_{i d, s}\right)^{-\frac{\theta_{s}}{1-\alpha_{s}}}\left(f_{i d, s}\right)^{1-\frac{\theta_{s}}{\left(\sigma_{s}-1\right)\left(1-\alpha_{s}\right)}}\left(t_{i, s}\right)^{-\frac{\alpha_{s} \theta_{s}}{1-\alpha_{s}}}} E_{d, s}
$$

Substituting in the definitions of the price index from (35) and bilateral trade from (36) gives equation (11) from the main text. The version of this equilibrium equation shown in the main text is short and intuitive. The version of this equation shown above is more practically useful for deriving the second equilibrium condition in changes and relating it to changes in trade costs, productivity, and environmental regulation.

\section{II.E Deriving Equation (12), the First Equilibrium Condition in Changes}

Recall the first equilibrium condition in levels, equation (9) from the main text:

$$
L_{o}=L_{o}^{e}+L_{o}^{p}+L_{o}^{t}+L_{o}^{m}+L_{o}^{n x}
$$

${ }^{1}$ The positive constant is given by $\chi_{s}=\frac{\left(\sigma_{s}\right)^{1-} \frac{\sigma_{s} \theta_{s}}{\left(\sigma_{s}-1\right)\left(1-\alpha_{s}\right)}}{\left(\sigma_{s}-1\right)^{-\frac{\theta_{s}}{1-\alpha_{s}}}} \frac{\alpha_{s} \theta_{s}}{\left(1-\alpha_{s}\right)^{-\theta_{s}}} \frac{\theta_{s}}{\theta_{s}-\left(\sigma_{s}-1\right)\left(1-\alpha_{s}\right)}$ 
This shows that labor in this model is demanded for five purposes: firm entry; production and abatement; pollution taxes; market entry; and net exports. We explain each in turn, then sum them to describe total labor demand.

First, labor in this model is used to pay the fixed cost for drawing a productivity (in other words, labor is demanded for firm entry). The labor demanded for this purpose equals the mass of entrepreneurs drawing a productivity times the fixed cost per draw:

$$
L_{o, s}^{e}=M_{o, s}^{e} f_{o, s}^{e}
$$

Second, labor in this model is used to producing widgets and abating pollution. The labor demanded for this purpose equals the mass of entrepreneurs drawing a productivity times expected labor for production and pollution abatement:

$$
\begin{aligned}
L_{o, s}^{p} & =M_{o, s}^{e} \mathbb{E}\left[l_{o d, s}(\varphi) \tau_{o d, s}\right] \\
& =M_{o, s}^{e} \theta_{s} f_{o, s}^{e}
\end{aligned}
$$

The second equality follows from substituting in several terms: $l_{o d, s}(\varphi)=q_{o d, s}(\varphi) /(\varphi(1-a(\varphi)))$ from assumption 2; demand (25); abatement investments (27); prices (28); the Pareto conditional density (32); and free entry (34).

Third, labor in this model is used to pay pollution taxes. The quantity of labor demanded for this purpose equals total expenditure on pollution taxes divided by the wage rate

$$
\begin{aligned}
L_{d, s}^{t} & =\frac{t_{d, s} Z_{d, s}}{w_{d}} \\
& =\frac{\alpha_{s}}{1-\alpha_{s}} \theta_{s} M_{d, s}^{e} f_{d, s}^{e}
\end{aligned}
$$

The second equality follows from substituting in several terms: demand (25); prices (28); abatement (27); pollution (30); and the Pareto conditional density (32).

Fourth, labor in this model is used to pay the fixed cost of entering foreign markets. The amount of labor demanded for this purpose equals the sum over all foreign countries of the mass of firms exporting to a country times the fixed cost of exporting to that country.

$$
\begin{aligned}
L_{d, s}^{m} & =\sum_{o} M_{o d, s} f_{o d, s} \\
& =\frac{\theta_{s}-\left(\sigma_{s}-1\right)\left(1-\alpha_{s}\right)}{\sigma_{s} \theta_{s}} \frac{E_{d, s}}{w_{d}}
\end{aligned}
$$

The second equality follows from calculating the expected revenue of exporters then substituting in demand (25); prices (28); and the productivity cutoff (33).

Fifth, labor is used to pay for trade deficits. The amount of labor demanded for this purpose equals the sum over all foreign countries of the mass of firms exporting to a country, times the first cost of exporting to that country:

$$
L_{d, s}^{n x}=-\frac{N X_{d, s}}{w_{d}} \frac{\left(\sigma_{s}-1\right)\left(\theta_{s}-\alpha_{s}+1\right)}{\sigma_{s} \theta_{s}}+\beta_{d, s} \frac{N X_{d}}{w_{d}}
$$

This trade imbalance term is defined so that the model can exactly match historic data on expenditure and production decisions.

Summing these five terms then solving for $L_{d}$ gives an expression for the labor market clearing condition:

$$
\begin{aligned}
L_{d} & =\frac{1}{1-\sum_{s} \frac{\theta_{s}-\left(\sigma_{s}-1\right)\left(1-\alpha_{s}\right)}{\sigma_{s} \theta_{s}} \beta_{d, s}} \\
& \sum_{s}\left[M_{d, s}^{e} f_{d, s}^{e}\left(\theta_{s}+1+\frac{\alpha_{s} \theta_{s}}{1-\alpha_{s}}\right)-\frac{\theta_{s}-\left(\sigma_{s}-1\right)\left(1-\alpha_{s}\right)-\sigma_{s} \theta_{s}}{\sigma_{s} \theta_{s}} \beta_{d, s} \frac{N X_{d}}{w_{d}}-\frac{N X_{d, s}}{w_{d}} \frac{\left(\sigma_{s}-1\right)\left(\theta_{s}-\alpha_{s}+1\right)}{\sigma_{s} \theta_{s}}\right]
\end{aligned}
$$


The left-hand side of this equation describes labor supply and the right-hand side labor demand. Writing the ratio of counterfactual to observed labor demand, $L_{d}^{\prime} / L_{d}$, and simplifying using the Pareto technology assumption (31), the Pareto conditional density (32), demand (25) and the free entry condition (34) gives the main text equation (12).

\section{II.F Deriving Equation (13), the Second Equilibrium Condition in Changes}

To derive equation (13), we write the second equilibrium condition in levels (11) under a counterfactual by adding an apostrophe to each variable. Each counterfactual variable can then be written as the product of that variable's baseline level and its proportional change (i.e., $x^{\prime}=\hat{x} / x$ ). Substituting in expenditures shares (37) and simplifying gives equation (13).

\section{II.G Deriving Equation (14), Proportional Changes in Pollution}

Recall the following from Assumption 3 of the model:

$$
z_{o d, s}(\varphi)=(1-a(\varphi))^{1 / \alpha_{s}} \varphi l_{o d, s}(\varphi)
$$

We then use abatement (27), prices (28), the Pareto distribution (31), and demand (25) to derive the following firm-level expected pollution emissions:

$$
\mathbb{E}\left[z_{o d, s}(\varphi) \tau_{o d, s} \mid \varphi>\varphi_{o d, s}^{*}\right]=\frac{\left(\sigma_{s}-1\right) \alpha_{s} \theta_{s}}{\theta_{s}-\left(\sigma_{s}-1\right)\left(1-\alpha_{s}\right)} \frac{w_{d}}{t_{o, s}} f_{o d, s}
$$

Again applying the Pareto distribution (31), bilateral demand (37), and taking ratios of counterfactual to baseline pollution gives equation (14).

\section{II.H Deriving Equation (19), the Foreign Competitiveness Shock}

We obtain equation (19) in the main text by expressing the expenditure shares equation (37) in changes and then solving for equation (18) from the main text.

$$
\hat{\Gamma}_{o d, s}^{*} \equiv\left(1 / \hat{b}_{o, s}\right)^{-\theta_{s}}\left(\hat{\tau}_{o d, s}\right)^{-\theta_{s} /\left(1-\alpha_{s}\right)}\left(\hat{f}_{o d, s}\right)^{1-\theta_{s} /\left(\sigma_{s}-1\right)\left(1-\alpha_{s}\right)}\left(\hat{t}_{o, s}\right)^{-\alpha_{s} \theta_{s} /\left(1-\alpha_{s}\right)}
$$

We do not need to measure the terms in parentheses on the right-hand part of equation (19) from the main text because they are specific to destination $d$ so appear in both the numerator and denominator of the part of this model where this shock is used (the second equilibrium equation in changes, equation (13)), and so cancel in that equation.

\section{II.I Deriving a Simpler Expression for the Environmental Regulation Shock}

To obtain the expression for environmental regulation described in equation (23), we express the first equilibrium condition (11) in changes then solve for $\hat{R}_{d, s}$. This derivation uses the fact that $\hat{M}_{o, s}^{e}=$ $\left(1 / \hat{w}_{o}\right)\left(\sum_{d} X_{o d, s}^{\prime} / X_{o d, s}\right)$

We obtain this expression for $\hat{M}_{o, s}^{e}$ in a few steps. First, we solve the expression for foreign competitiveness in equations (18) and (19) for the change in trade flows, $\hat{\lambda}_{o d, s}$. Second, we substitute this into the second equilibrium condition in changes in equation (13). Finally, we simplify the result to obtain this expression for $\hat{M}_{o, s}^{e}$. 


\section{Data Overview and Additional Empirical Details}

\section{III.A Matching the 1990 Annual Survey of Manufacturers to the 1990 National Emis- sions Inventory}

We match the 1990 Annual Survey of Manufacturers (ASM) to the 1990 National Emissions Inventory using name and address string matching techniques. The ASM does not provide name and address information for plants, but the ASM can be linked to the Census Business Register via a unique, longitudinal identifier that does. The Business Register consists of the universe of establishments in the United States on an annual basis and forms the basis for the more commonly known and used Longitudinal Business Database (LBD).

We perform a match between the 1990 NEI and the Business Register for each Business Register year between 1985 and 1996. Both the NEI and the Business Register contain establishment level name and address information that we use to perform the match: county, state, SIC code (4-digit, 3-digit, and 2-digit), facility name, street, city, and zip code. We perform exact matching on county, state, and SIC codes and "fuzzy" matching on facility name, street, city, and zip code. We use the "COMPGED" feature of SAS's PROC SQL to create a "generalized edit distance" score reflecting the degree of difference between two text strings. For each variable in which we use fuzzy matching techniques, we choose a score that minimizes both false positives and false negatives by visually checking the performance of the matches.

We then iterate over combinations of the match variables listed above, selecting the match with the highest score in each round, and removing the residual observations from each dataset before matching again. At the end of the matching process, we are able to match 77.4 percent of the 1990 NEI manufacturing observations (i.e., SIC code between 2000-3999). The match percentage also reflects the fact that the ASM is a sample and not a survey, and thus we should not expect a match rate near 100 percent.

In addition, the unmatched plant observations are not significantly different along emissions totals, relative to the matched observations. For each pollutant, we ran a plant-level regression of emissions on an indicator for whether the plant matched the census data, controlling for 4-digit SIC fixed effects and clustering standard errors by 4-digit SIC codes. Of 6 pollutants, the coefficient on the match variable is significant at the 10 percent level (though not at 5 percent) for $\mathrm{PM}_{10}$ and $\mathrm{PM}_{2.5}$; for other pollutants we fail to reject the null hypothesis that matched and unmatched plants have the same emissions. For the plants that are matched and emit particulate matter, the matched plants tend to emit slightly more particulates than the unmatched plants. Not all ASM plants appear in the NEI because the NEI is only designed to include data from plants with at least 100 tons per year of one of the major pollutants.

\section{III.B Product Level Decomposition: Details}

Section I in the text describes the statistical decomposition using the product-level production data from the Census and Annual Survey of Manufacturers (CMF and ASM, respectively). Here we provide additional details.

Bernard, Redding, and Schott (2011) provide a detailed overview of the Manufacturing Product trailer for research purposes. In terms of descriptive statistics, the typical two-digit SIC code in Manufacturing has 24 four-digit industries and 76 five-digit products, although there is heterogeneity across industries in the amount of product detail. For example, the number of products per sector ranges from a low of 12 in Leather (SIC 31) to a high of 178 in Industrial Machinery (SIC 35) (Bernard, Redding, and Schott, 2011). ${ }^{2}$

Within the CMF and ASM product trailers, there are several industries which report only aggregate product codes (i.e., within a 4-digit industry, more than 95 percent of output is produced in a product code

\footnotetext{
${ }^{2}$ As noted by Bernard, Redding, and Schott (2011), there is also substantial variation in the precision of product classifications. For example, Passenger Cars (SIC 37111) and Combat Vehicles (SIC 37114) are examples of products in the Motor Vehicle industry (SIC 3711), while Textbook Binding and Printing (SIC 27323) and Religious Books, Binding and Printing (SIC 27323) are examples of products in the Book Printing industry (SIC 2732).
} 
that ends in "-", "0", or "W"). In the case that 50 percent or more of the product shipments within in a 4-digit SIC industry come from one of these aggregate product codes, we aggregate to the 4-digit SIC level.

There are two primary issues that emerge when looking at changes in the composition of products and how these affect manufacturing emissions over time. The first issue is associated with the introduction of new products; we calculate emissions factors using total product-level production and emissions in 1990. If new products are introduced after 1990, they will not have an emissions factor, and thus will lead to false inferences from the decomposition. In order to address product entry, we fold all new products into the adjacent product category, as defined by 5 -digit SIC product codes. This implicitly assumes that the emissions factor from the new product is the same as the emissions factor calculated for the adjacent product code.

The second issue emerges from the transition between SIC and NAICS product code definitions between 1997 and 1998. We construct a product code crosswalk between 5-digit SIC product codes and 7 digit NAICS product codes. This allows us to construct a consistent 5-digit SIC by year dataset from 1990 until 2008. We develop this product-level SIC-NAICS concordance using 3 separate but complimentary strategies:

1. For the industries that only report aggregate product shipments (i.e., at the level of 4-digit SIC codes or 6-digit NAICS codes), we use the NBER-CES crosswalk which provides a linkage between 4-digit SIC codes and 6-digit NAICS codes. In the event that a 6-digit NAICS code maps into more than one 4-digit SIC code, the NBER-CES crosswalk provides value shares in order to apportion NAICS output to the relevant SIC code.

2. For products that are consistently reported at the NAICS 7-digit product level, we develop a crosswalk using the 1997 Census of Manufacturing product trailer. In 1997, Census collected both NAICS and SIC product codes which we use to build the crosswalk. For 7-digit NAICS product codes that map into more than one 5-digit SIC product code, we construct apportionment shares based on the fraction of total 1997 output that is split between the respective SIC codes.

3. Lastly, there are some 7-digit NAICS codes in years 1998+ that do not match either of the two crosswalks above. For these residual product codes, we use a crosswalk developed by the Bureau of Labor Statistics between SIC and NAICS product codes. ${ }^{3}$ There are still some cases for which NAICS 7-digit product codes map into more than one 5-digit SIC product code. In these cases, the BLS does not provide relative output shares for the "many to 1" crosswalk that would allow us to apportion NAICS output to the relevant SIC product code. This lack of apportionment for split products means that the product series in years 1998+ will overstate the amount of output for NAICS product codes that map into multiple SIC product codes. We adjust for this structural break by multiplying the scale + composition line in years $1998+$ by an adjustment factor. This adjustment factor is computed by fitting a linear trend to years 1996 and 1997 and projecting the 1998 point; the value that we multiply the observed 1998 value to recover the predicted 1998 value is the adjustment factor we use to scale all post-1998 output.

Once we have a consistent 5-digit SIC product-level dataset, we construct product shares in each year by taking the total product output produced in a given year and dividing that by total manufacturing output in that year. In non-Census years, we use the weights provided by the Census to scale up plant-level output by the inverse sampling probability of the survey. We multiply these product shares by the product-level emissions factors and sum over all products in a year. Lastly, we multiply this annual number by total manufacturing output in that year in order to recover the scale+composition line in Figures 3 and 1.

\footnotetext{
${ }^{3}$ Source: https://urldefense.proofpoint.com/v2/url?u=http-3A_-www.bls.gov_ppi_ppinaictosic15. htm\&d=AwIFaQ\&c=-dg2m7zWuuDZOMUcV7Sdqw\&r=a0JqX4ibH77Bx2Kpq1YnZLhOhR2TzpM1Zpf zjHqqTT0\&m= ikhWR7s5FQkUNMczenUZrOI6MF1WL89tekAhlHFe5qE\&s=SnuKGRQabLYEWjLd020HuSmBxmbRIODIBoHFRNj25y0\&e= (accessed on July, 12014$)$.
} 


\section{III.C Additional Data Details}

\section{Concordances}

We use several publicly available industry concordance files to express all datasets in the same classification systems. Whenever possible, we use concordance files that provide weights or shares. When shares or weights for multiple variables are available, we use employment shares. In cases where a given observation cannot be linked at the most detailed possible industry code (e.g., 6-digit NAICS code to 4-digit SIC code), we construct concordances for each possible further aggregation of this industry (e.g., 5-digit NAICS to 4-digit SIC, then 4-digit NAICS to 4-digit SIC, etc.). We link each observation at the most detailed possible industry level.

The subsection above describes linking SIC and NAICS product codes. To concord SIC and NAICS industry codes, we use a file constructed in Fort and Klimek (2016). This file takes an internal concordance file from the U.S. Census then cleans and documents it, and imputes missing values for some narrowly divided industry cells by using averages from more aggregate industry categories. Unlike standard census NAICS-SIC concordances, this file provides shares; and unlike the NBER-CES database, it represents all industries and does not only focus on manufacturing.

To concord between different years of NAICS codes (e.g., between 1997 NAICS and 2002 NAICS; or between 2002 NAICS and 2007 NAICS), we use concordance files available in the U.S. Census Bureau's Factfinder application. The Census Bureau calls these "Industry Bridge Statistics" and gives them the table code 00CBDG2.

To concord NAICS codes to ISIC codes, we use a crosswalk file from Statistics Canada. This file does not provide data on weights, so we define weights according to the number of industries linked. For example, if one NAICS industry is linked to 5 different ISIC industries, we assign 20 percent of the NAICS industry to each of the ISIC industries.

\section{Gross Output Data}

We setup gross output using these data as follows. First, we concord reporting sectors. Some country $\times$ years report values for combinations of two-digit ISIC codes (e.g., one value covering both ISIC $=15$ and ISIC $=16$ ). In these cases, we take reports from the same country in other years, calculate the share of output coming from each of the two underlying ISIC 2-digit codes in those other years, and apportion the focal year to the two codes according to those shares.

We use a few steps to to incorporate country $\times$ years not in the OECD data. First, we extract data on each country $\times$ year's total manufacturing GDP from the World Bank's World Development Indicators (WDI), which covers both OECD and non-OECD countries. Second, we calculate the ratio of manufacturing GDP (from WDI) to manufacturing gross output (from OECD STAN) for the OECD in total, separately by year. This ratio gradually declines from 0.33 in the year 1990 to 0.26 in 2008. Dekle, Eaton, and Kortum (2008) report a similar value for this ratio of 0.31 . Third, we divide the WDI manufacturing GDP values by the GDP/Output ratios calculated in the second step to calculate gross output per country $\times$ year, for both OECD and non-OECD countries. Fourth, we calculate the composition of total OECD manufacturing gross output across the 17 sectors in our data, separately by year. Fifth, we assign the country $\times$ year gross output calculated in step three to sectors using the proportions calculated in step four. For OECD countries, we use reported data from OECD STAN; for other countries, we use these calculated values.

As discussed in the main text, we use these values for years 1990-1995. For years 1995-2008, we use production and trade data from the World Input Output Dataset (WIOD), which begins in the year 1995 (Timmer, Dietzenbacher, Los, Stehrer, and de Vries, 2015). WIOD directly reports gross output for the U.S. and other countries, including a rest-of-the-world category, so does not require the aforementioned 
imputation. We scale each production and trade flow in WIOD so they exactly match the OECD gross output data in 1995.

\section{Data for Estimating Pollution Elasticity}

We use data on pollution emissions from NEI, the value of shipments and value of production costs from ASM, and pollution abatement costs from $\operatorname{PACE}\left(z, q\right.$, and $a$, respectively). ${ }^{4}$ We "winsorize" the reported emissions data at the 99th percentile of the 4-digit NAICS-year emissions distribution, and we use sample weights from both the Annual Survey of Manufacturers and the Pollution Abatement Costs and Expenditure Survey to inflate survey values to be nationally representative. Total abatement costs consist of the sum of abatement operating costs plus the rental cost of capital associated with the observed abatement capital at a plant. ${ }^{5}$ Total expenditures consist of the sum of expenditures on salary and wages, materials, energy, and the industry-specific capital rental rates for a given level of capital stock.

\section{Manufacturing and Energy Consumption Survey and $\mathrm{CO}_{2}$ Emissions}

MECS is a nationally representative survey of U.S. manufacturing which was conducted in 1991, 1994, 1998, 2002, 2006 and 2010. We download publicly available tables, which are available at the 2-digit SIC or 3digit NAICS level. We extract data on total inputs of energy for heat, power, and electricity generation by industry, measured in trillions of BTUs. These data exclude energy used as feedstock (e.g., they exclude the petroleum which is a physical part of plastics).

For confidentiality reasons, public versions of the MECS data supress a few fuel $\times$ industry $\times$ year cells. We impute these values as follows. First, we calculate total BTUs for the fuel $\times$ year, and subtract BTUs for industry $\times$ years within that fuel that are not suppressed. Second, within each year, we then calculate the share of all BTUs (total across fuels) that each industry accounts for. Finally, we allocate the non-specified BTUs (calculated in the first step) across industries according to the relative proportions calculated in the second step.

Given these data on million BTU of each energy source, we calculate $\mathrm{CO}_{2}$ emissions using physical emissions rates from the U.S. Environmental Protection Agency.

\section{EPA Air Program Markets Data}

In order to operate cap-and-trade programs like the $\mathrm{NO}_{x}$ Budget Trading Programs, the EPA maintains a public database listing each facility which participates in the program and its attributes. ${ }^{6}$ We obtain a list of facilities which were regulated under the $\mathrm{NO}_{x}$ Budget Trading Program in each year of its operation, 2003-2007. Each facility includes identifying information such as longitude and latitude, address, and a generic industry description, which we use to link these data to the National Emissions Inventory.

\footnotetext{
${ }^{4}$ We proxy for measures of physical output $q_{i, t}$ using plant revenue, deflated by industry-specific output price deflators, where the industry-specific output price deflators come from the NBER-CES database.

${ }^{5}$ Capital rental rates are from unpublished data constructed by the Bureau of Labor Statistics for use in computing their Multifactor Productivity series. These data are commonly used in the productivity literature to proxy for industry-specific capital rental rates. See e.g., Syverson (2011). We only observe abatement capital stocks in 2005 (not 1990). We impute 1990 abatement capital stocks using our observed measure of depreciation expenditures in both 1990 and 2005. Specifically, we use the 2005 ratio of abatement capital stocks to abatement depreciation expenditures, and we multiply this ratio by the 1990 abatement depreciation expenditure for a plant to back out the 1990 abatement capital stock of the plant.

${ }^{6}$ The data are available at https://urldefense.proofpoint.com/v2/url?u=http-3A__ampd.epa. gov_ampd_\&d=AwIFaQ\&c=-dg2m7zWuuDZOMUcV7Sdqw\&r=a0JqX4ibH77Bx2Kpq1YnZLhOhR2TzpM1ZpfzjHqqTT0\&m= ikhWR7s5FQkUNMczenUZr0I6MFlWL89tekAhlHFe5qE\&s=7mYZMH3I9I3bQFxPnze5IKdiE9IML9vBovn4qZuymUw\&e=. These data were formerly called the Clean Air Markets Database.
} 


\section{III.D Macroeconomic Parameters}

To estimate the elasticity of substitution across product varieties, we use the implication of the model that a sector's expenditure on labor for production is proportional to the sector's revenue:

$$
w_{o} L_{o, s}^{p}=\left(1-\alpha_{s}\right) \frac{\sigma_{s}-1}{\sigma_{s}} R_{o, s}
$$

Here $L_{o, s}^{p}$ represents labor used in production and $R_{o, s}$ represents revenue. ${ }^{7}$ We use the 1990 Annual Survey of Manufactures to calculate these elasticities separately for each of the 17 aggregated ISIC sectors. Intuitively, this approach is observing markups in data, then using our assumption of the market structure (monopolistic competition) to back out the demand elasticity which rationalizes those markups.

Column 4 of Table 2 presents our estimates of $\sigma_{s}$ for each sector. ${ }^{8}$ The elasticity of substitution ranges from 2.89 to 8.18 across industries, with a cross-sector mean of 4.76 . We expect a smaller elasticity of substitution for industries with more differentiated products. The pattern across sectors generally follows this pattern. The largest elasticity of 8.18 in absolute value is for the Coke, Refined Petroleum, and Nuclear Fuels sector, which has fairly homogeneous products. The smallest elasticity of 2.89 is for the Medical, Precision, and Optical Products sector, which has fairly differentiated products. These correspond to markups of between 14 and 53 percent, which fits the range from other published studies, which for U.S. manufacturing industries typically range from 10 to 50 percent (Hall, 1986; Martins, Scarpetta, and Pilat, 1996; Ganapati, Shapiro, and Walker, 2016).

Next, we estimate the shape parameter of the Pareto distribution of firm productivities. We rely on the fact that if the distribution of firm productivities is Pareto with shape parameter $\theta_{s}$, then the distribution of firm sales is Pareto with shape parameter $\theta_{s} /\left(\sigma_{s}-1\right)$. The Pareto tail cumulative distribution function is $\operatorname{Pr}\left\{x>X_{i, s}\right\}=\left(b_{i, s} / X_{i, s}\right)^{\theta_{s} /\left(\sigma_{s}-1\right)}$ for $X_{i, s} \geq b_{i, s}$. Taking logs gives

$$
\ln \left(\operatorname{Pr}\left\{x>X_{i, s}\right\}\right)=\gamma_{0, s}+\gamma_{1, s} \ln \left(X_{i, s}\right)+\epsilon_{i, s}
$$

We estimate equation (39) separately for each sector $s$, and the coefficient $\gamma_{1, s}$ in each regression is generally close to negative one. The Pareto shape parameter is then given by $\theta_{s}=\gamma_{1, s}\left(1-\sigma_{s}\right)$.

We use a subset of the firm-level data to estimate equation (39). Because selection into exporting can bias these estimates (di Giovanni, Levchenko, and Ranciere, 2011), we estimate this regression using only domestic sales. Additionally, since the Pareto distribution best fits the right tail of the firm distribution, we estimate these regressions using firms above the 90 th percentile of sales within each sector. ${ }^{9}$

\footnotetext{
${ }^{7}$ In the model, this prediction reflects only wage payments used for production. In applying this prediction empirically, we measure all factor payments in the data (not merely wages), and we treat all factor payments in the data as productive (since the data do not separately measure fixed entry and marketing costs). Firm revenues are "inventory-adjusted" total value of shipments for a plant in 1990, and firm costs consist of expenditures on labor, parts and materials, energy, and capital.

${ }^{8}$ The reported elasticity is calculated as $\sigma_{s}=\left(1-\alpha_{s}\right) /\left(\left(1-\alpha_{s}\right)-w L_{s} / X_{s}\right)$, where $\alpha_{s}$ is the pollution elasticity estimated above and $w L_{s} / X_{s}$ is factor costs divided by the value of shipments. Columns 1-3 of Table 2 present these intermediate inputs into the construction of $\sigma_{s}$.

${ }^{9}$ In the census microdata, we measure domestic sales as inventory-adjusted total value of shipments minus the value of export shipments. Estimating the regression using only the upper tail of firm sizes follows the literature by taking a set of firms for which the relationship between firm rank and size is approximately linear (Gabaix, 2009; di Giovanni, Levchenko, and Ranciere, 2011). To determine the percentile cutoff for these regressions, we bin the data into values of firm size that are equidistant from each other on the $\log$ scale, then collapse the rank/size data to the bin level for 10 bins. We examine the scatter plot of these points overlaid by the linear fit to these points. In general, the upper 90th percentile of the sales distribution is strongly linear with respect to firm rank.
} 
Table 1: Sensitivity Analysis: U.S. Pollution Emissions in Counterfactual Divided by 1990 Emissions, Separately for Each Shock

\begin{tabular}{|c|c|c|c|c|c|}
\hline & $\begin{array}{c}\text { Foreign } \\
\text { Competitiveness } \\
\text { (1) }\end{array}$ & $\begin{array}{c}\text { U.S. } \\
\text { Competitiveness } \\
(2)\end{array}$ & $\begin{array}{c}\text { U.S. } \\
\text { Environmental } \\
\text { Regulation } \\
(3)\end{array}$ & $\begin{array}{c}\text { U.S. } \\
\text { Expenditure } \\
\text { Shares } \\
(4)\end{array}$ & $\begin{array}{l}\text { Trade } \\
\text { Deficits } \\
\quad(5)\end{array}$ \\
\hline 1. Actual Change & \multicolumn{5}{|c|}{46.464} \\
\hline 2. Main Estimate & 95.429 & 81.188 & 47.528 & 111.28 & 102.33 \\
\hline 3. No Firm Heterogeneity & 93.504 & 83.868 & 47.526 & 111.25 & 102.30 \\
\hline 4. Parameter $\theta$ : Top 50 Percent & 89.757 & 83.64 & 48.161 & 110.82 & 104.17 \\
\hline 5. Parameter $\theta$ : Top 25 Percent & 91.064 & 83.333 & 48.015 & 110.95 & 103.66 \\
\hline 6. Parameter $\alpha$ : $0.25 \times$ Main Estimates & 95.354 & 75.549 & 48.845 & 111.28 & 102.33 \\
\hline 7. Parameter $\alpha$ : $4 \times$ Main Estimates & 93.487 & 88.595 & 46.042 & 111.26 & 102.32 \\
\hline 8. Partial Equilibrium & 100.000 & 100.000 & 48.98 & 100.000 & 100.000 \\
\hline
\end{tabular}

Notes: This table presents a set of sensitivity analyses for the main set of counterfactuals in the text. For the sensitivity analysis listed in each row, we calculate each counterfactual separately for each of the six criteria pollutants. The table shows the unweighted mean of these results across these pollutants. We show the mean outcome averaged across years 2005 and 2008. Row 1 presents the actual observed change in pollution emissions between 1990 and 2005-2008, averaged across the six pollutants. The value of 40.47 means that emissions in the years 2005-2008 were 40.47 percent of their value in 1990 . Row 2 shows the main estimates from the model, where each column corresponds to a separate counterfactual. For example, column (1) shows that if foreign competitiveness took its actual historic value and all other shocks were held fixed, then manufacturing emissions in 2005-2008 would have been 107.14 percent of their observed 1990 values. Row 3 shows counterfactuals in a model where parameters are chosen so all firms have the same productivity and there is no firm heterogeneity. Rows 4 and 5 explore sensitivity of these counterfactuals to changes in the Pareto shape parameters that govern the distribution of firm productivity. Rows 6 and 7 explore model sensitivity to changes in the estimated pollution elasticity.

\section{III.E Discussion of Other Shocks, Wages, and Firm Entry Changes}

Appendix Figure 3 shows the time path of the historical shocks in the paper. ${ }^{10}$ Although we recover the value of each shock for each country $\times$ sector, it is cumbersome to describe values for 17 different sectors. Instead, we plot shocks separately for "clean" and "dirty" sectors. Dirty industries are defined as those with a value of the pollution elasticity $\alpha_{s}$ above the economy-wide mean of 0.011 , and clean industries are defined as those with a value of this pollution elasticity below 0.011 .

Appendix Figure 3a shows that foreign expenditure shares on dirty versus clean goods changed relatively little until 2005, when spending on dirty industries grew by around 10 percent. U.S. expenditure shares show similar patterns. This increase in expenditure shares for dirty goods is especially driven by the increasing expenditure in the Coke, Refined Petroleum, and Nuclear Fuels sector, reflecting increases in global commodity prices. ${ }^{11}$

Our measures of these historic shocks depend on the changes in wages in each country and changes in

\footnotetext{
${ }^{10}$ The model and counterfactuals account for competitiveness shocks to each country. As discussed earlier, although the price index $\hat{P}_{d, s}$ appears in our measure of competitiveness shocks, we don't need these price data to analyze counterfactuals. This is because destination price indices appear in only the numerator and denominator of the second equilibrium condition and cancel. As a result, the historical shocks to U.S. and foreign competitiveness outside of a particular counterfactual are not informative, and we omit competitiveness shocks from Appendix Figure 3.

${ }^{11}$ This stylized fact that the share of U.S. expenditure on energy products nearly doubled between 2004 and 2008 appears in other data. For example, the Energy Information Agency Energy Information Administration (2011) records that consumer expenditure on all petroleum products grew in nominal terms from $\$ 470$ billion in the year 2004 to $\$ 871$ billion in the year 2008 .
} 
Table 2: Sensitivity to Starting Values and Algorithms

\begin{tabular}{lcc}
\hline & $\begin{array}{c}\text { Minimized Objective } \\
\text { Function }\end{array}$ & $\begin{array}{c}\text { 2008 } \\
\text { Difference in Pollution, } \\
\text { Regulation-only } \\
\text { Counterfactual }\end{array}$ \\
\hline Main Results & $1.32 \mathrm{E}-30$ & - \\
Starting Values Randomly Chosen: & $2.48 \mathrm{E}-30$ & $3.98 \mathrm{E}-13$ \\
$\quad$ Mean & $4.31 \mathrm{E}-31$ & $4.26 \mathrm{E}-14$ \\
$\quad$ Minimum & $7.81 \mathrm{E}-29$ & $1.42 \mathrm{E}-14$ \\
$\quad$ Maximum & $(3.11 \mathrm{E}-30)$ & $9.29 \mathrm{E}-15$ \\
$\quad$ Standard Deviation & $1.32 \mathrm{E}-30$ & 0 \\
Algorithm: Trust-Region Reflective & $1.32 \mathrm{E}-30$ & 0 \\
Algorithm: Levenberg-Marquardt & & \\
\hline
\end{tabular}

Notes: This table presents a set of sensitivity analyses for the counterfactuals presented in the paper, for $\mathrm{NO}_{x}$ emissions. The table varies the starting values and the algorithm associated with solving the system of nonlinear equations used in our counterfactuals. The main results in the paper use a starting value equal to one and a trust-region, dogleg algorithm. This table presents results from a randomly chosen set of starting values drawn from a uniform distribution [0.75,1.25]. The table reports the mean, minimum, maximum, and standard deviation of the 1,000 different results. The last two rows of the table present results using two different minimization routines. The second column shows the absolute value of the difference in the pollution emissions under a regulation-only counterfactual as calculated in a given row relative to the value calculated in the first row.

firm entry in each country and sector. Appendix Figure 4 plots these values. U.S. wages stagnated in the 1990s as U.S. output grew more slowly than global output. U.S. wages grew slightly in the late 1990s and early 2000s, as U.S. output growth modestly outpaced global output growth. Wages then declined in the 2000s as growth from foreign countries, especially China, accelerated. Foreign wages display the opposite pattern: modest growth in the early 1990s and late 2000s but a slight decrease in intervening years.

Appendix Figure 4 also shows patterns in firm entry. In both the U.S. and abroad, entry grew more quickly in dirty sectors than in clean sectors, as indicated by the solid line rising after the year 2005 in panels (c) and (d). This increase in entry to dirty sectors in the late 2000s reflects rising energy prices and revenues - greater value of output in dirty sectors increases the expected profit from entry, attracting more firms to these sectors.

One additional issue in describing the shocks concerns trade imbalances. In a dynamic model, trade imbalances would represent intertemporal concerns like saving or consumption smoothing. In the comparative statics we examine here, trade imbalances appear as transfers from one country to another. The natural way for this static model to exactly recreate historic data is to allow for separate shocks to trade imbalances. In the decomposition, we read off actual trade imbalances from the data. ${ }^{12}$

\section{III.F Algorithm to Calculate Equilibrium}

To analyze counterfactuals, we use country $\times$ industry data from the year 1990 on production, trade, and U.S. pollution emissions $\left(X_{o d, s}\right.$ and $\left.Z_{o, s}\right)$, and the parameter vectors for each industry: the pollution elasticity, elasticity of substitution, and Pareto shape parameter $\left(\alpha_{s}, \sigma_{s}\right.$, and $\left.\theta_{s}\right)$. With the full set of data and parameters, we then use the following algorithm to solve for a specific counterfactual:

\footnotetext{
${ }^{12}$ We define net exports, $N X_{o}$, as a country's exports minus its imports. As in Hsieh and Ossa (2016), we also allow scaled sectoral imbalances, given by $N X_{d, s}\left(\sigma_{s}-1\right)\left(\theta_{s}-\alpha_{s}+1\right) / w_{d} \sigma_{s} \theta_{s}$.
} 
1. Characterize the counterfactual scenario by choosing values for shocks to foreign and U.S. competitiveness, U.S. environmental regulation, and expenditure shares in each of the years 1990-2008 $\left\{\hat{\Gamma}_{o d, s}\right.$, $\hat{t}_{o, s}$, and $\left.\hat{\beta}_{o, s}\right\}$. These values can be hypothetical or they can describe the actual, historical values of these shocks.

2. Find the changes to wages and firm entry in each country $\times$ sector $\times$ year $\left(\hat{w}_{o}\right.$ and $\left.\hat{M}_{o, s}^{e}\right)$ which make the equilibrium conditions (12) and (13) hold with equality for all countries and sectors and years, by solving a system of nonlinear equations and then inputting the values chosen in step $1 .{ }^{13}$ This system represents $N+N S-1$ variables in $N+N S-1$ unknowns: one unknown wage change per country, one unknown firm entry change per country $\times$ sector, and one unknown excluded as numeraire.

3. Use equation (14) to measure the change in U.S. pollution emissions, given the values from steps 1 and 2 .

The historic values of shocks to foreign and domestic competitiveness, environmental regulation, and expenditure shares are $\left\{\hat{\Gamma}_{o d, s}^{*}, \hat{t}_{o, s}^{*}, \hat{\beta}_{o, s}^{*}\right\}$, calculated using equations (19) through (22). By construction, these values solve the two equilibrium conditions (12) and (13) in every country, industry, and year for the wage changes and firm entry changes $\left(\hat{w}_{o}^{*}\right.$ and $\left.\hat{M}_{o, s}^{e *}\right)$ which actually occurred. Hence, if we take observed levels of trade, pollution emissions, and production from the initial year 1990, add the shocks $\left\{\hat{\Gamma}_{o d, s}^{*}, \hat{t}_{o, s}^{*}, \hat{\beta}_{o, s}^{*}\right\}$ which actually occurred between 1990 and some future year, and calculate the new equilibrium, we recover the historic value of pollution from that year. However, we are interested in what pollution would have been if shocks had not equaled their historic values.

To decompose the change in pollution into the effects of the separate shocks, we study a specific set of counterfactuals. Consider the shock to foreign competitiveness. To measure how foreign competitiveness affected pollution, we define the shocks as follows:

$$
\left\{\hat{\Gamma}_{o d, s}, \hat{t}_{o, s}, \hat{\beta}_{o, s}\right\}= \begin{cases}\left\{\hat{\Gamma}_{o d, s}^{*}, 1,1\right\} & \text { if } o \neq U . S . \\ \{1,1,1\} & \text { if } o=U . S .\end{cases}
$$

This says that the foreign competitiveness shock $\hat{\Gamma}_{o d, s}$ took on its historic value $\hat{\Gamma}_{o d, s}^{*}, o \neq U . S$., but other shocks remained fixed at their 1990 values (i.e., the proportional change for every other shock equals one). Given the shocks defined in equation (40), we use steps 2 and 3 of the algorithm to recover the pollution emitted in this counterfactual. We do a similar calculation for each shock separately. For example, to measure the pollution change due to environmental regulation, we define the shocks as $\left\{\hat{\Gamma}_{o d, s}, \hat{t}_{o, s}, \hat{\beta}_{o, s}\right\}=\left\{1, \hat{t}_{o, s}^{*}, 1\right\}$. We then follow steps 2 and 3 of the algorithm described above to measure the implied pollution under these shocks.

Three additional points may clarify this algorithm. First, setting all shocks equal to their historic values at once recreates the historic decline in pollution. Second, although we are choosing the shocks to characterize a counterfactual, the firm-level decisions in the model - like entry, exit, abatement, production, and exports - are all adjusting freely in response to the shocks. Third, we analyze the model separately for each pollutant.

Appendix Table 2 explores the sensitivity of the results to different sets of starting values needed for the algorithm to solve systems of nonlinear equations (12) and (13). We randomly draw 1,000 different sets of starting values from the uniform distribution $[0.75,1.25] .{ }^{14}$ Each set of starting values represents changes in wages in each country and firm entry decisions in each country $\times$ sector. The objective function appears to

\footnotetext{
${ }^{13}$ To solve the system of nonlinear equations, we use a standard trust-region dogleg algorithm. However, as we discuss below and show in Appendix Table 2, other algorithms and randomly-chosen starting values give equivalent results.

${ }^{14}$ We choose this range to cover common values of shocks observed in data and described in Appendix Figure 4. Some starting values well outside this region fail to converge.
} 
be somewhat flat in a narrow range around the main set of results; different starting values obtain slightly different values of the changes in wages and firm entry decisions which are not numerically equivalent to the main results. However, column (1) shows that the differences between these equilibria are very small and appear only between the 29th and 31st decimal point. Because we only have 32 digits of calculation precision, these differences in equilibria may reflect numerical precision due to computational limits. We also report results using two alternative algorithms for solving systems of nonlinear equations - a trust-region reflexive algorithm and a Levenberg-Marquardt algorithm. Both yield very similar, though not numerically equivalent values of the objective function, and yield the same estimate of how regulation affects pollution.

Column (2) of Appendix Table 2 shows that the ratio of U.S. pollution emissions in 2008 relative to 1990 is nearly identical in every set of starting values and algorithms we use. Across the thousand alternative sets of starting values, the standard deviation is 8.33E-31. These results suggest that our quantitative conclusions are the same with other starting values or algorithms.

\section{III.G Additional Model Sensitivity Analyses}

We now consider the sensitivity of the paper's main results to parameter estimates and model assumptions. Table 1 begins by investigating model sensitivity to alternative parameter specifications. The first row shows that by 2008, $\mathrm{NO}_{x}$ emissions from U.S. manufacturing were 46.46 percent of their 1990 values. The paper's main estimates imply that environmental regulation alone would have caused pollution emissions to equal 47.53 percent of their 1990 value by 2008 (column (3), row (2)). Rows 3 and 4 explore how sensitive this conclusion is to changes in the underlying Pareto shape parameter estimates. Because the Pareto distribution best approximates the size distribution for the upper tail of firms, our main estimates of these parameters use the largest 10 percent of firms in each industry. Estimating the Pareto shape parameters using the top 50 percent of firms in each industry, or using the top 25 percent of firms in each industry, hardly affects the main conclusions. These two alternatives imply that environmental regulation would have led $\mathrm{NO}_{x}$ emissions to be 48.16 or 48.02 percent of their 1990 value by 2008, which are extremely close to the main results.

Rows (5) and (6) of Appendix Table 1 explore sensitivity to changes in the pollution elasticity $\alpha_{s}$. Row (5) assumes that the pollution elasticity is one-fourth of our estimated values, and row (6) assumes that the true values of $\alpha_{s}$ are four times the values of our main estimates. The former implies that environmental regulation alone would have led pollution emissions to be 48.85 percent of their 1990 value in 2008; the latter implies that environmental regulation alone would have led pollution emissions to be 46.04 percent of their 1990 value by 2008 . These alternative parameter values modestly affect the magnitude of how environmental regulation affects manufacturing $\mathrm{NO}_{x}$ emissions. However, across the four alternative sets of results, the qualitative conclusion persists that regulation explains most of the change in pollution.

\section{III.H Pollution Intensity and Total Factor Productivity: Details}

Figure 2 plots the relationship between plant level pollution intensity in total factor productivity. This section provides additional details underlying this figure. We use the 1990 Annual Survey of Manufacturers (ASM) which provides information on input decisions and total output at the plant level. We match the ASM to the National Emissions Inventory (NEI) using name and address matching techniques. Details of the match can be found in Appendix III.A. We use the sampling weights in the ASM to adjust plant-level output by the inverse sampling probability of a plant in the survey.

For each plant and each pollutant we divide total emissions by inventory adjusted real output. ${ }^{15} \mathrm{We}$ use industry-specific price deflators from the CES-NBER Productivity database to deflate output using

\footnotetext{
${ }^{15}$ Inventory adjusted total output is defined as the total value of shipments, minus the difference between finished goods inventory between the beginning and end of the year, minus the difference between work in progress inventory at the beginning and end of the period.
} 
an SIC-4, industry-level index normalized to 1 in 2008. We then compute a plant-level index measure of total factor productivity, using a Cobb-Douglas production technology and assuming constant returns to scale. ${ }^{16}$ Production inputs include labor, capital, and materials. We approximate the output elasticities of production inputs using industry-level cost shares from the NBER-CES productivity database. All inputs were deflated using industry, input-specific price deflators from the NBER-CES productivity database.

We divide the sample into 10 deciles based on total factor productivity. We then compute the mean values of log productivity and log pollution per unit of real output within each decile, weighting the decile mean by plant-level inventory-adjusted, real output. Figure 2 plots the results for each of the six pollutants in our sample. Each pollutant scatter plot is accompanied by a linear fit, relating plant-specific emissions intensities to total factor productivity at the same plant. The line is fit to the entire sample, not simply the decile means.

\footnotetext{
${ }^{16}$ Plant TFP is computed as its logged output minus a weighted sum of its logged labor, capital, materials, and energy inputs. That is

$$
T F P_{i t}=y_{i t}-\alpha_{l t} l_{i t}-\alpha_{k t} k_{i t}-\alpha_{m t} m_{i t}-\alpha_{e t} e_{i t}
$$

where the weights $\alpha_{j}$ are the input elasticities of input $j \in\{l, k, m, e\}$. Index productivity measures are common in the literature partly because they are easy to construct and also because they are a nonparametric first-order approximation to a general production function. See e.g., Syverson (2011).
} 


\section{References}

Bernard, A. B., S. J. Redding, and P. K. Schott (2011): "Multi-Product Firms and Trade Liberalization," Quarterly Journal of Economics, 126(3), 1271-1318.

Dekle, R., J. Eaton, and S. Kortum (2008): "Global Rebalancing with Gravity: Measuring the Burden of Adjustment," IMF Staff Papers, 55(3), 511-539.

di Giovanni, J., A. A. Levchenko, and R. Ranciere (2011): "Power laws in firm size and openness to trade: Measurement and implications," Journal of International Economics, 85, 42-52.

Energy Information Administration (2011): "Annual Energy Review," Discussion paper, EIA.

Fort, T. C., And S. D. KlimeK (2016): "The Effects of Industry Classification Changes on U.S. Employment Composition," Mimeo, Dartmouth.

Gabaix, X. (2009): "Power Laws in Economics and Finance," Annual Review of Economics.

Ganapati, S., J. S. Shapiro, and R. Walker (2016): "Energy Prices, Pass-Through, and Incidence in U.S. Manufacturing," Discussion paper, NBER Working Paper 22281.

Hall, R. (1986): "Market Structure and Macroeconomic Fluctuations," Brookings Papers on Economic, 2, $285-322$.

Hsien, C.-T., And R. Ossa (2016): "A Global View of Productivity Growth in China," Journal of International Economics, 102, 209-224.

Martins, J. O., S. Scarpetta, and D. Pilat (1996): "Mark-Up Ratios in Manufacturing Industries," Discussion paper, OECD Economics Department Working Papers No. 162.

Syverson, C. (2011): "What Determines Productivity?," Journal of Economic Literature, 49(2), 326-365.

Timmer, M. P., E. Dietzenbacher, B. Los, R. Stehrer, and G. J. De Vries (2015): “An Illustrated User Guide to the World Input-Output Database: the Case of Global Automotive Production," Review of International Economics, 23, 575-605. 